\title{
Initial Results from the Variable Intensity Sonic Boom Propagation Database
}

\author{
Edward A. Haering, Jr., ${ }^{*}$ Larry J. Cliatt, II, ${ }^{\dagger}$ and Thomas J. Bunce \\ NASA Dryden Flight Research Center, Edwards, California, 93523-0273 \\ Thomas B. Gabrielson, ${ }^{\S}$ Victor W. Sparrow, ${ }^{* *}$ and Lance L. Locey ${ }^{\dagger \dagger}$ \\ Pennsylvania State University, University Park, Pennsylvania, 16802
}

\begin{abstract}
An extensive sonic boom propagation database with low- to normal-intensity booms (overpressures of $0.08 \mathrm{lbf} / \mathrm{ft}^{2}$ to $2.20 \mathrm{lbf} / \mathrm{ft}^{2}$ ) was collected for propagation code validation, and initial results and flight research techniques are presented. Several arrays of microphones were used, including a $10 \mathrm{~m}$ tall tower to measure shock wave directionality and the effect of height above ground on acoustic level. A sailplane was employed to measure sonic booms above and within the atmospheric turbulent boundary layer, and the sailplane was positioned to intercept the shock waves between the supersonic airplane and the ground sensors. Sailplane and ground-level sonic boom recordings were used to generate atmospheric turbulence filter functions showing excellent agreement with ground measurements. The sonic boom prediction software PCBoom4 was employed as a preflight planning tool using preflight weather data. The measured data of shock wave directionality, arrival time, and overpressure gave excellent agreement with the PCBoom4-calculated results using the measured aircraft and atmospheric data as inputs. $\mathrm{C}$-weighted acoustic levels generally decreased with increasing height above the ground. A-weighted and perceived levels usually were at a minimum for a height where the elevated-microphone pressure-rise time history was the straightest, which is a result of incident and groundreflected shock waves interacting.
\end{abstract}

\section{Nomenclature}

ASEL $\quad=$ A-weighted sound exposure level

BADS $=$ boom amplitude and direction sensor

BASS $=$ boom amplitude and shape sensor

CSEL = C-weighted sound exposure level

DGPS $=$ differential global positioning system

FTE $\quad=$ flight-test engineer (of the sailplane)

GPS $=$ global positioning system

HUD = head-up display

INS $=$ inertial navigation system

IRIG = Inter-Range Instrumentation Group

IT $\quad=$ information technology

LCASB $=$ Loudness Code for Asymmetric Sonic Booms

NASA $=$ National Aeronautics and Space Administration

$\mathrm{PC}=$ personal computer

$\mathrm{PL} \quad=$ Stevens Mark VII perceived level

RQDS $=$ Research Quick Data System

\footnotetext{
* Aerospace Engineer, Research Aerodynamics, Mail Stop D-2228, AIAA nonmember.

Aerospace Engineer, Research Aerodynamics, Mail Stop D-2228, AIAA member.

$\$$ Aerospace Engineer, Research Aerodynamics, Mail Stop D-2228, AIAA nonmember.

$\S$ Senior Scientist, Applied Research Lab, 218 Applied Science Building, AIAA nonmember.

** Associate Professor, Graduate Program in Acoustics, 201 Applied Science Building. AIAA Senior member.

${ }^{\dagger \dagger}$ Research Assistant, Graduate Program in Acoustics, 201 Applied Science Building, AIAA nonmember.
} 


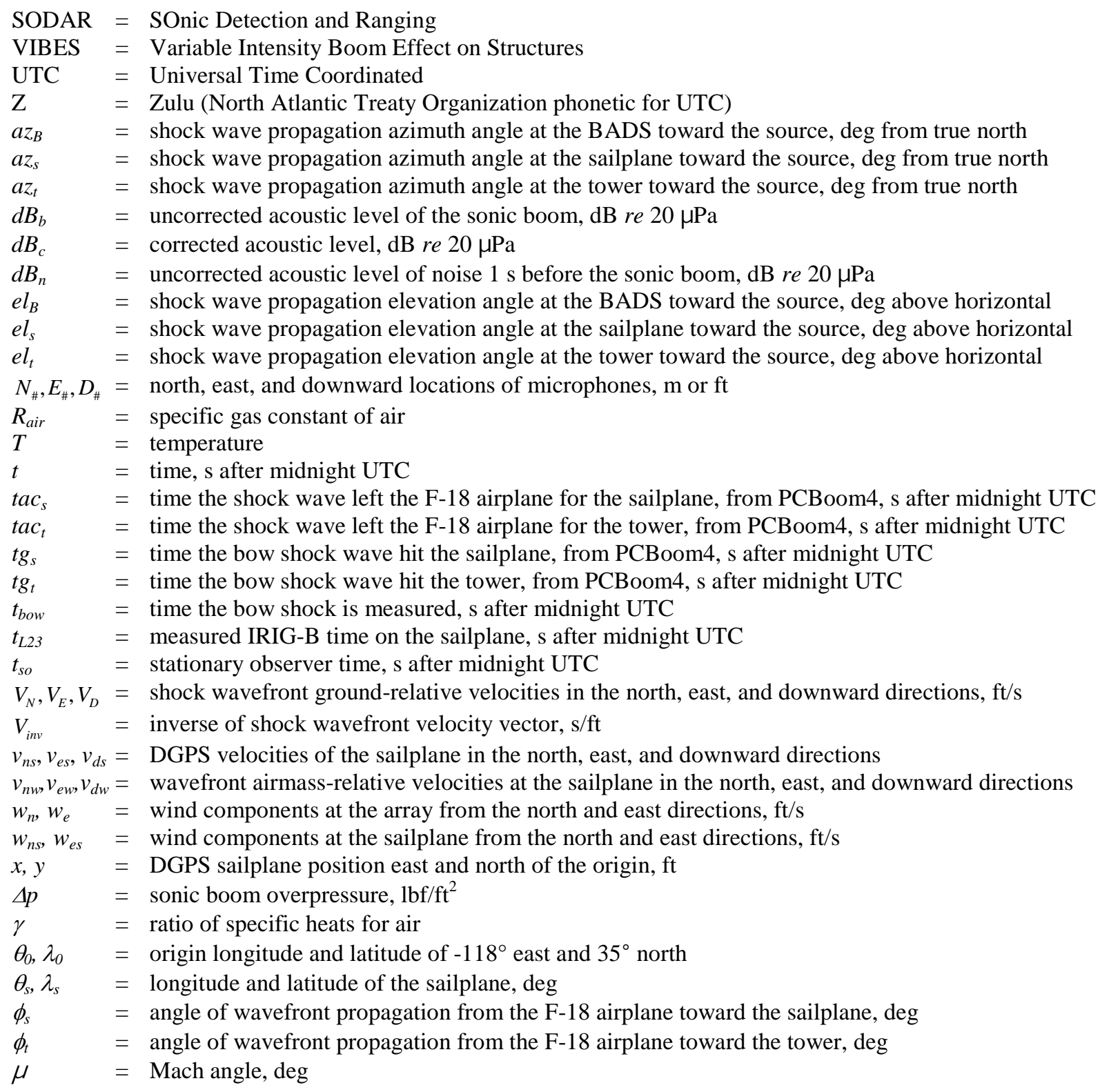

\section{Introduction}

series of flights generating low- to conventional-intensity sonic booms were flown in July 2007 to investigate their effect on a house of modern construction, and to provide a database for the validation of sonic boom propagation codes. This project is known as House VIBES (Variable Intensity Boom Effect on Structures), part of the National Aeronautics and Space Administration (NASA) Fundamental Aeronautics', Aeronautics Research Mission Directorate's, Supersonics Research Program. The United States Air Force Test Pilot School at Edwards Air Force Base (Edwards, California, USA), the Gulfstream Corporation (Savannah, Georgia, USA), and Pennsylvania State University (University Park, Pennsylvania, USA) also were participants in the project. Seven flights were flown with NASA Dryden Flight Research Center (Edwards, California, USA) F-18 airplanes (McDonnell Douglas, now the Boeing Company, Chicago, Illinois, USA) generating 31 low-intensity and 12 normal-intensity N-waves. An extra flight was flown to validate the airdata calibration of the airplanes. These sonic booms at the house ranged in overpressure from $0.08 \mathrm{lbf} / \mathrm{ft}^{2}$ to $2.20 \mathrm{lbf} / \mathrm{ft}^{2}$, and had risetimes of approximately $50 \mathrm{~ms}$ to $0.7 \mathrm{~ms}$. These risetimes were determined from 0 to 100 percent of maximum overpressure on a ground-level microphone. 
This house structural test is a follow-on test to one performed on an older house the previous year. ${ }^{1}$ The data from this newer house are not part of this paper, but these supersonic flights gave the opportunity to also measure other sonic boom propagation phenomena, outlined below. Bütikofer and Thomann ${ }^{2}$ reported that A-weighted sound levels were lower at $1.2 \mathrm{~m}$ than at $10.0 \mathrm{~m}$ heights far to the side of a jet engine aircraft, where the received noise is dominated by low frequencies. Since the low-intensity sonic booms for these flights have low propagation elevation angles it was of interest to see if sonic boom acoustic level varied with height over $10 \mathrm{~m}$, since most residences are of this scale. A $10 \mathrm{~m}$ tall tower with 10 microphones along its height and four ground-level microphones around its base was erected in an empty field a few hundred feet from the house. These tower data can be used to determine the effects of height on shock wave incidence and reflection angles, reflection factor, and attenuation or amplification. Ground impedance data were taken at the $10 \mathrm{~m}$ tall tower consisting of white noise and swept-sine recordings in order to determine ground impedance as a function of frequency, but this analysis is not yet complete.

Advances in computational techniques have made it possible to design supersonic aircraft having something other than the normal-intensity $\mathrm{N}$-wave sonic boom. ${ }^{3}$ The sonic booms generated by these new aircraft are referred to as "low-booms" because they in theory will be quieter and less annoying than normal-intensity sonic booms. Such "low-boom" designs could lead to commercial supersonic flight in the near future. Before such aircraft can be built, engineers must come up with a way to model the effects of the atmosphere. They need to understand how the atmosphere will alter the "low-boom" waveform. One way to do this is by modeling the atmosphere as a finiteimpulse-response filter.

A sailplane was instrumented with microphones, and flown above the planetary turbulent boundary layer to intercept the shock wave on its way to the tower. The finite-impulse-response filter is estimated from the sailplane measurement and the ground measurement. The resulting filter then is a representation of the atmosphere at those two points in space and time. The filter can be used as a design tool to investigate the variability of proposed "lowboom" waveforms, with the intention of producing an acceptably quiet supersonic aircraft.

The airborne and ground systems used in this project will be presented, along with the maneuvers, preflight planning, and analysis techniques used. Representative sonic boom flight results will be shown along with comparisons to the sonic boom prediction code PCBoom $4 .{ }^{4}$ The Appendix contains details of the system hardware and flight research techniques used, as well as tabulated data from all the supersonic passes.

\section{System Descriptions}

The two main aircraft of this project will now be described, including the instrumentation used. A variety of sensors at and near the ground as well as their recording systems will be described. Atmospheric data were also gathered from various sensors, and these are also described.

\section{A. The F-18B Sonic Boom Generating Airplane}

The NASA F-18 airplanes, tail numbers 852 (a two-seat trainer B model), Fig. 1, and 850 (a single-seat A model), are fighter airplanes built by McDonnell Aircraft (now the Boeing Company, Chicago, Illinois). Details of the instrumentation used on these F-18 airplanes are given in the Appendix. 


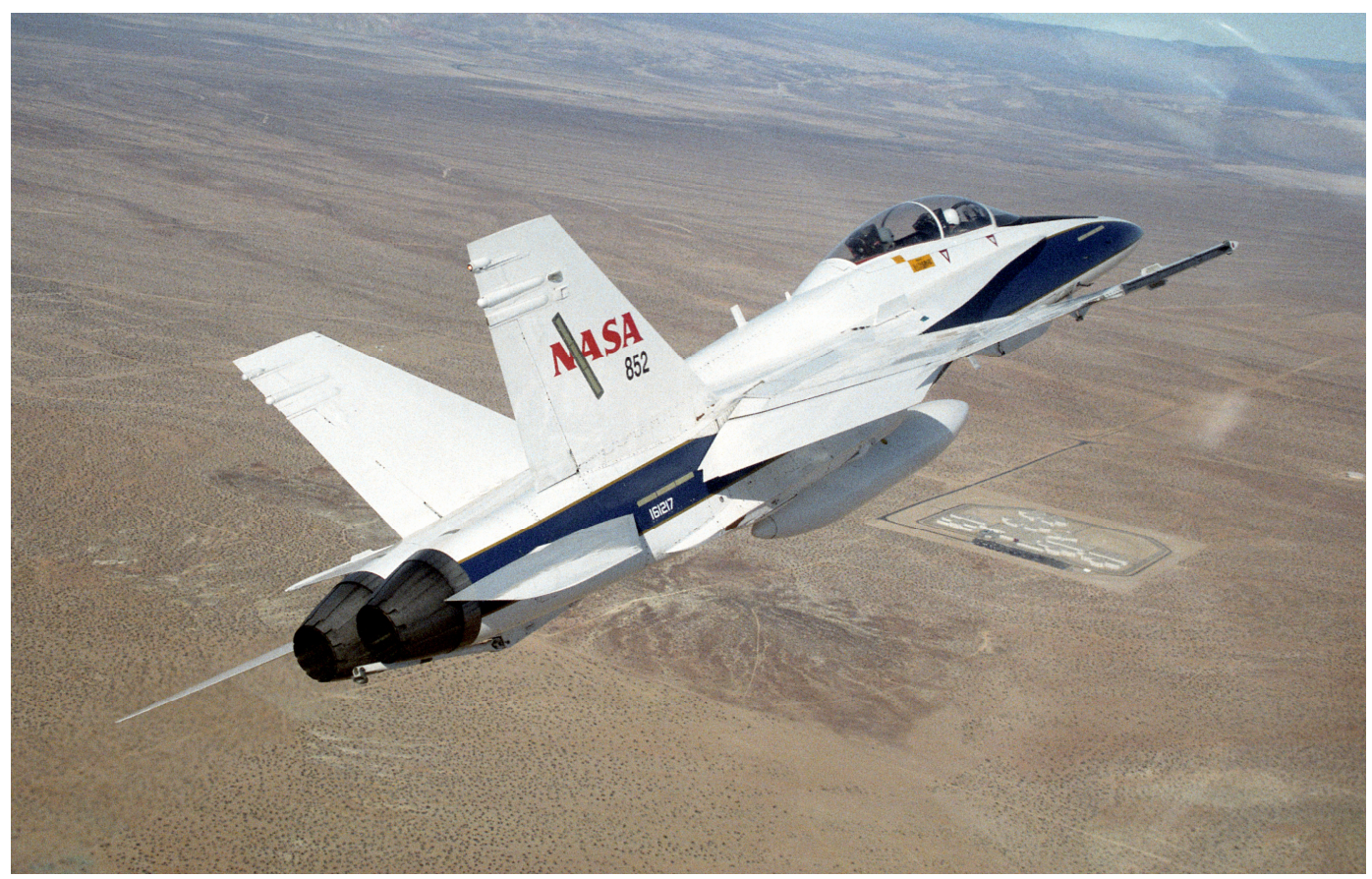

Figure 1. The instrumented NASA F-18B airplane, tail number 852, used for most of the sonic boom flights.

\section{B. The $10 \mathrm{~m}$ Microphone Tower}

A microphone tower approximately $130 \mathrm{~m}$ from the house held an array of ten microphones at $0,1.2,2,3,4,5$, $6,7,8$, and $10 \mathrm{~m}$ above the ground. Four microphones on groundboards were positioned at $5 \mathrm{~m}$ east and $10 \mathrm{~m}$ east, and at $5 \mathrm{~m}$ south and $10 \mathrm{~m}$ south of the tower, as shown in Fig. 2 through Fig. 4 . The $0 \mathrm{~m}$ tower microphone was also on a groundboard. Some data loss occurred due to conflicts between data recording software and mandated information technology (IT) security software. Details of the tower construction, microphones, recording equipment, and ground impedance measurements are given in the Appendix. 


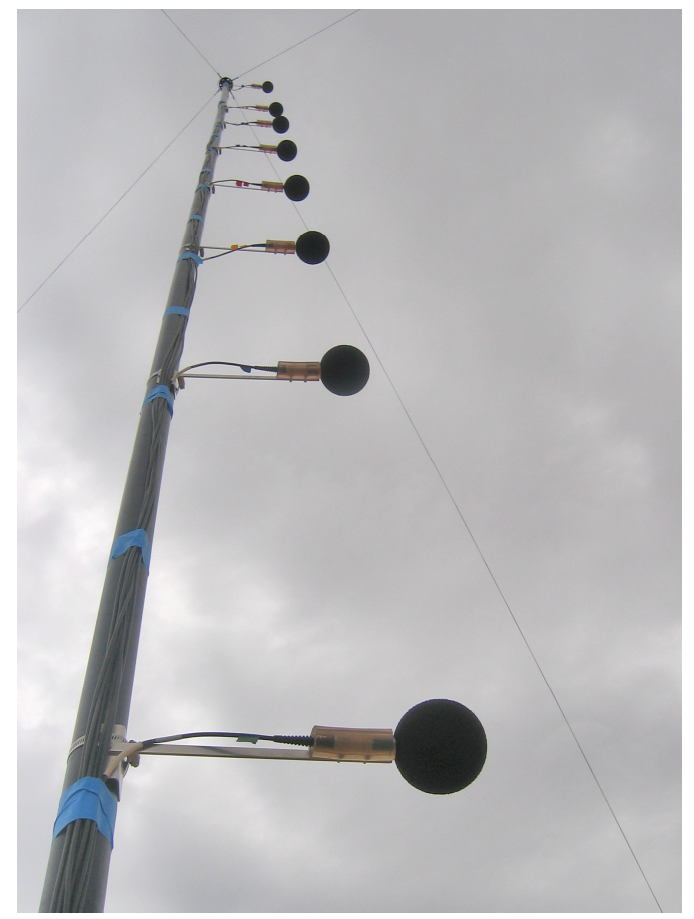

Figure 2. The $10 \mathrm{~m}$ tall tower with microphones at $2 \mathrm{~m}$ to $10 \mathrm{~m}$; the four guy-wires can be seen connected at the apex of the tower.

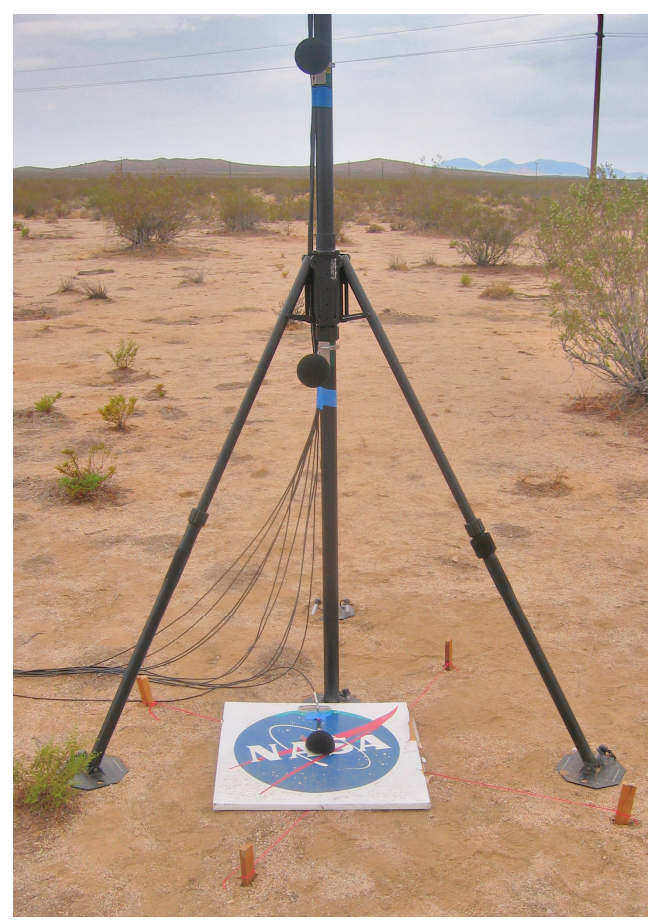

Figure 3. The $10 \mathrm{~m}$ tall tower with microphones at $1.2 \mathrm{~m}$ and $0 \mathrm{~m} ; 2 \mathrm{ft}$ by $2 \mathrm{ft}$ by 0.75 inch groundboards were used under the ground-level microphones. 


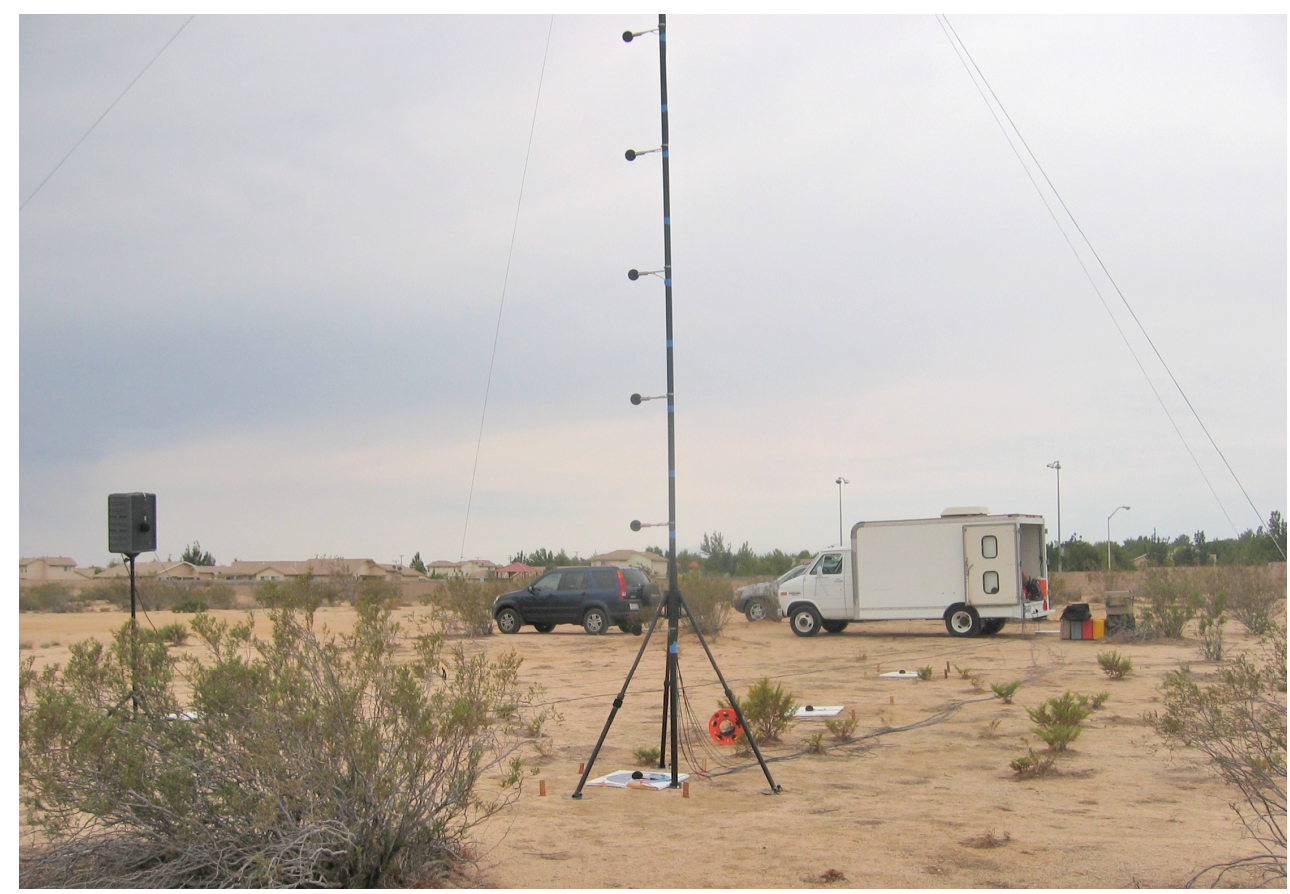

Figure 4. Tower, $5 \mathrm{~m}$ south and $5 \mathrm{~m}$ east groundboards, $10 \mathrm{~m}$ south groundboard, white noise loudspeaker, and support vehicles.

\section{The L-23 Sailplane Far-field Probing Aircraft}

The sailplane used for these measurements is a Super-Blanik L-23, Fig. 5, manufactured by the Let Aircraft Industries Company (Czech Republic), and was provided and operated by the U.S. Air Force Test Pilot School at Edwards Air Force Base. The L-23 is a two-place metal sailplane with a $16 \mathrm{~m}(52.5 \mathrm{ft})$ wingspan and a $540 \mathrm{~kg}(1190$ lb) gross takeoff weight.

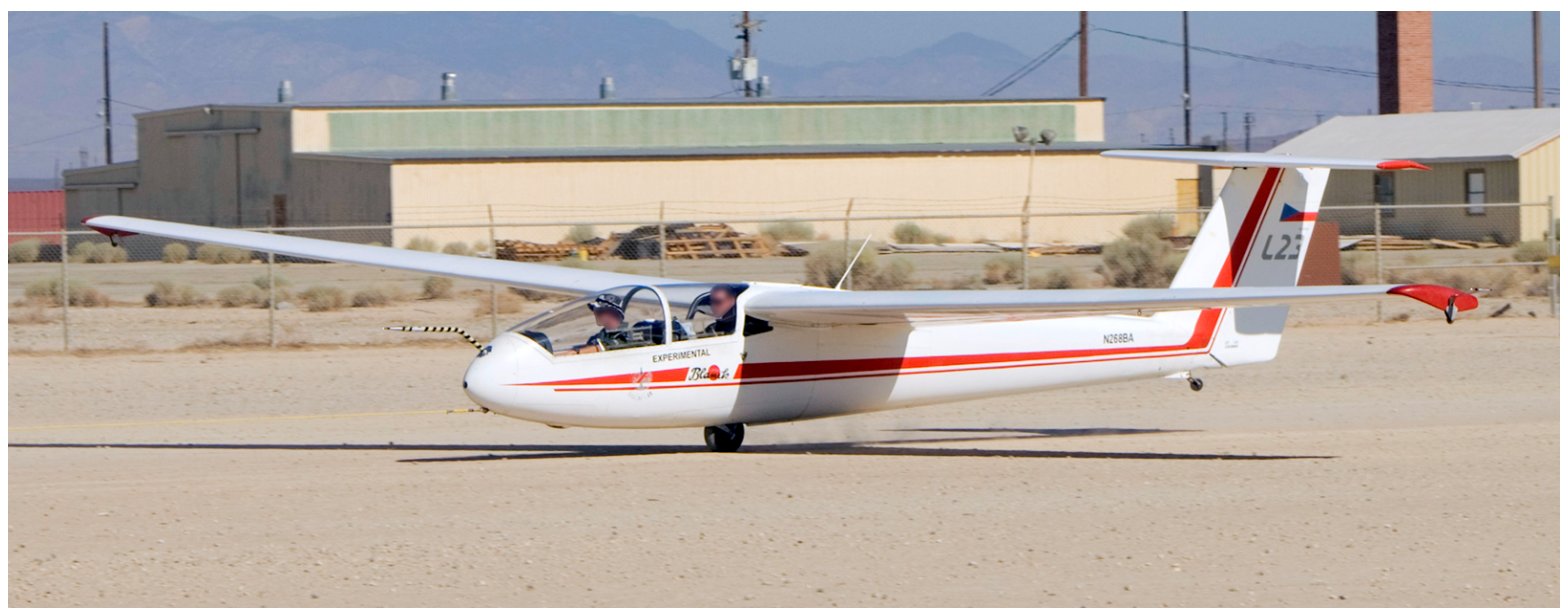

Figure 5. The United States Air Force Test Pilot School L-23 Super-Blanik sailplane.

The L-23 was configured with two external microphones: a wingtip-mounted microphone, and a noseboommounted microphone, Fig. 6 . The Appendix contains more detailed information about the sailplane instrumentation system. 


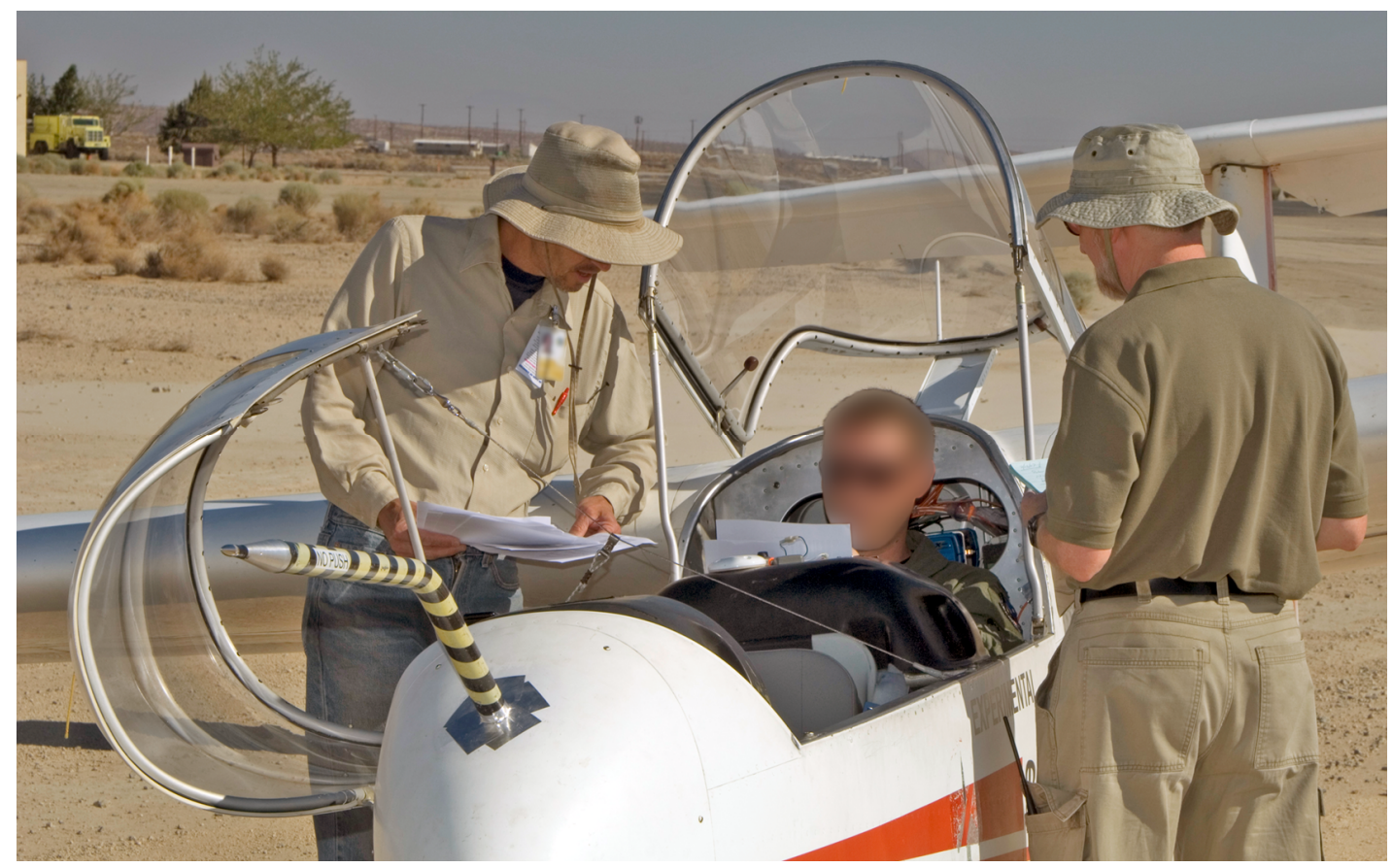

Figure 6. The sailplane's noseboom-mounted microphone and bullet-nosed windscreen.

\section{Other Sensors}

A variety of ground-based sensors were employed in this project, and a map showing their locations is presented in Fig. 7. The coordinates of these sensors are given in Table I. ${ }^{5}$

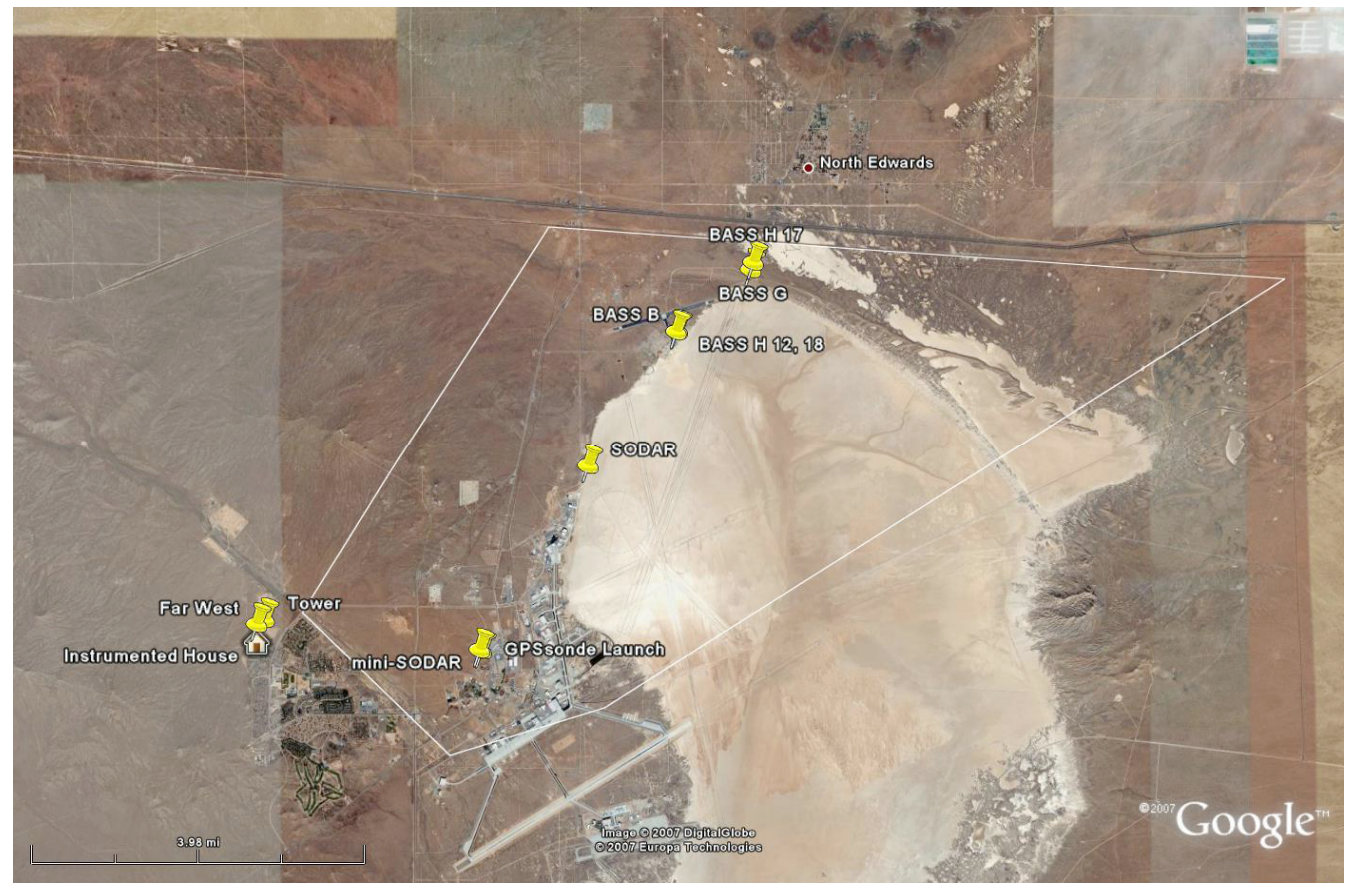

Figure 7. Map of local Edwards Air Force Base showing sailplane operating area as white outline, and selected other sensor locations; aerial map from GoogleEarthPro ${ }^{\mathrm{TM}}$.

The nine-year-old, single-story, duplex, uninhabited house, Fig. 8, is located in a residential neighborhood of Edwards Air Force Base, and was instrumented with over 100 sensors for sound and vibration. 


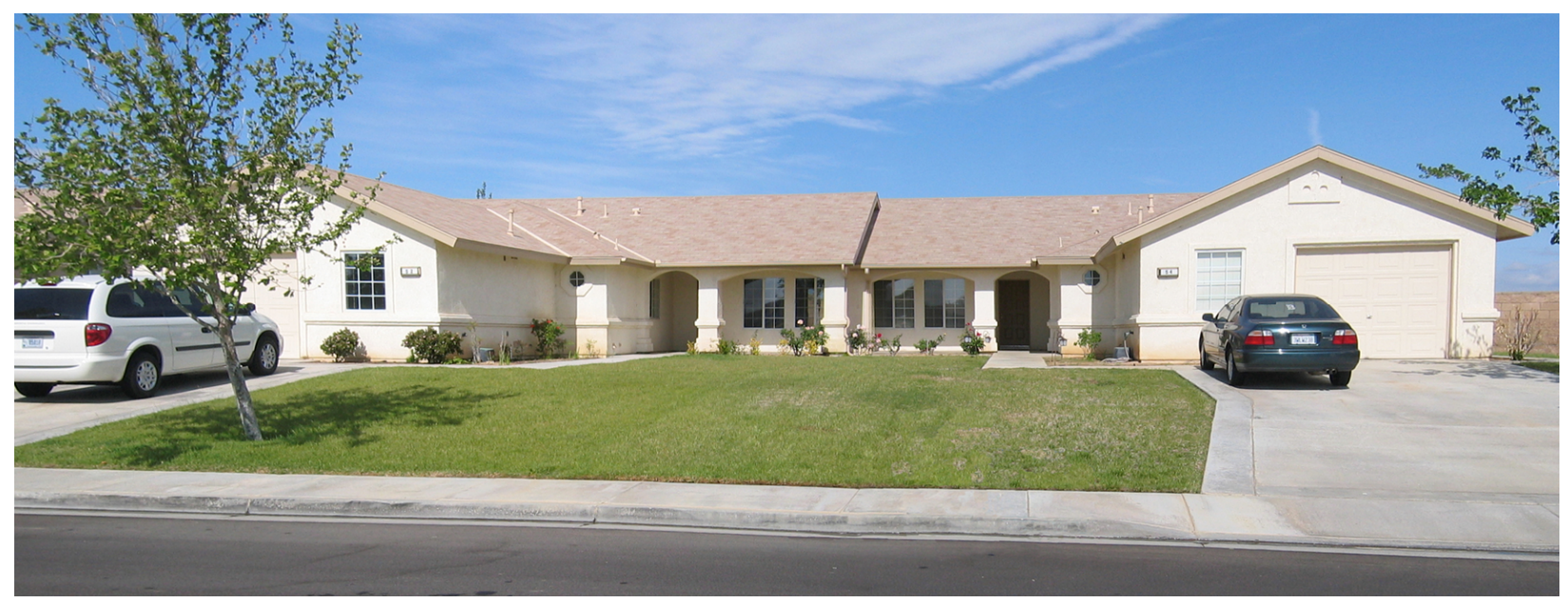

Figure 8. The duplex house used; the unit on the left was uninhabited and instrumented, the unit on the right was occupied by a family.

In addition to the array of microphones at the tower, a microphone named "far west" was placed approximately $350 \mathrm{ft}$ to the west of the house in a field, as shown in Fig. 9. This microphone was recorded by the instrumentation in the house, and was intended to give a recording away from the influences of structures. All microphone data were time-tagged with global positioning system (GPS) -based Inter-Range Instrumentation Group Format B (IRIG-B) ${ }^{6}$ time, to correlate with aircraft data.

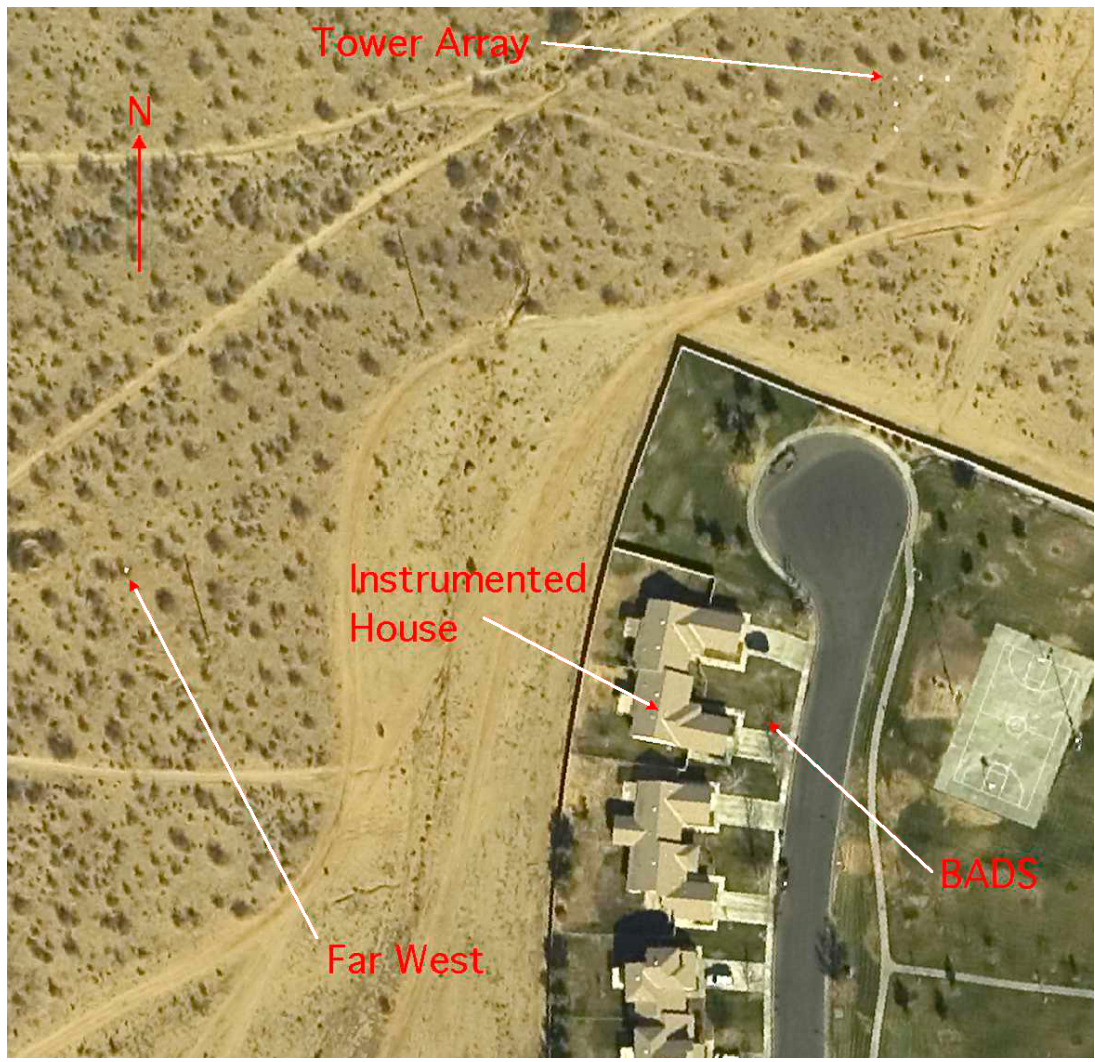

Figure 9. Aerial ER-2 photograph of instrumented house, tower array, far west microphone, and BADS location. White $2 \mathrm{ft}$ by $2 \mathrm{ft}$ groundboards are in place at the far west and tower array locations, but the $10 \mathrm{~m}$ tower is not erected. 
A Boom Amplitude and Direction Sensor (BADS) which is an octahedron with a pressure transducer on each of its six vertices, was used in the front yard of the house to measure shock wave angles. The BADS is shown in Fig. 10. The BADS data, like the $10 \mathrm{~m}$ tower data, were time-tagged using a GPS receiver. Several Boom Amplitude and Shape Sensors (BASS) were deployed scattered about where a focused sonic boom from the low-boom dive might be. The BASS units are single-transducer versions of the BADS, and both can be autonomous, recording at 8333 samples per second. Reference AIAA-2005-0010 fully describes these systems. ${ }^{7}$ The autonomous feature of the BADS to trigger on a sonic boom fails for the very quiet low booms, and so a manual trigger was employed. At times the operator did not trigger the BADS at the proper time, and those data were not recorded.

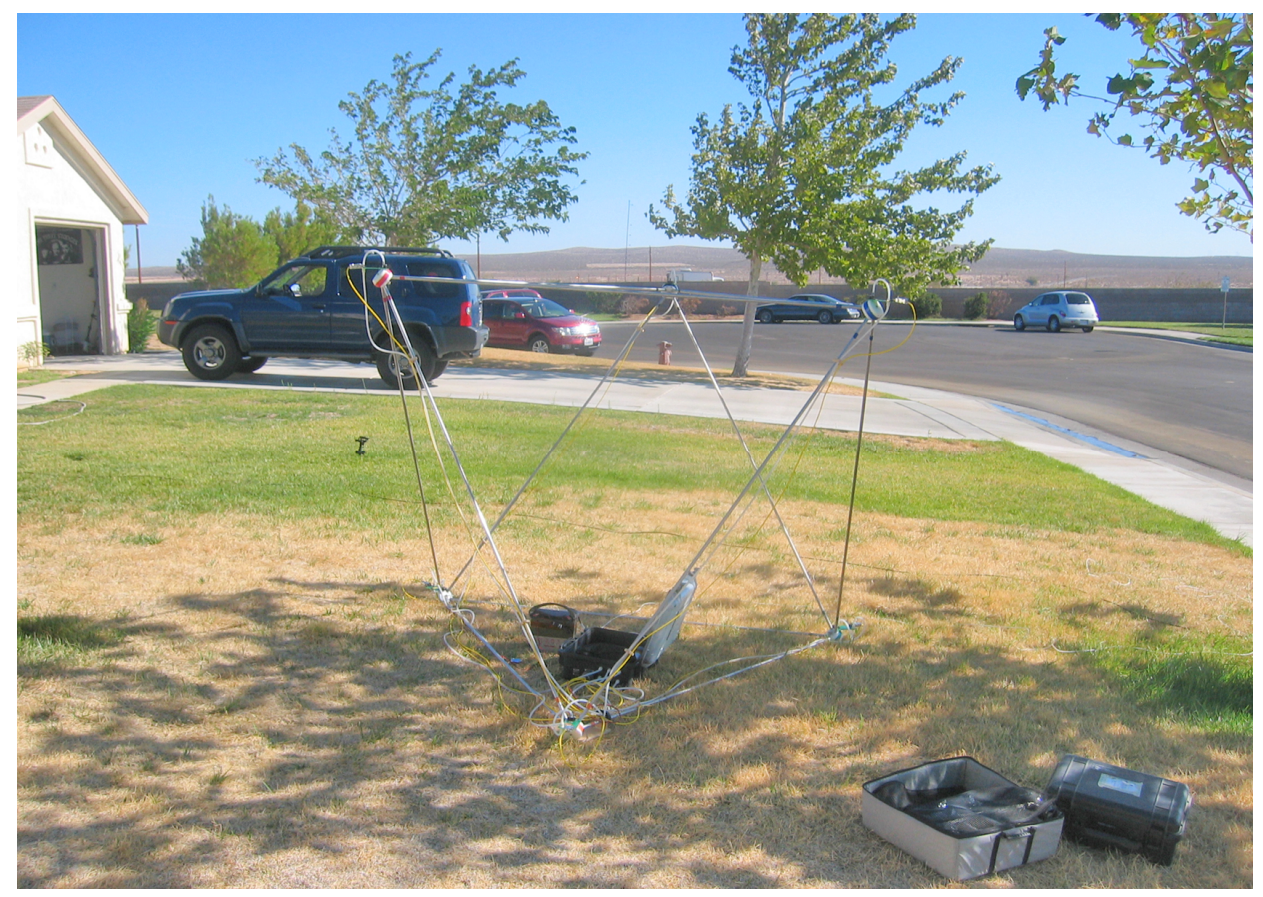

Figure 10. The BADS in the front yard of the house.

Whereas the BADS gives a six-element sensor array with a geometric scale of approximately $1.8 \mathrm{~m}$, and the tower array gives a 14-element sensor array with a $10 \mathrm{~m}$ scale, using a single sensor at the BADS (at node 1), another single sensor at the tower ( $0 \mathrm{~m}$ at the tower), and the one far west microphone give a three-element nearly horizontal array with approximately a $130 \mathrm{~m}$ scale. This sensor arrangement will be called the large triple array throughout this paper. The sonic boom arrival time at each sensor can be used to calculate the azimuth angle of the sonic boom. Since these three sensors are in a nearly horizontal plane, they yield no information about the elevation angle of the sonic boom.

Atmospheric measurements were taken on the ground and from weather balloons, and these are described in more detail in the Appendix.

\section{Maneuvers and Analysis}

For each aircraft, the flight maneuvers used, preflight waypoint planning, and data analysis techniques will be described. Sonic boom data analysis techniques will also be presented.

\section{A. Airdata Calibration}

Sonic boom propagation direction is very sensitive to the true Mach number of the vehicle. While the production F-18 airdata computer (ADC) gives sufficiently accurate airspeed, Mach, and altitude for its military mission, a higher accuracy is needed for sonic boom research. Details of the airdata calibration are given in the Appendix.

American Institute of Aeronautics and Astronautics 092407 


\section{B. Low-boom Dives}

To generate the low-intensity sonic booms a novel Mach 1.1, 53 deg dive maneuver ${ }^{8}$ was employed. Very low overpressures of less than $0.1 \mathrm{lbf} / \mathrm{ft}^{2}$ are felt approximately $20 \mathrm{nmi}$ downrange from the aircraft with very loud focused booms near the dive point, as well as a continuum of sonic boom overpressures between these two extremes. Using preflight weather balloons to determine the temperature and wind profile in excess of 50,000 ft, PCBoom4 was used to predict the sonic boom carpet, both in location and intensity, Fig. 11. The dive point of the F18 airplane was selected to put the desired overpressure at the house and tower while preventing very loud (defined as $2 \mathrm{lbf} / \mathrm{ft}^{2}$ or higher) sonic booms from impacting nearby populated areas. PCBoom 4 was also used to determine the sailplane waypoints used to intercept the shock waves. Details of this maneuver are given in the Appendix.

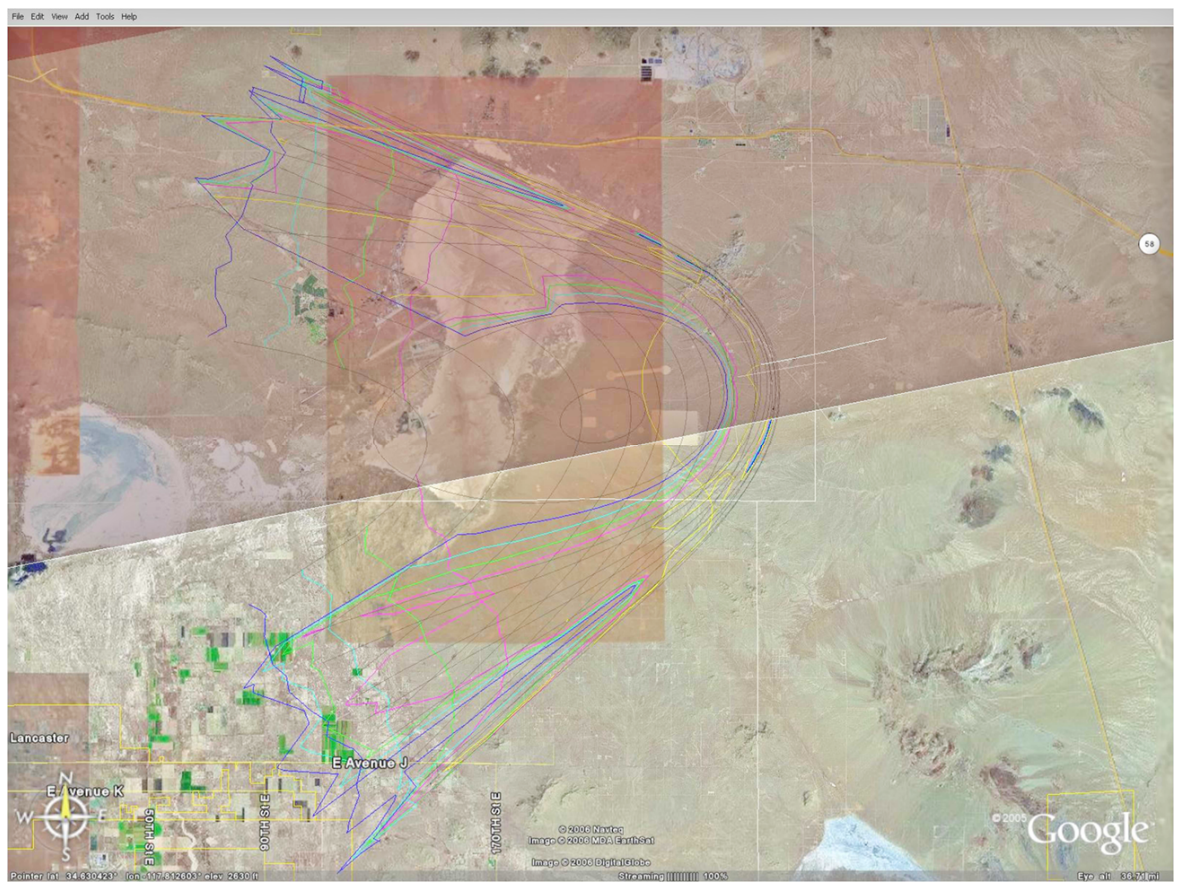

Figure 11. Low-boom dive sonic boom footprint superimposed on GoogleEarthPro ${ }^{\mathrm{TM}}$ map.

\section{Normal Booms}

In order to generate sonic boom overpressures $\left(1.0 \mathrm{lbf} / \mathrm{ft}^{2}\right.$ to $\left.2.0 \mathrm{lbf} / \mathrm{ft}^{2}\right)$ usually heard from conventional supersonic aircraft, which we call "normal" booms, the F-18 airplane was flown at a true Mach number of 1.25 and a pressure altitude of 32,000 ft. The track of the F-18 airplane was adjusted based on preflight weather balloons and PCBoom4 output to achieve the desired overpressure and boom direction. Three different boom propagation directions were selected to present different loadings on the house. The sailplane was also used on these flights to intercept the sonic boom that hit the tower and house. The Appendix contains details of how these test points were flown.

\section{Waypoint Planning}

The processes used to achieve the desired sonic boom on the ground sensors and the sailplane is described in detail in the Appendix. In a general sense, PCBoom4, along with preflight GPSsonde weather balloon data, were used for these calculations.

\section{E. Sailplane Waypoint Acquisition}

In order for the sailplane to intercept the particular shock wave on its way to the ground microphone, the sailplane crew needed to achieve the desired waypoint (latitude, longitude, and altitude) at the predetermined time, heading into the shock wave propagation direction, at the most acoustically quiet airspeed, all while remaining within the sailplane operating area. The sailplane crew has a most demanding task in this multi-dimensional aerial ballet, and this task is detailed in the Appendix. 


\section{F. Raypath Determination}

At a particular instant in time and at a particular direction, a shock wave emanates from the F-18 airplane along a curving raypath and hits the sailplane. If the sailplane were perfectly positioned, this raypath would continue downward until ending at the tower location. An analysis was performed to determine how closely the sailplanemeasured sonic boom came to the tower, and this analysis is detailed in the Appendix. This analysis was performed for each supersonic pass, and the results are shown in Fig. 12 and Fig. 13. Each sailplane raypath endpoint at the ground is denoted with an "x," with the flight and pass number beside the symbol: for example, 1086P3 for flight number 1086, pass number 3 .

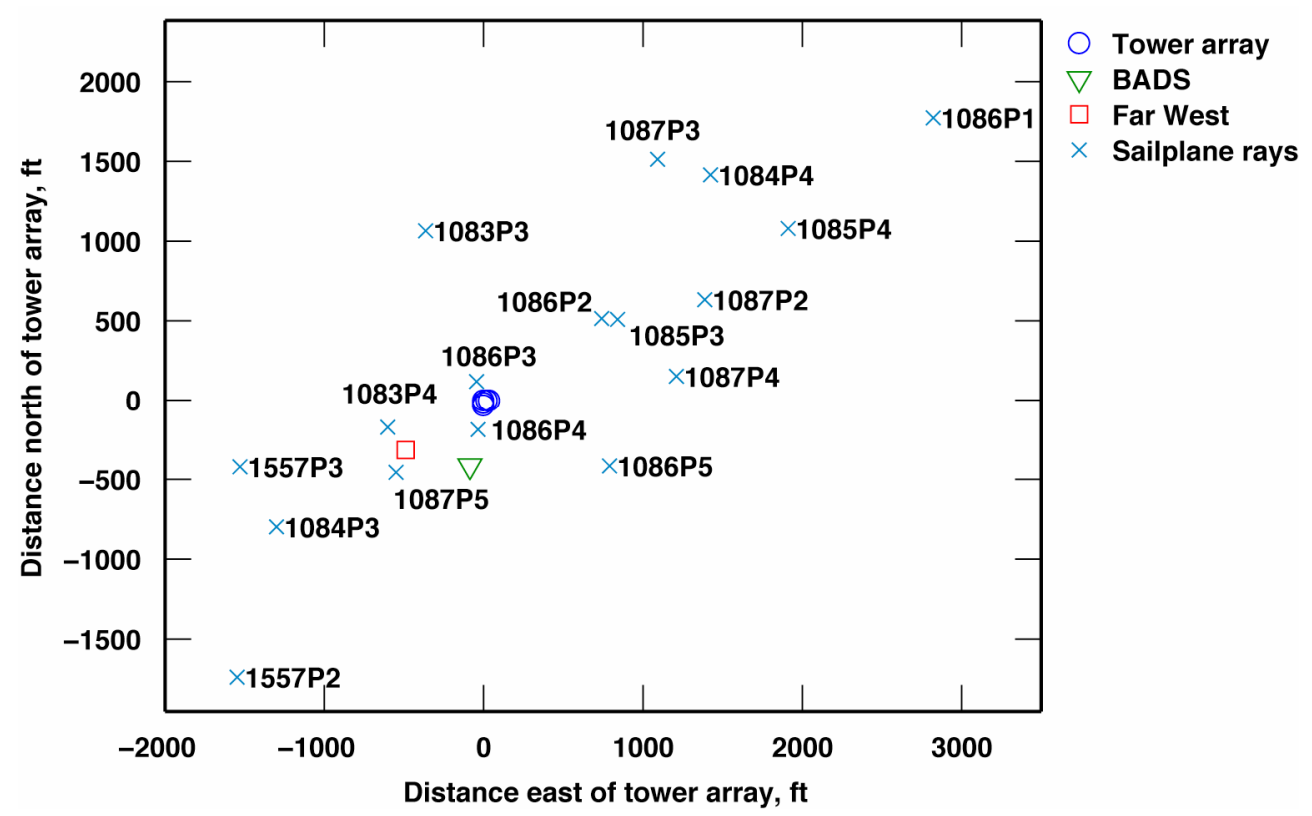

Figure 12. Sailplane raypath endpoints in relation to ground sensors.

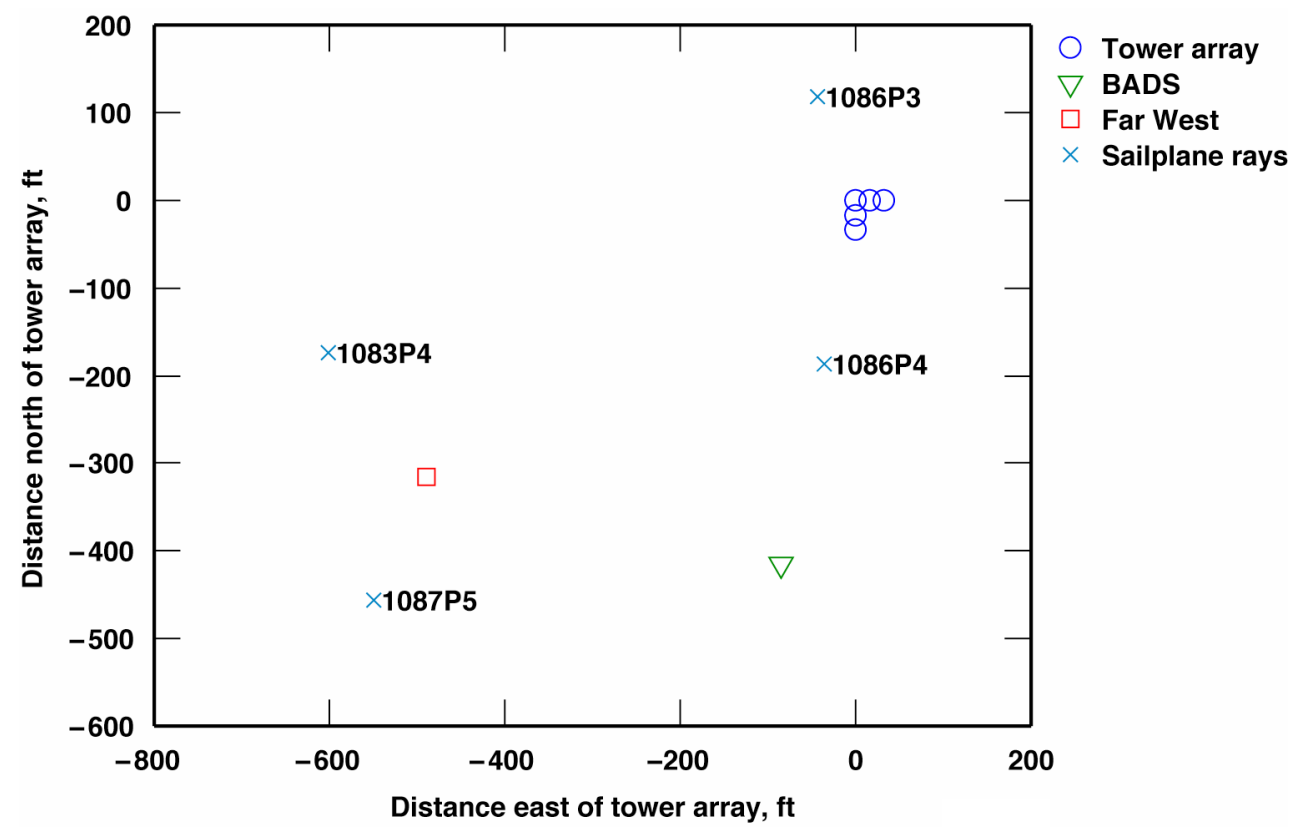

Figure 13. Sailplane raypath endpoints in relation to ground sensors, closeup near ground sensors. 
The mean of the sailplane raypath endpoints lies approximately $1000 \mathrm{ft}$ northeast of the tower array, and this distance is approximately the mean of the measured inertial navigation system (INS) drift. Two raypaths hit very close to the tower array: flight 1086, passes 3 and 4 . Flight 1083, pass 4, and flight 1087, pass 5, hit very close to the far west microphone. These passes will be considered for the turbulence filtering analysis given below.

\section{G. Sailplane Signature Corrections}

\section{Pressure Corrections}

Several pressure corrections are made to the boom waveforms recorded from the sailplane. In contrast to ground recordings, the sailplane-measured waveforms are superimposed on a slowly varying background pressure. These slow variations in background pressure correlate well with altitude fluctuations ${ }^{9}$ as the sailplane descends, and the variations are sufficiently distinct from the booms that this varying background can be removed. A time-domain correction filter is then applied to the waveform that lowers the frequency response from $0.54 \mathrm{~Hz}$ to $0.10 \mathrm{~Hz}$, which removes the bowing of the expansion portion of the $\mathrm{N}$-wave. This correction filter is also used on ground-measured data for the determination of the idealized maximum overpressures and the turbulence filters described below. Details of these corrections are given in the Appendix.

\section{Geometric Corrections to Stationary Observer}

After the low-frequency response correction filter, the waveforms' timescale is adjusted to remove the effects of platform motion on the recording. If the sailplane is flying toward the oncoming acoustic wave, the sample points will be closer together with respect to the true pressure waveform than the same sampling rate used with a stationary microphone. The timescale of the sailplane waveform can be adjusted to produce the equivalent stationarymicrophone waveform. Details of this adjustment are given in the Appendix.

\section{H. Idealized Maximum Overpressure}

Due to the effects of a range of atmospheric irregularities and aircraft influences such as atmospheric perturbations, turbulence, and variations in flight parameters, some pressure signatures lack the ideal $\mathrm{N}$-wave structure. This is sometimes due to the superimposing of the $\mathrm{N}$-wave and $\mathrm{U}$-wave or other propagation attributes. The most common phenomena are spiking and rounding of the waveform. Pierce ${ }^{10}$ attributes the spiking effect to inward, concave rippling on the front of the shock, due to inhomogeneities in the atmosphere. This leads to a focusing of the rays, causing spiking. The rounding of the waveforms for HouseVIBES correlated with the low-intensity, greater rise time booms.

To determine the idealized maximum overpressure for these measured ground-level sonic boom signatures an extrapolation was performed on the data to reconstruct the $\mathrm{N}$-wave and locate the peak pressure, which is illustrated in Fig. 14 and Fig. 15. Through least squares analysis, fits of the initial pressure rise and subsequent pressure drop were calculated. The data used for each fit represent the "clean" portion of the rise and expansion of the signature, data before or after rounding or spiking. This analysis was performed on the $0 \mathrm{~m}$ microphone data of the tower, after the $0.1 \mathrm{~Hz}$ correction filter (see section K titled "Section III.G.1 Details (Pressure Corrections)" of the Appendix, below) was applied, to compute the total (incident and reflected) magnitude of the overpressure experienced at the ground. The intersection of the projected lines from the two least squares fits defines the idealized maximum overpressure of the signature. This method mitigates any distortion of the signature due to turbulence effects. 


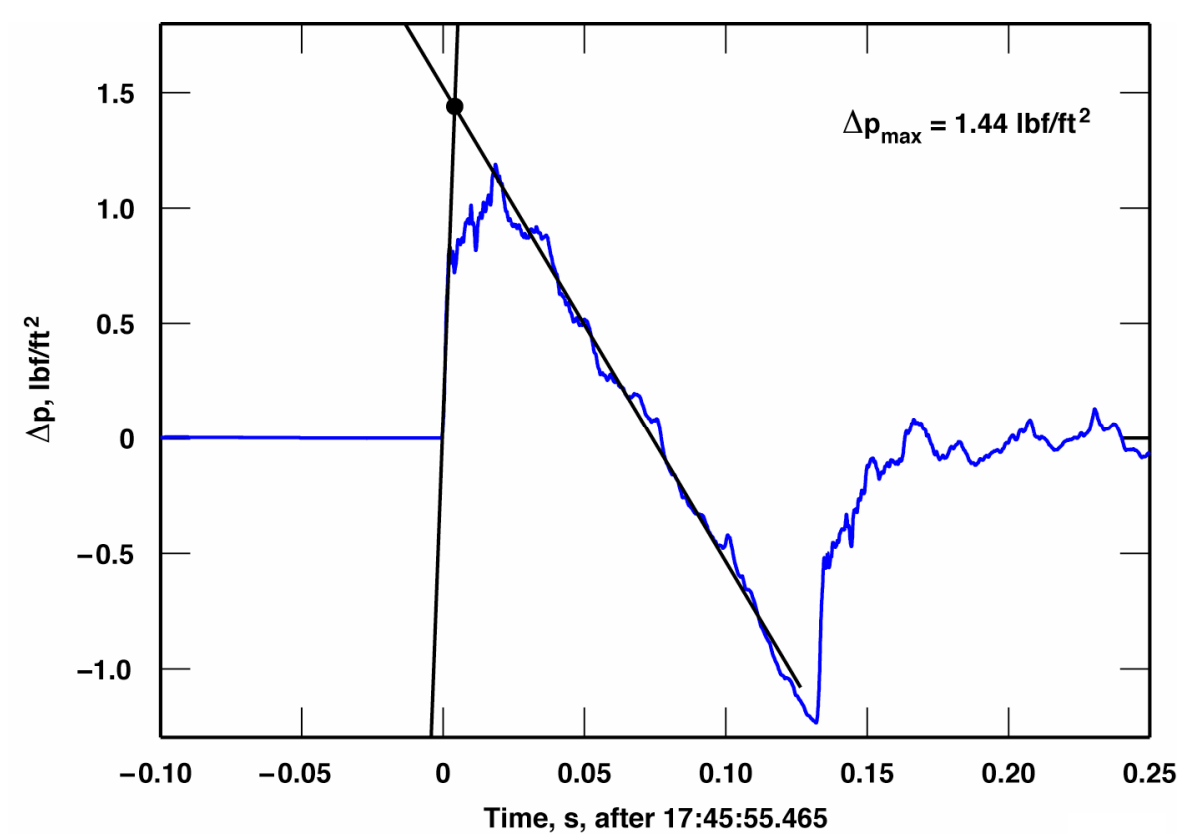

Figure 14. Computation of idealized maximum overpressure, flight 1086, pass 3.

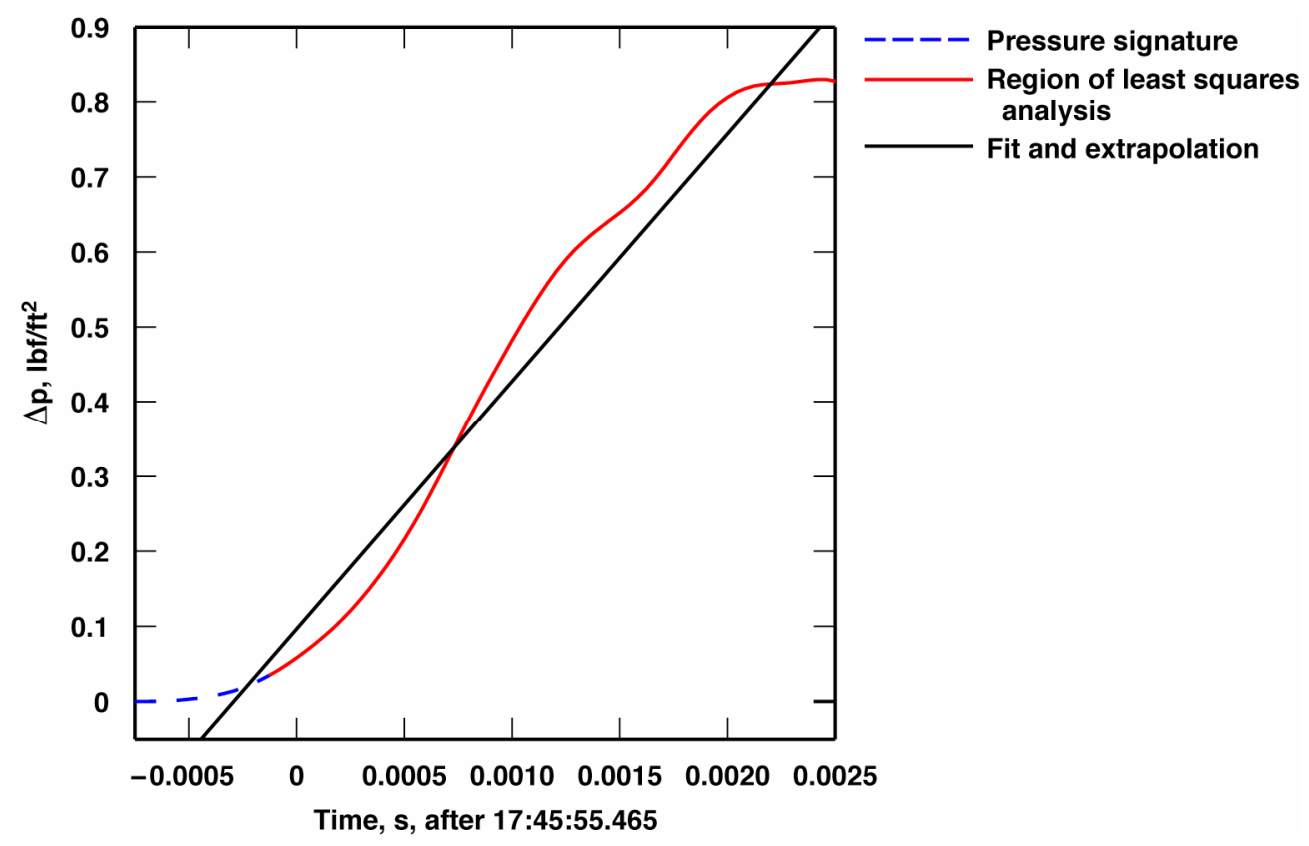

Figure 15. Closeup of bow shock, computation of idealized maximum overpressure, flight 1086, pass 3 .

\section{Shock Wave Directionality}

The differences in the incident bow shock arrival times and the distances between the microphone locations were used to compute the propagation elevation and azimuth (heading) angles. The arrival times from each channel were obtained by interpolation of the data, finding the time that the pressure, with the "preboom" extracted, crossed a predetermined value (typically on the order of $0.005 \mathrm{lbf} / \mathrm{ft}^{2}$ to $0.010 \mathrm{lbf} / \mathrm{ft}^{2}$ ). The "preboom" is the initial pressure level, defined by a small sample range before the bow shock. The elevation and azimuth angles were derived from the sonic boom wavefront velocity components, computed as the inverse vector of the least squares fit solution from the difference in arrival times and distances measured between microphones, as shown in Eq. (1): 


$$
\left[V_{i n v}\right]=\left[\begin{array}{ccc}
\left(N_{2}-N_{1}\right) & \left(E_{2}-E_{1}\right) & \left(D_{2}-D_{1}\right) \\
\left(N_{3}-N_{1}\right) & \left(E_{3}-E_{1}\right) & \left(D_{3}-D_{1}\right) \\
\vdots & \vdots & \vdots \\
\left(N_{n}-N_{1}\right) & \left(E_{n}-E_{1}\right) & \left(D_{n}-D_{1}\right)
\end{array}\right] \backslash\left[\begin{array}{c}
\left(t_{\text {bow }_{2}}-t_{\text {bow }_{1}}\right) \\
\left(t_{\text {bow }_{3}}-t_{\text {bow }_{1}}\right) \\
\vdots \\
\left(t_{\text {bow }_{n}}-t_{\text {bow }_{1}}\right)
\end{array}\right]
$$

where the operation "l" is the least-squares Gaussian elimination operator. ${ }^{11}$ The velocity components are computed from the resulting inverse velocity vector in Eq. (2):

$$
\left[\begin{array}{c}
V_{N} \\
V_{E} \\
V_{D}
\end{array}\right]=\left(\left\|\left[V_{i n v}\right]\right\|^{-1}\right)^{2}\left[V_{i n v}\right]
$$

The elevation and azimuth angles are computed using Eq. (3) and Eq. (4).

$$
\begin{gathered}
\mathrm{e} l=\tan ^{-1}\left(\frac{V_{D}}{\sqrt{V_{N}^{2}+V_{E}^{2}}}\right) \cdot\left(\frac{180}{\pi}\right) \text { degrees } \\
a z=\tan ^{-1}\left(\frac{V_{E}}{V_{N}}\right) \cdot\left(\frac{180}{\pi}\right) \text { degrees }
\end{gathered}
$$

where $N, E$, and $D$ are the north, east, and down positions of the microphones, given in Table II. The BADS uses a magnetic compass with pitch and roll sensors to determine the orientation of its truss to level and true north. The variable $t_{\text {bow }}$ is the bow shock arrival time for each channel, and the subscript " 1 " denotes the first microphone to record the sonic boom. Equation (1) through Eq. (4) are used: for the BADS using 6 channels, for the $10 \mathrm{~m}$ tower using 14 channels, and for the large triple array (BADS Channel $1,10 \mathrm{~m}$ tower at $0 \mathrm{~m}$ height, and far west) as three channels with the height column in Eq. (1) assumed to be zero.

The computed elevation and azimuth angles are with respect to the ground for use with the structural acoustic data taken at the house. PCBoom4 reports angles with respect to the airmass, which differs from Eq. (3) and Eq. (4) due to winds. For the windiest test day the difference in angles between ground relative and airmass relative data is on the order of a few hundreths of a degree.

In this paper all computed azimuth and elevation angles of the sonic booms are for the incident bow shock only. Future work could be performed with the same technique on the tail shocks and U-waves, which should yield different angles. This technique is most correct when the incident and reflected shocks are clearly separated in time. For microphones close to the ground, shock thickening can cause the initial rise of the reflected shock wave to overlap onto the incident shock wave, skewing the measured arrival time. Limited analysis shows that including the near-ground microphones for shock waves with the greatest shock thickening caused computed elevation angle depression on the order of $1^{\circ}$, as compared with excluding the near-ground microphones. The data in this paper use all available microphones for a given array.

The ambient atmospheric temperature at the array can be computed, Eq. (5), from the speed of sound (the speed of the local sonic boom propagation), which is the magnitude of the previously defined velocity components, $V_{N}, V_{E}$, and $V_{D}$, including the effects of the corresponding wind components, $w_{n}$ and $w_{e}$. It is assumed that the wind direction is horizontal, that is, no vertical wind component exists.

$$
T=\frac{\left(V_{N}+w_{n}\right)^{2}+\left(V_{E}+w_{e}\right)^{2}+V_{D}^{2}}{\gamma R_{\text {air }}}
$$


Here, $\gamma$ is the specific heat ratio and $R_{\text {air }}$ is the specific gas constant of air. Notice that, while neglecting the wind may introduce only a few hundredths of a degree error in shock wave directionality, the effect on the temperature computation is much more substantial, influencing it by as much as $20^{\circ} \mathrm{F}$. The calculated temperature is used as a cross-check to the shock direction calculations.

\section{J. Acoustic Metric Calculation}

In order to determine the acoustic levels of each sonic boom, the data for each channel were analyzed using the Loudness Code for Asymmetric Sonic Booms (LCASB). ${ }^{12}$ The LCASB was designed by the NASA Langley Research Center, Hampton, Virginia, and calculates various acoustic metrics for a pressure data set. These metrics include Stevens Mark VII perceived level ${ }^{13}$ (PL), A-weighted sound exposure level ${ }^{14}$ (ASEL) values, and $\mathrm{C}$-weighted sound exposure level ${ }^{14}$ (CSEL) values.

For HouseVIBES, clips of the recorded pressure data containing only the sonic boom signature itself (from 0.025 $\mathrm{s}$ prior to the bow shock to 0.025 to $0.075 \mathrm{~s}$ after the tail shock) were used to compute the metrics, and so included the reflected shocks. The data were also artificially faded over a $0.025 \mathrm{~s}$ interval to a zero pressure level before and after the segments using an exponential decaying algorithm. Taking into consideration various possible sources of noise during the recordings (specifically, instrumentation and environmental noise) LCASB computations from similarly clipped and equal duration data segments taken $1 \mathrm{~s}$ before each sonic boom were used to diminish the influence of noise using Eq. (6):

$$
d B_{c}=10 \cdot \log _{10}\left(10^{\frac{d B_{b}}{10}}-10^{\frac{d B_{n}}{10}}\right)
$$

where $d B_{b}$ is the uncorrected acoustic level of the sonic boom selection and $d B_{n}$ is the uncorrected acoustic level of the equal duration selection $1 \mathrm{~s}$ prior to the sonic boom. The resulting, corrected acoustic levels $\left(d B_{c}\right)$ were related to the location of their channel in the microphone placement geometry, and a profile of the change of acoustic level with respect to distance above the ground was established for each recording.

\section{K. Turbulence Filters}

Atmospheric filter functions were derived from flight 1086, pass 4. Other flights were investigated, but were ultimately rejected, either because the waveform measured by the sailplane was rounded similar to the flight 1087 , pass 5 data in Fig. 16 (lacked sufficient high-frequency content) or because the raypath hit the ground away from the sensor location, Fig. 12. Five ground-level microphones at the tower location were used with the one sailplane measurement. 


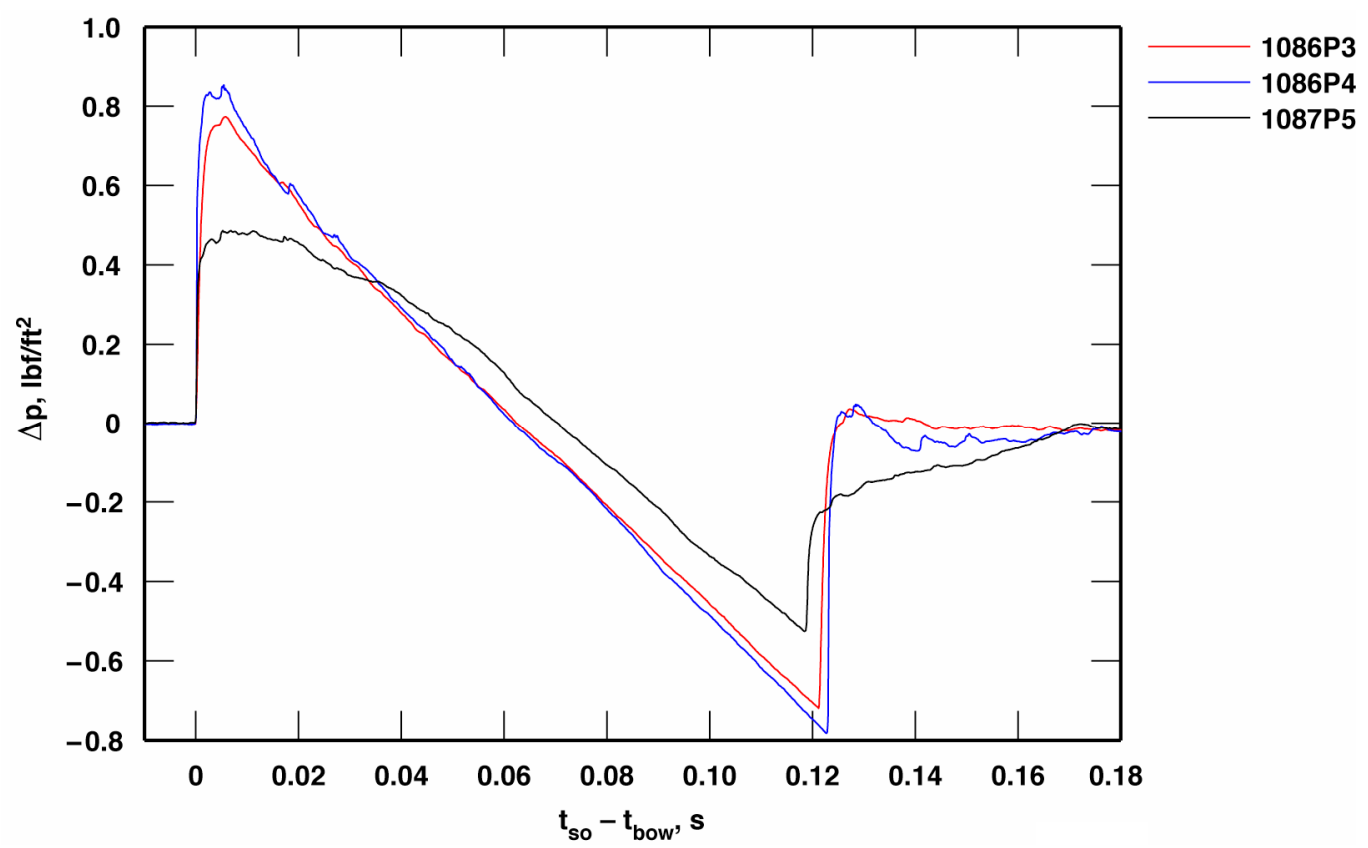

Figure 16. Three selected sailplane measurements, after being corrected for motion and low-frequency corrected.

All waveforms were low-frequency corrected to $0.1 \mathrm{~Hz}$, as described in the Appendix. Filter functions were derived by a matrix-based deconvolution method. ${ }^{15}$ A pseudo-inverse matrix was estimated which was then used to produce a set of filter coefficients which convert the positive pressure waveform (as measured by the sailplane, after being corrected for motion with Eq. (7) in the Appendix) into the measurement made on the ground. The negative pressure portion of the sailplane waveform was not used.

\section{Sonic Boom Flight Results}

A large matrix of all the supersonic passes located in the Appendix will now be presented, along with selected results showing representative features and some outliers. While not attempting to be exhaustive in its presentation, enough detail is shown to give the reader a sense of the kinds and qualities of the data for further analysis of this extensive database, which should be published in digital form before 2009 . Table III contains results from the $10 \mathrm{~m}$ tower, Table IV presents BADS results, Table V shows the far west and large triple array results, and the sailplane and F-18 airplane data are given in Table VI. All of these tables contain PCBoom4-calculated parameters in comparison to the measured data. Missing measured data in the tables is due to personal computer (PC) problems at the $10 \mathrm{~m}$ tower (a loss of 3 passes, or 7 percent), manual triggering errors at the BADS (a loss of 4 passes, or 9 percent), recording problems at the instrumented house for far west (1 pass lost, or 2 percent) or the sailplane returning to base after reaching its minimum test altitude (a loss of 15 passes, or 35 percent). Missing PCBoom 4 data in the tables is due to the sensor being beyond calculated Mach cutoff, but there was still an evanescent wave present (6 passes, or 14 percent).

\section{A. Ground Data}

1. BADS, $10 \mathrm{~m}$ Tower, and Large Triple Array Measured Data versus PCBoom4-computed Data

The 14 microphones of the $10 \mathrm{~m}$ tower taken as a medium-sized array and the six pressure transducers of the BADS taken as a small array yield shock arrival time and least squares azimuth and elevation shock wave angles. The large triple array taken as a large array yields shock wave azimuth angles. Low-intensity sonic booms that had idealized maximum overpressures of between $0.11 \mathrm{lbf} / \mathrm{ft}^{2}$ to $0.71 \mathrm{lbf} / \mathrm{ft}^{2}$ recorded elevation angles from near zero to $30^{\circ}$, with the higher overpressures having the higher elevation angles. For the 10 normal-intensity maneuvers recorded by the tower the idealized maximum overpressures ranged from $1.12 \mathrm{lbf} / \mathrm{ft}^{2}$ to $1.62 \mathrm{lbf} / \mathrm{ft}^{2}$ with elevation angles between $14^{\circ}$ and $24^{\circ}$. 
These measured azimuth and elevation angles were differenced with PCBoom4-derived azimuth and elevation angles using the measured F-18 airplane data and atmospheric data. Figure 17 shows the cumulative percentage of this magnitude difference for the BADS and the $10 \mathrm{~m}$ tower, and azimuth angle difference alone for the large triple array. It shows that the larger the array, the better the agreement with PCBoom4. For a given array size, azimuth has nearly the same or better agreement than elevation to PCBoom4. This is to be expected as these data include the near-ground microphone data, which can depress the calculated elevation angles. The BADS angular agreement with PCBoom4 is better than $2.6^{\circ}$ for half the sonic booms, and the same quantity is $1.5^{\circ}$ for the $10 \mathrm{~m}$ tower, and $0.6^{\circ}$ in azimuth for the large triple array. This is comparing the ground-relative angles as determined by the arrays with the airmass-relative angles calculated by PCBoom4. The difference in these two angle types is due to groundlevel winds, but is only on the order of a few hundredths of a degree.

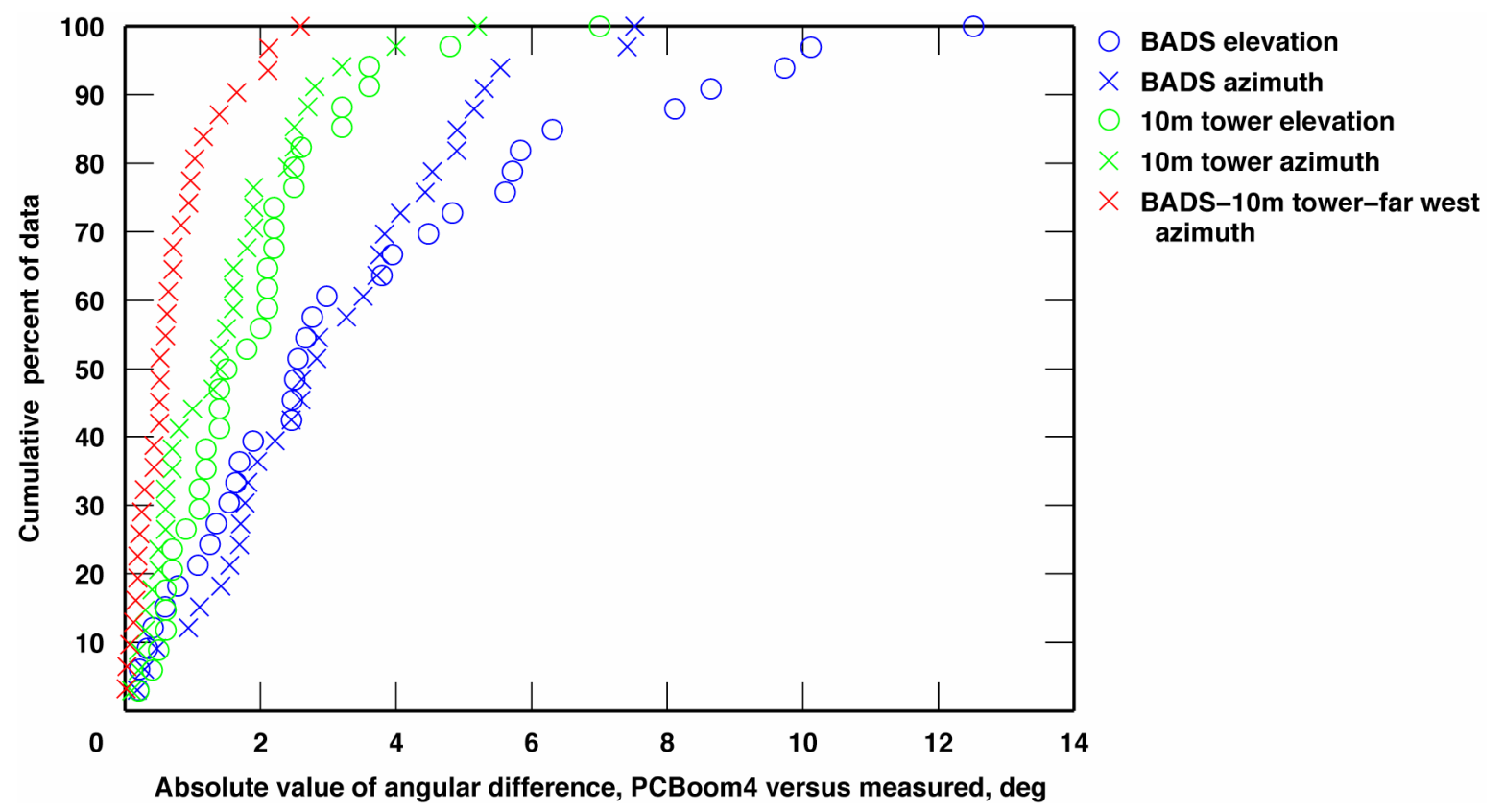

Figure 17. Angular difference in azimuth and elevation between PCBoom 4 and the BADS, $10 \mathrm{~m}$ tower, and large triple array.

Ambient temperatures were calculated using Eq. (5), and the results are shown in Table III and Table IV. For those passes when measured temperatures were not available due to hardware problems, estimates from nearby sensors (at the house or the tower) were made, and those are noted in the tables. Differences of up to $25^{\circ} \mathrm{F}$ (or Rankine) are seen on the $10 \mathrm{~m}$ tower data, but this corresponds to only a 2.3 percent difference in the speed of sound, and much worse for the BADS, with a maximum temperature difference of $83^{\circ} \mathrm{F}$ or 7.3 percent difference in the speed of sound. Figure 18 shows the speed of sound difference for the $10 \mathrm{~m}$ tower and BADS, and these data show that 70 percent of the sonic booms had less than 1.2 percent difference on the $10 \mathrm{~m}$ tower and 2 percent difference on the BADS. 


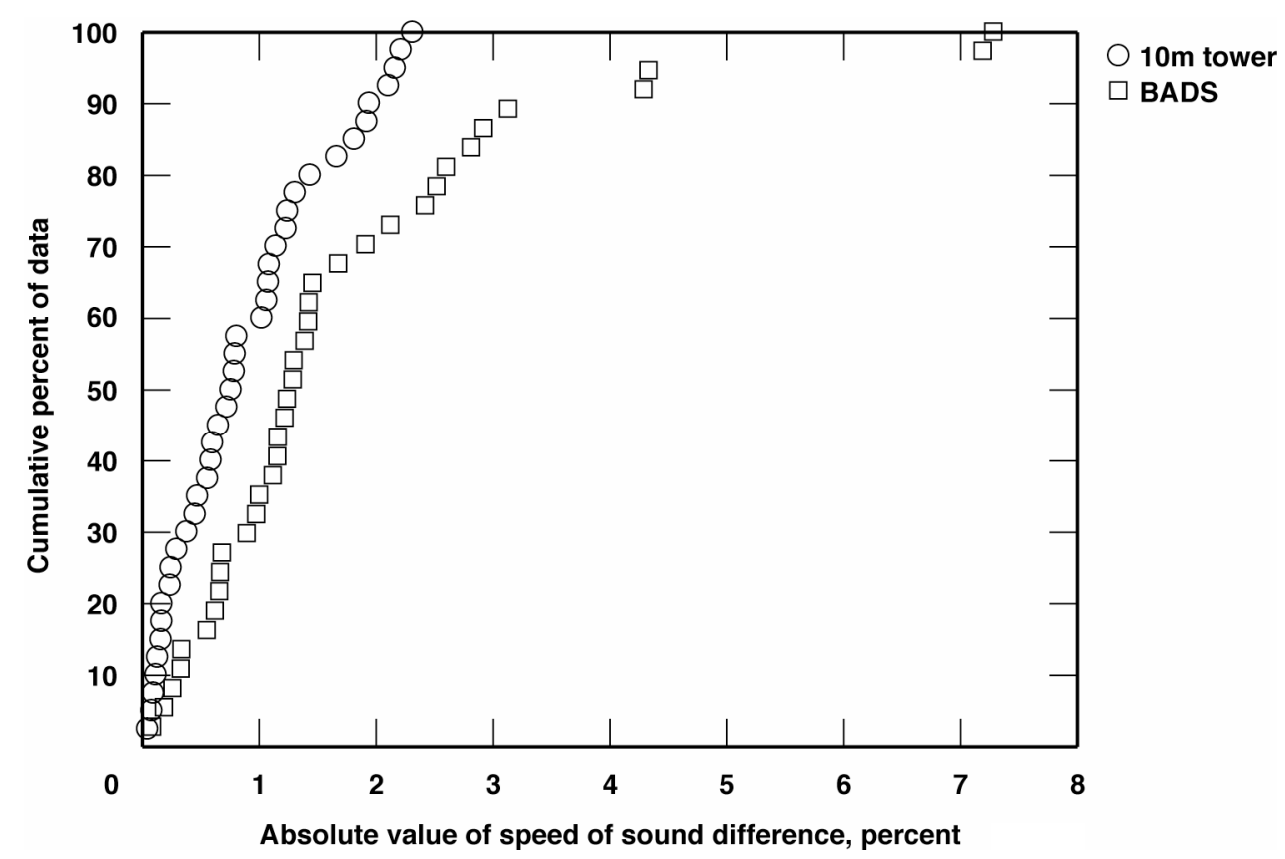

Figure 18. Speed of sound difference between measured with ambient temperatures and computed with the $10 \mathrm{~m}$ tower and BADS data.

The sonic boom arrival time difference is shown in Fig. 19, with both arrays yielding better than $0.2 \mathrm{~s}$ for 60 percent of the sonic booms. The idealized maximum overpressures from the $10 \mathrm{~m}$ tower center ground-level microphone were differenced with the PCBoom4-computed overpressure, and this is shown in Fig. 20. Approximately 70 percent of the sonic booms had agreement better than $0.1 \mathrm{lbf} / \mathrm{ft}^{2}$.

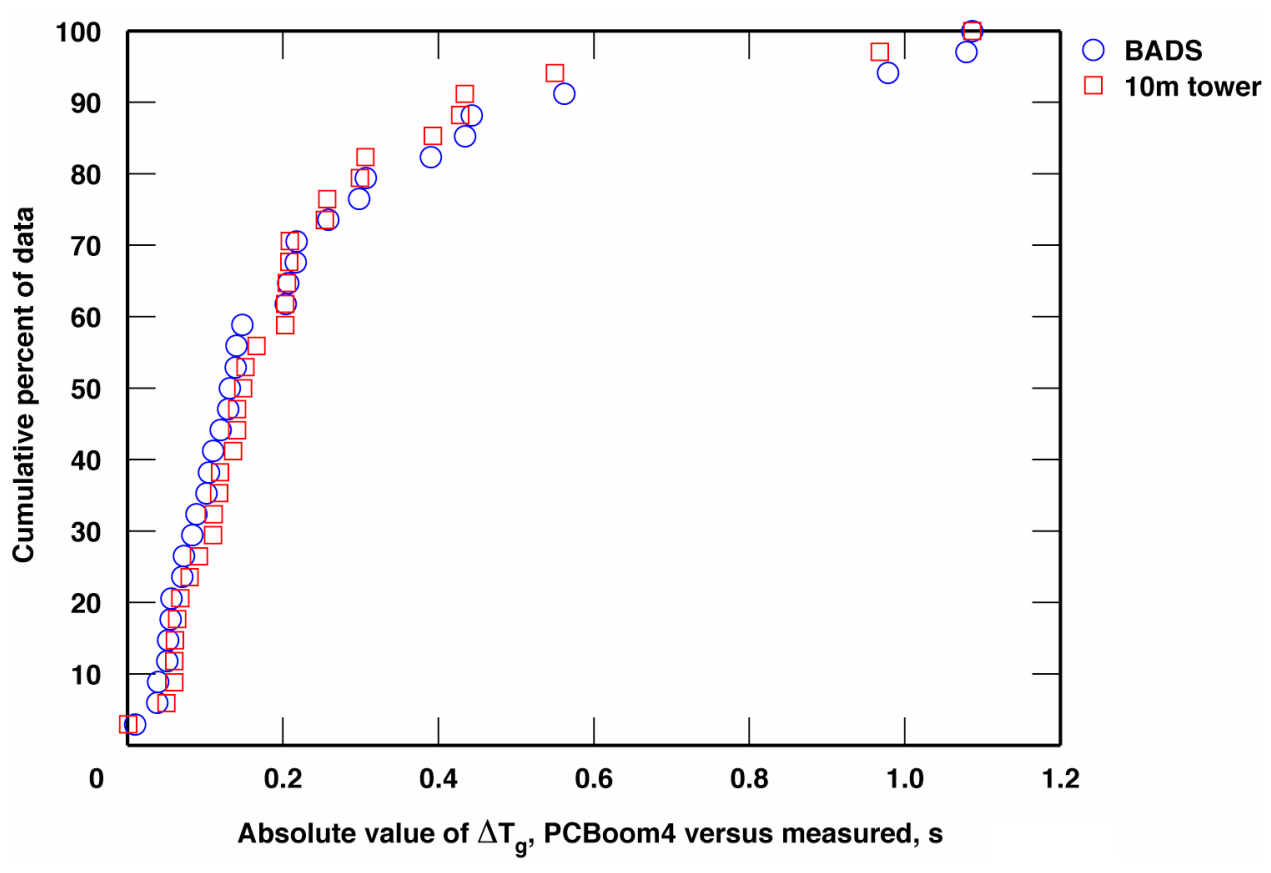

Figure 19. Time of arrival difference between PCBoom4 and BADS and $10 \mathrm{~m}$ tower data. 


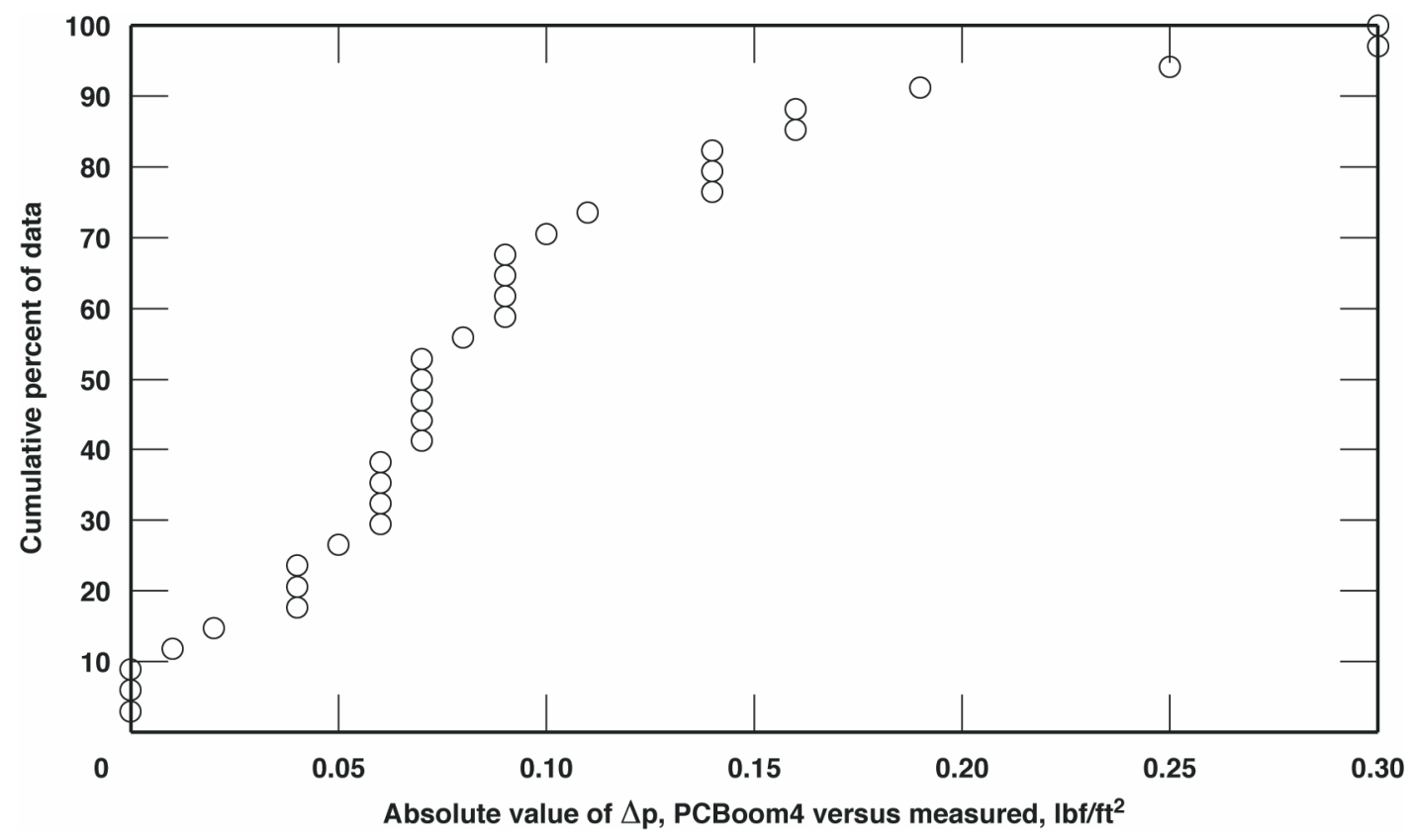

Figure 20. Idealized overpressure difference between PCBoom 4 and $10 \mathrm{~m}$ tower data.

The level of agreement of the measured shock wave directionality, arrival time, and overpressure levels to that calculated by PCBoom4 is considered excellent.

\section{Shock Structure and Acoustic Levels}

Nine sonic booms have been selected to show features of their bow shock structure as compared to the calculated acoustic levels of the entire $\mathrm{N}$-wave, including the reflected waves.

An evanescent wave of $0.09 \mathrm{lbf} / \mathrm{ft}^{2}$ overpressure was recorded on flight 1083, pass 1, as shown in Fig. 21 with an inset plot of the entire signature. These data show that all the microphone time histories from the tower over-plot onto one trace, showing the elevation angle is practically zero and there is a reflection factor of nearly 1.0, meaning no reflection occurred. The rise time is on the order of $50 \mathrm{~ms}$, and the shape of the signature is very much like a sine wave. PCBoom 4 does not calculate a sonic boom at this location, being past the Mach cutoff. Figure 22 shows the acoustic levels for this wave in terms of ASEL, CSEL, and PL. There is no systematic variation of acoustic level with height, and the microphone $10 \mathrm{~m}$ to the east of the tower shows a higher acoustic level. As a personal, qualitative statement, these evanescent waves are often not noticed over normal conversation. 


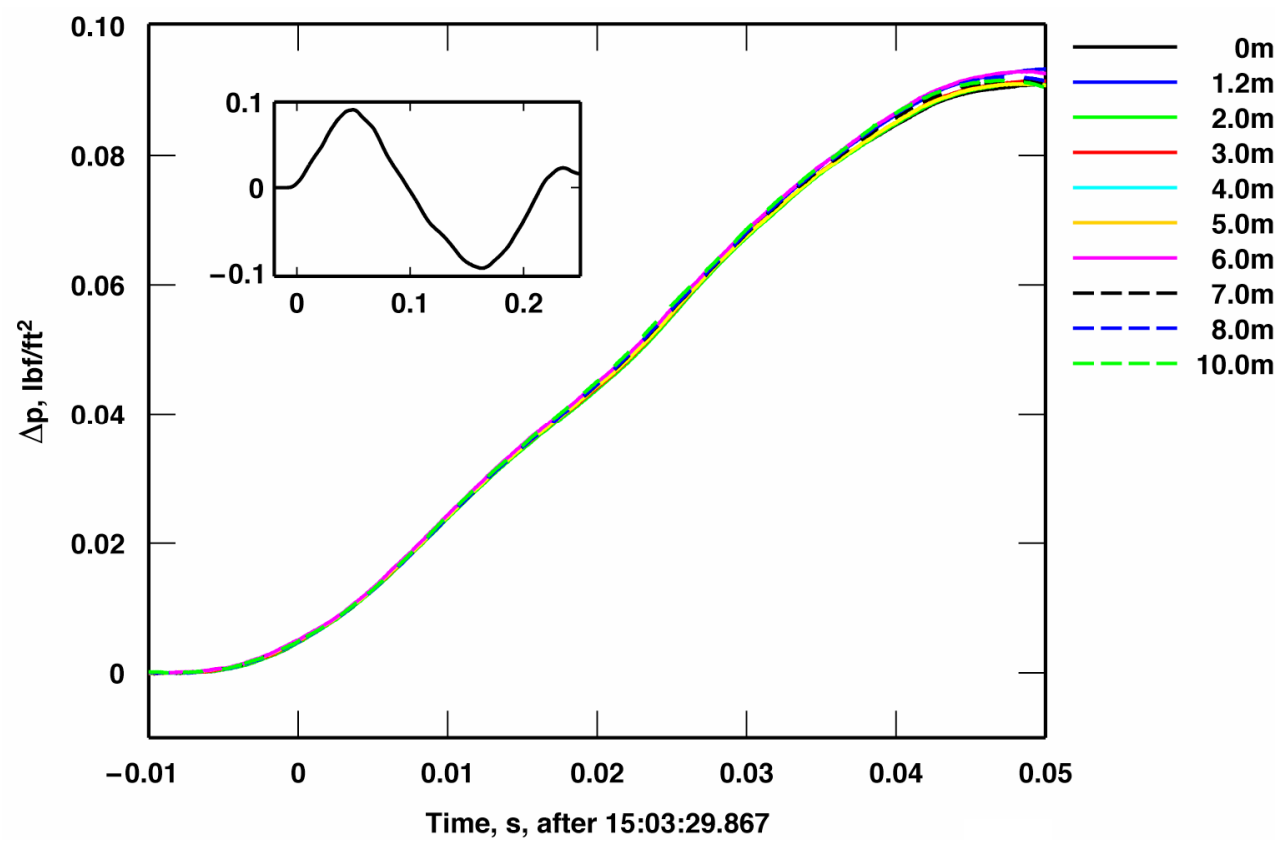

Figure 21. Initial pressure rise from evanescent wave as measured along the height of the $10 \mathrm{~m}$ tower, flight 1083, pass 1; the inset plot shows the entire signature.

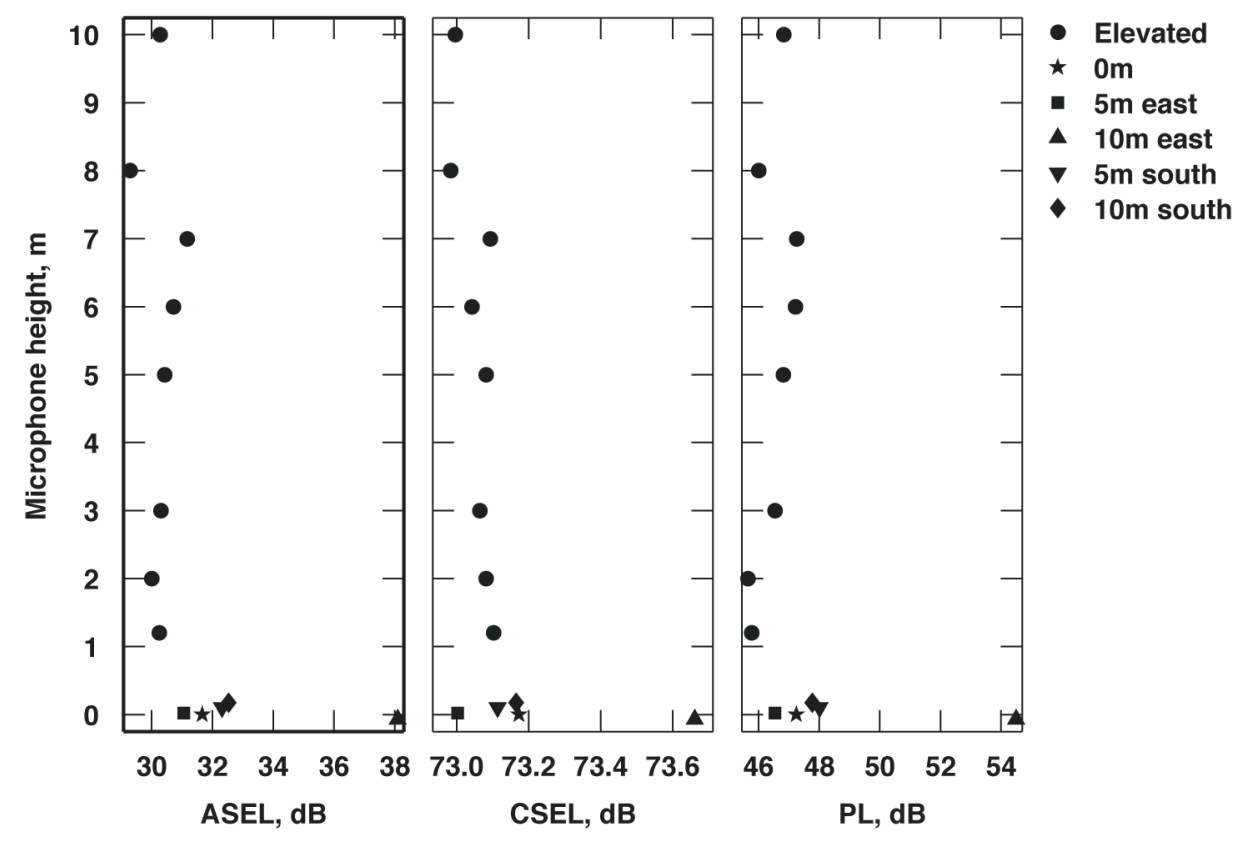

Figure 22. Acoustic levels in ASEL, CSEL, and PL as a function of height; flight 1083, pass 1.

The next five sonic booms illustrated are of idealized maximum overpressures from $0.33 \mathrm{lbf} / \mathrm{ft}^{2}$ to $0.66 \mathrm{lbf} / \mathrm{ft}^{2}$, namely flight 1557 , passes 4,5 and 2 ; flight 1083 , pass 3 ; and flight 1085 , pass 6 . The bow shock structure can be seen in Fig. 23 through Fig. 27, showing the incident shock wave hitting the $10 \mathrm{~m}$ microphone first, and then each microphone down the tower to the $0 \mathrm{~m}$ microphone, which has nearly double the overpressure of the elevated microphones. The reflected shock waves then work their way up the tower, each reflected shock wave trace rejoining the $0 \mathrm{~m}$ microphone trace. Figure 25 shows most cleanly where all the elevated data cross over the groundlevel data, at approximately $t=0.004 \mathrm{~s}$. Prior to this time, only the incident shock wave is measured at the higher

American Institute of Aeronautics and Astronautics 
microphones. The microphones from approximately $3 \mathrm{~m}$ and down are measuring both the incident and reflected shocks at $\Delta p=0.005 \mathrm{lbf} / \mathrm{ft}^{2}$, the threshold pressure used to determine arrival times for Eq. (1). The microphone at 4 $\mathrm{m}$ was operating erratically for some of these passes, and so data are not shown for those times.

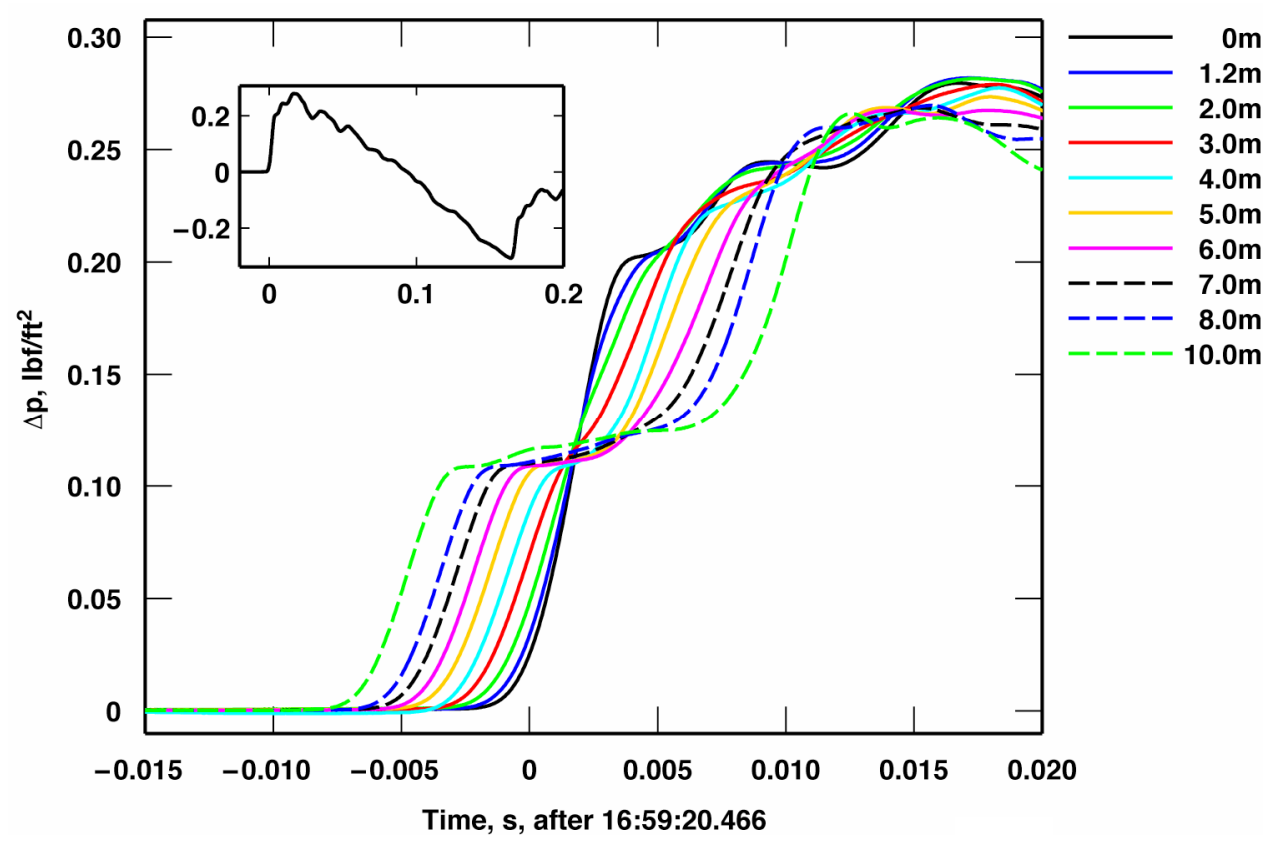

Figure 23. The $10 \mathrm{~m}$ tower microphones, flight 1557, pass 4 .

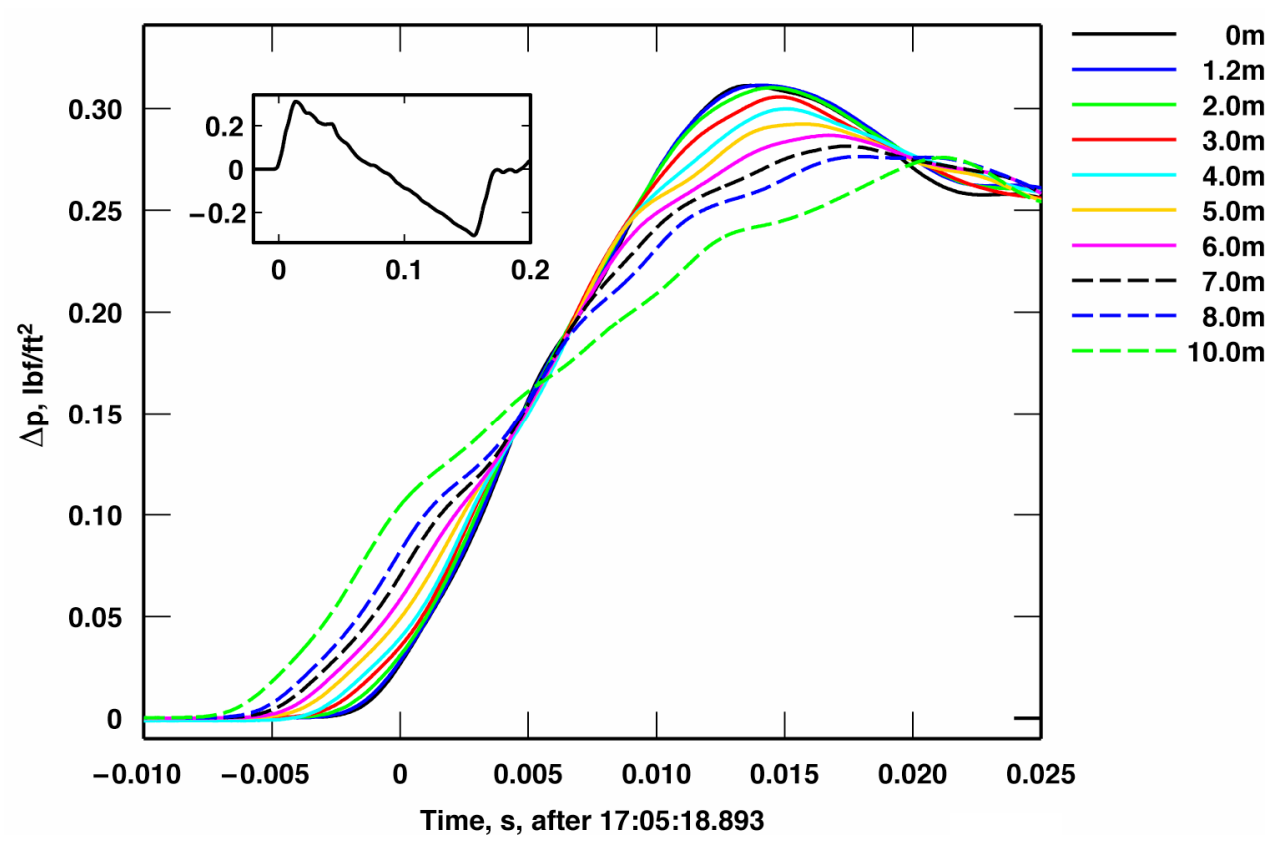

Figure 24. The $10 \mathrm{~m}$ tower microphones, flight 1557, pass 5. 


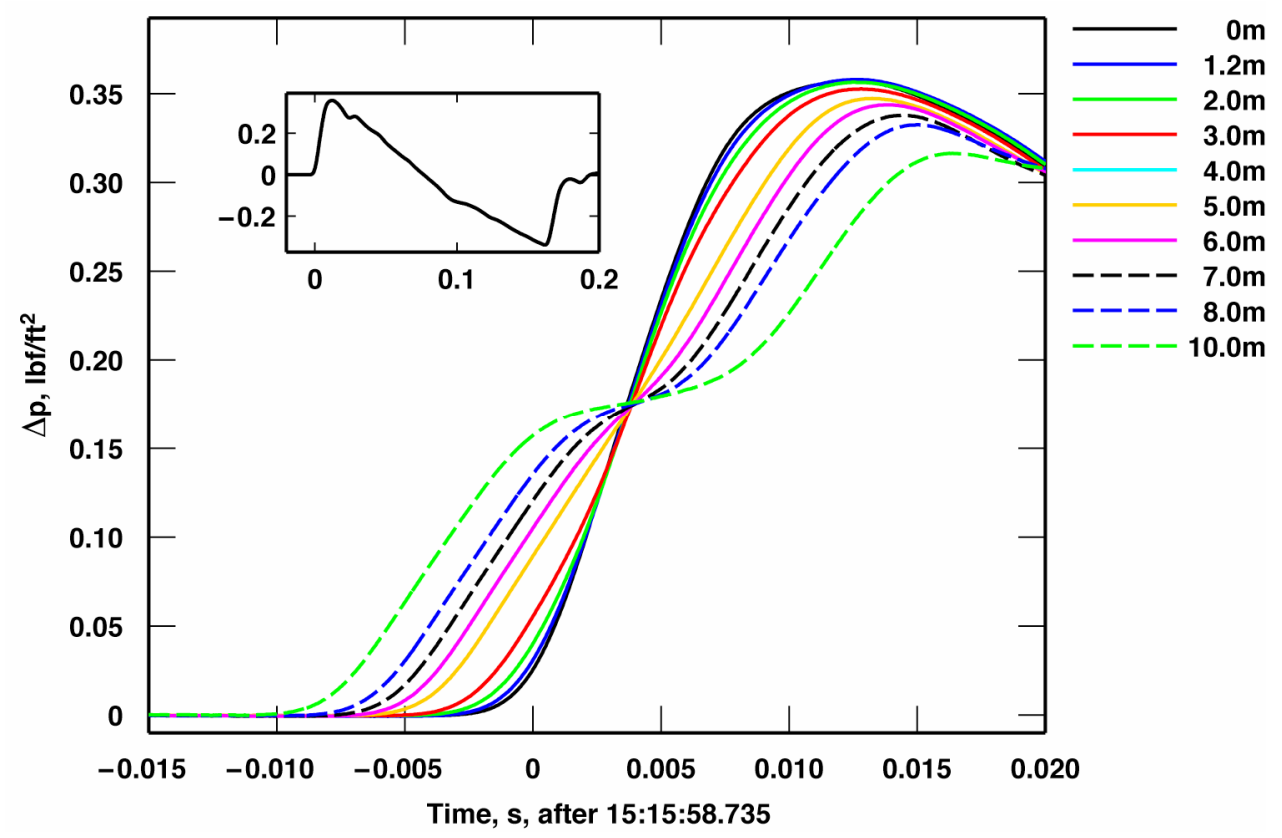

Figure 25. The $10 \mathrm{~m}$ tower microphones, flight 1083, pass 3 .

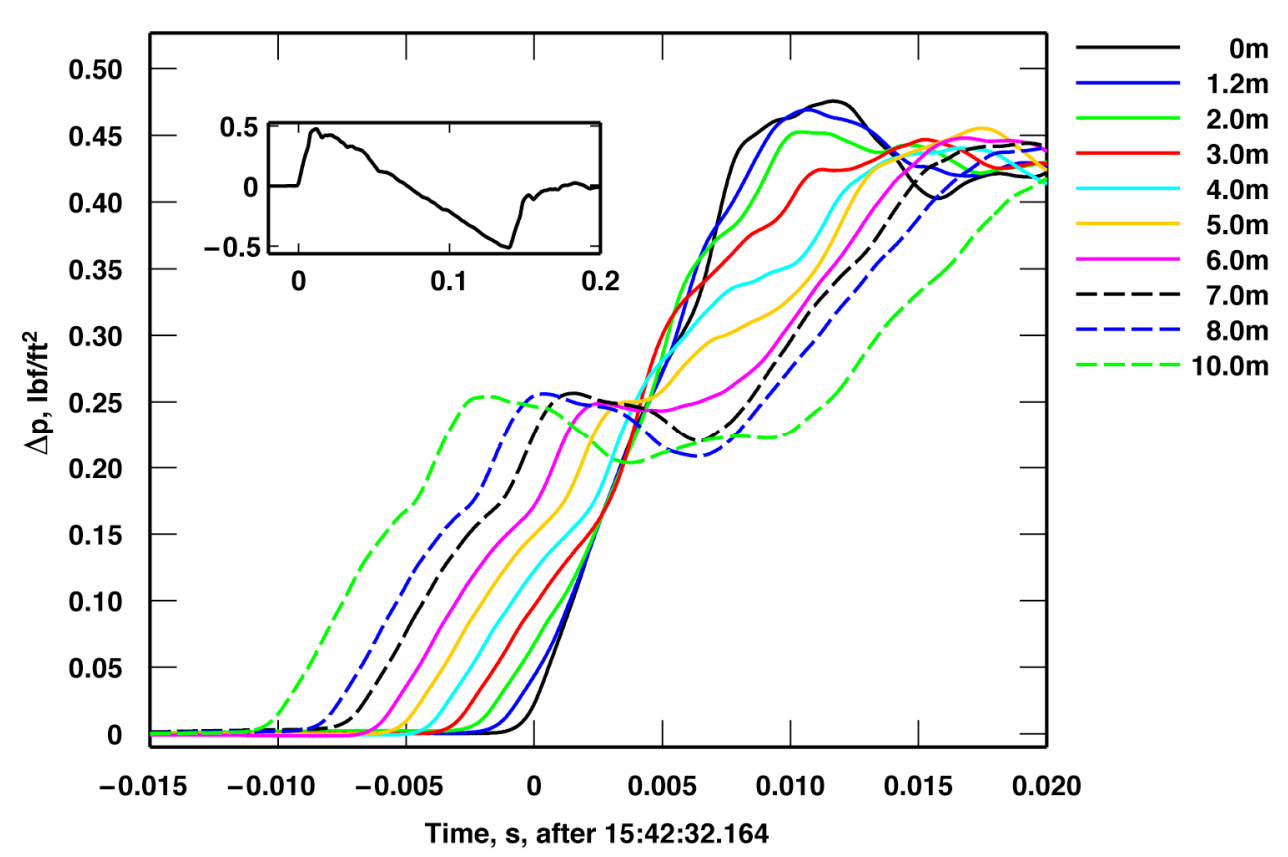

Figure 26. The $10 \mathrm{~m}$ tower microphones, flight 1085, pass 6. 


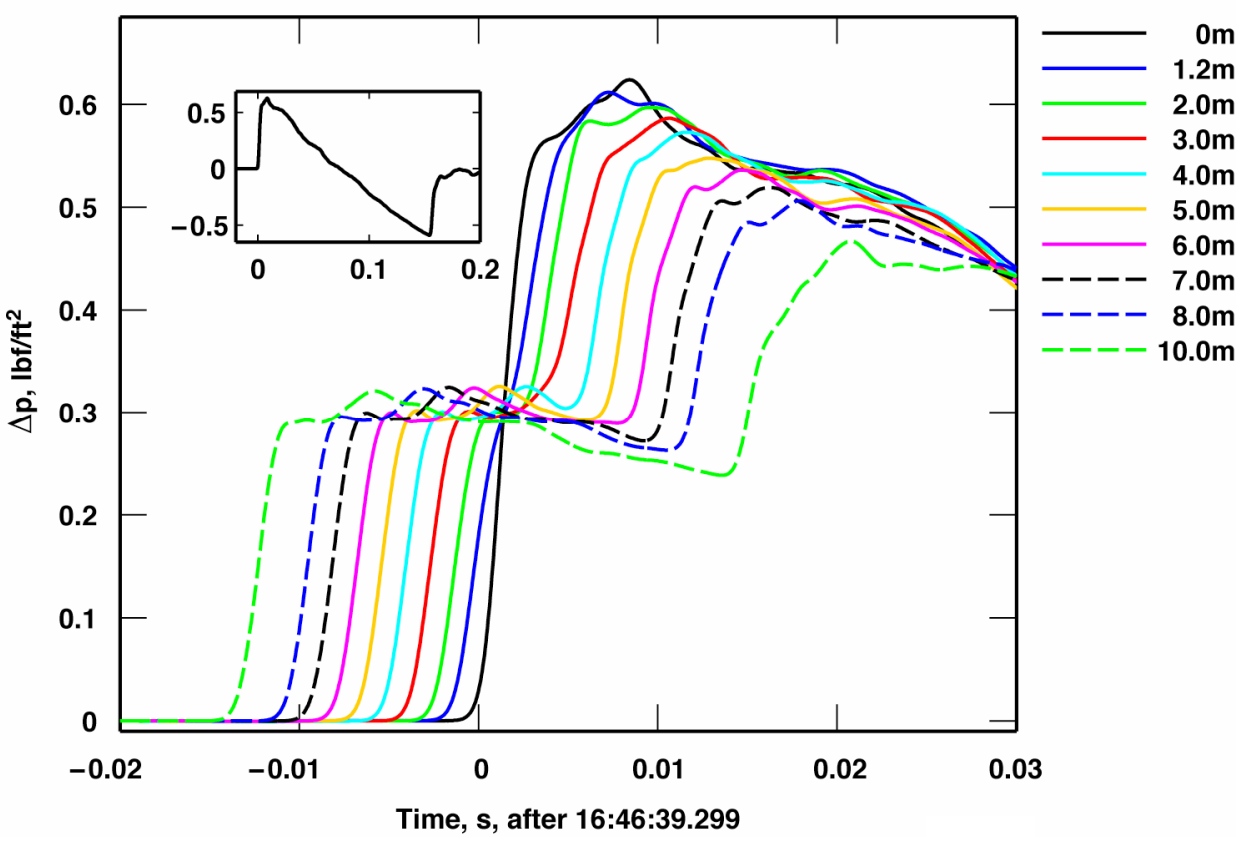

Figure 27. The $10 \mathrm{~m}$ tower microphones, flight 1557, pass 2.

Figure 28 shows the microphone time histories from Fig. 27, each shifted in time such that the initial rises coincide, including the ground microphones $5 \mathrm{~m}$ and $10 \mathrm{~m}$ to the east and south. It shows how the time histories of the elevated microphones all over-plot with nearly equal slope to $t=0.0025 \mathrm{~s}$, which is approximately half of the ground-level microphone slope. After $t=0.0025 \mathrm{~s}$, the reflected shock begins to hit the elevated microphones, shown by the traces nearly doubling in value.

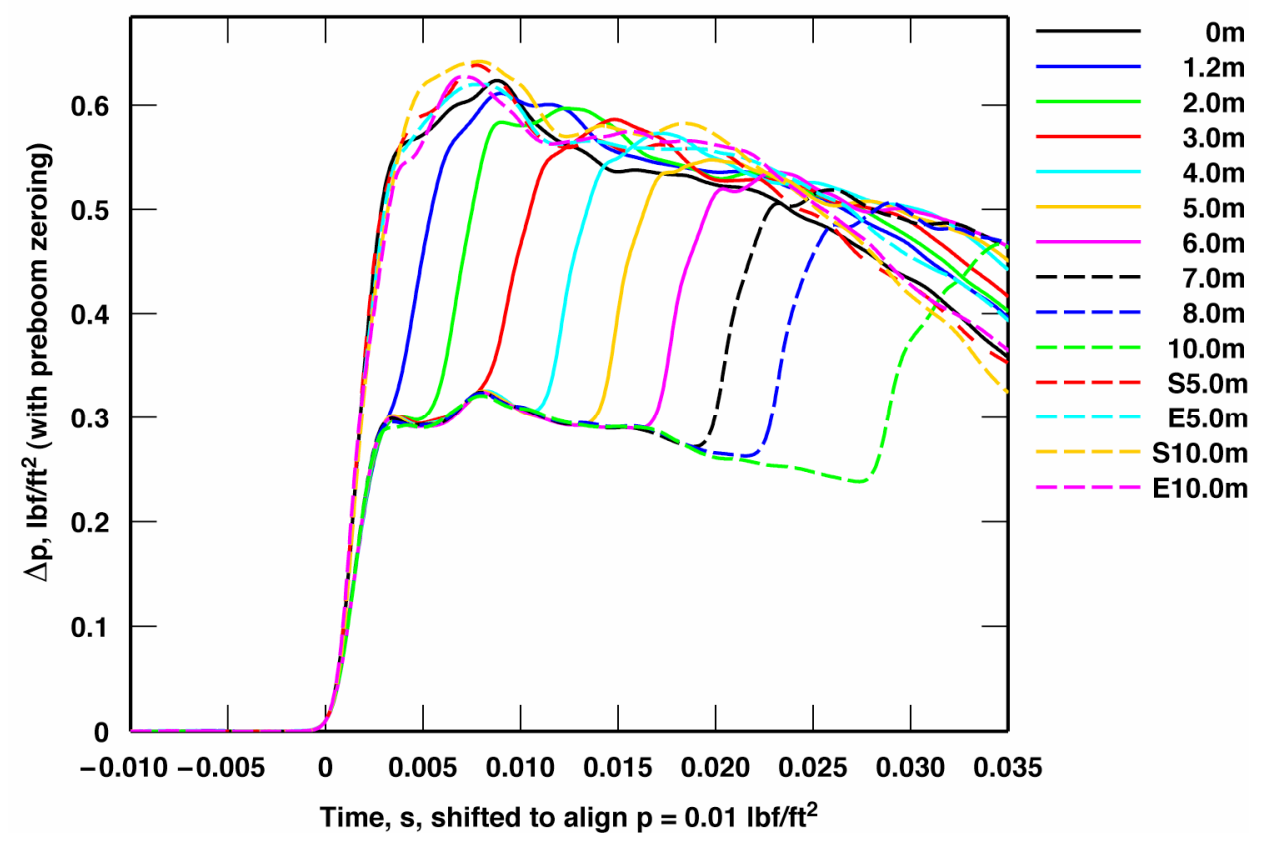

Figure 28. The $10 \mathrm{~m}$ tower microphones, including all five ground microphones, shifted in time to align initial rise; flight 1557, pass 2 . 
The acoustic levels of these low sonic booms are shown in Fig. 29 through Fig. 33, and in each the CSEL decreases with an increase in height, most with either a linear or a concave-upward structure. Figure 30 from flight 1557, pass 5 is notable as the CSEL data are concave-downward with height. There were four passes measured (not plotted in this paper) that had minimum CSEL values at an intermediate height.

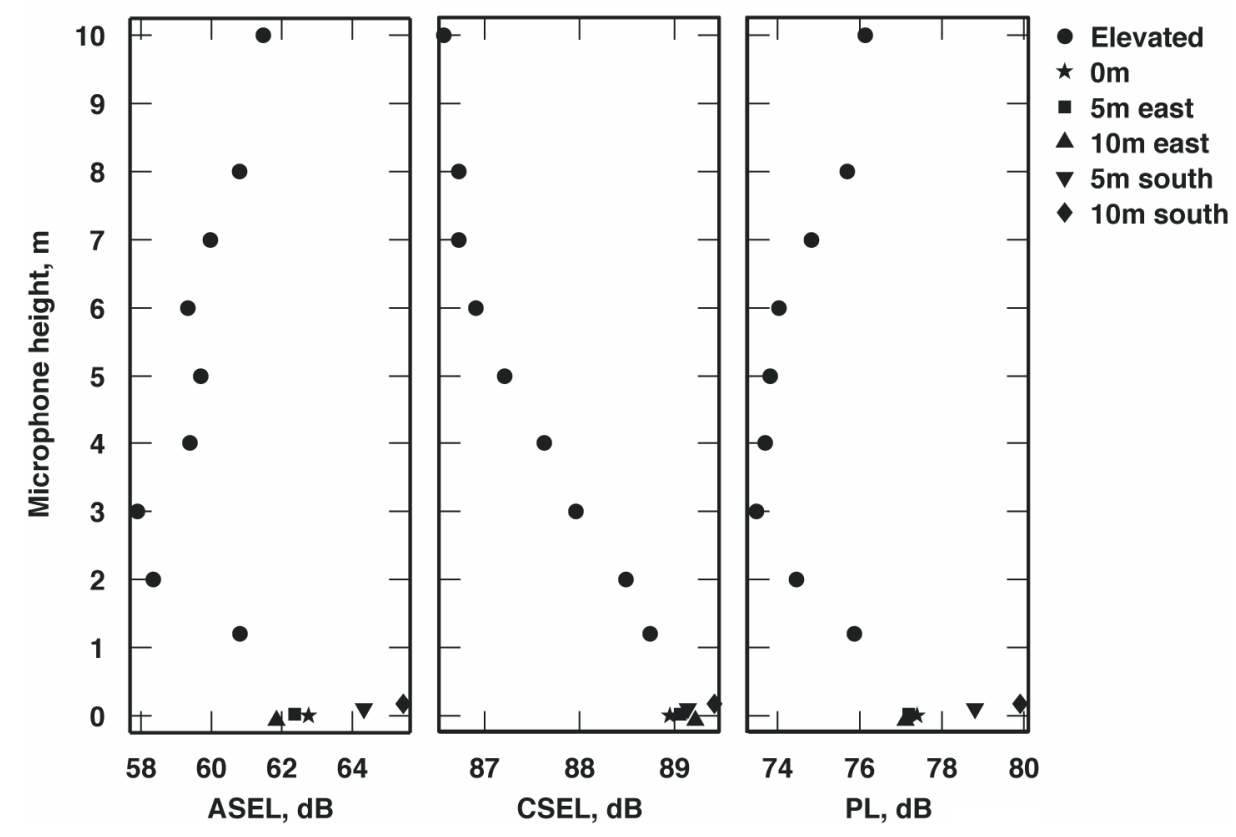

Figure 29. Acoustic levels in ASEL, CSEL, and PL as a function of height; flight 1557, pass 4.

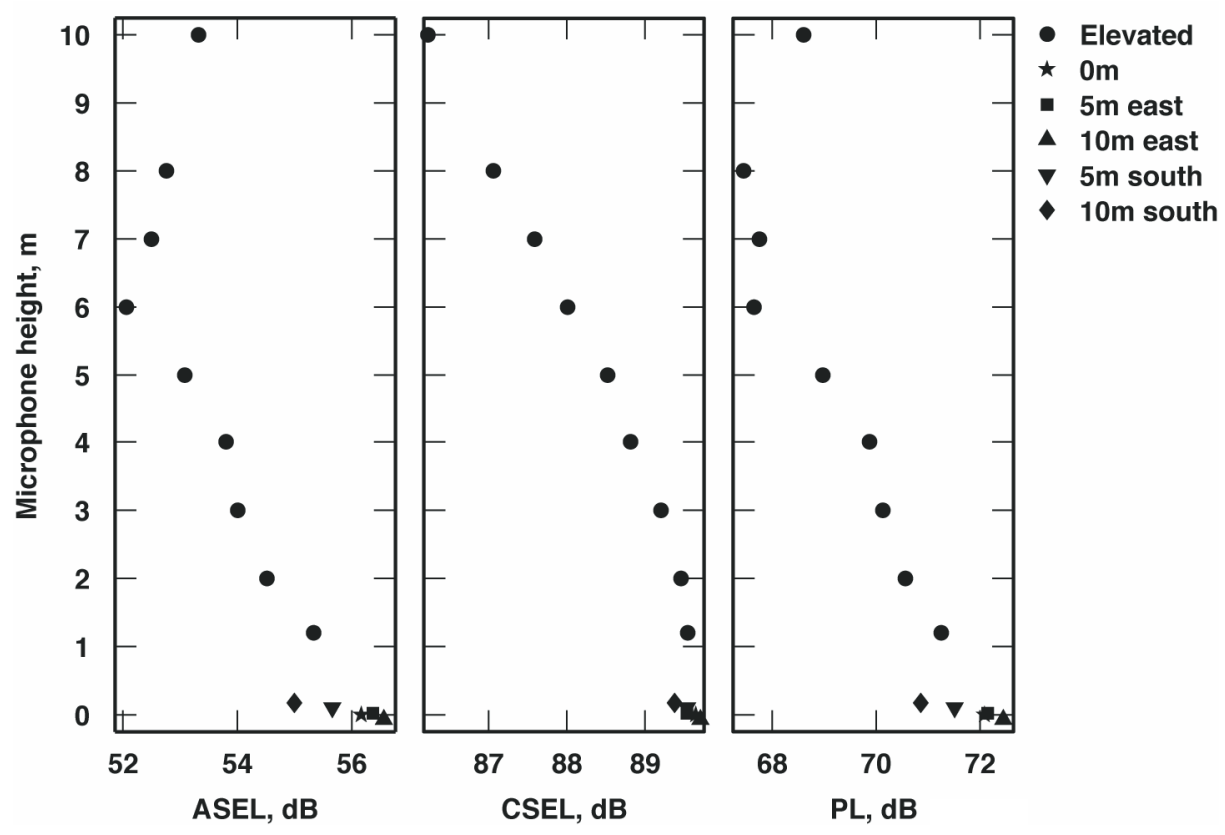

Figure 30. Acoustic levels in ASEL, CSEL, and PL as a function of height; flight 1557, pass 5. 


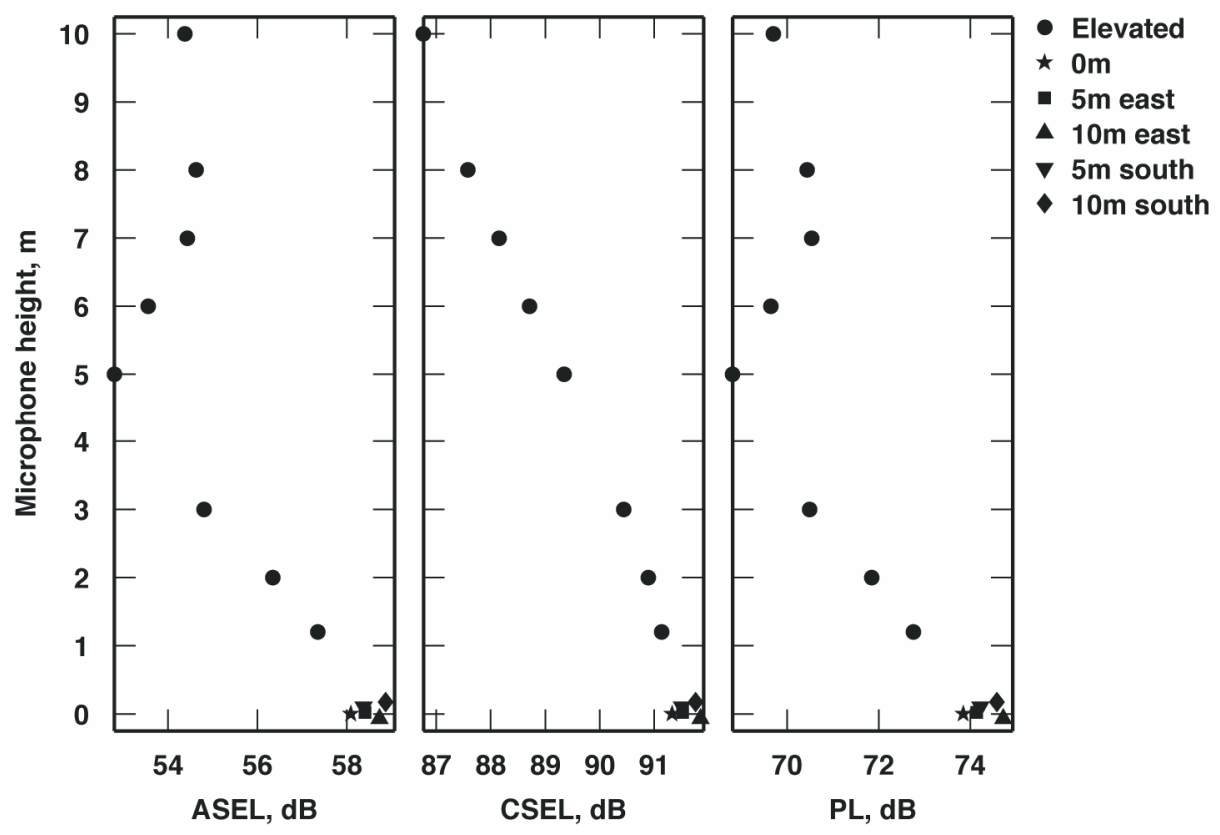

Figure 31. Acoustic levels in ASEL, CSEL, and PL as a function of height; flight 1083, pass 3.

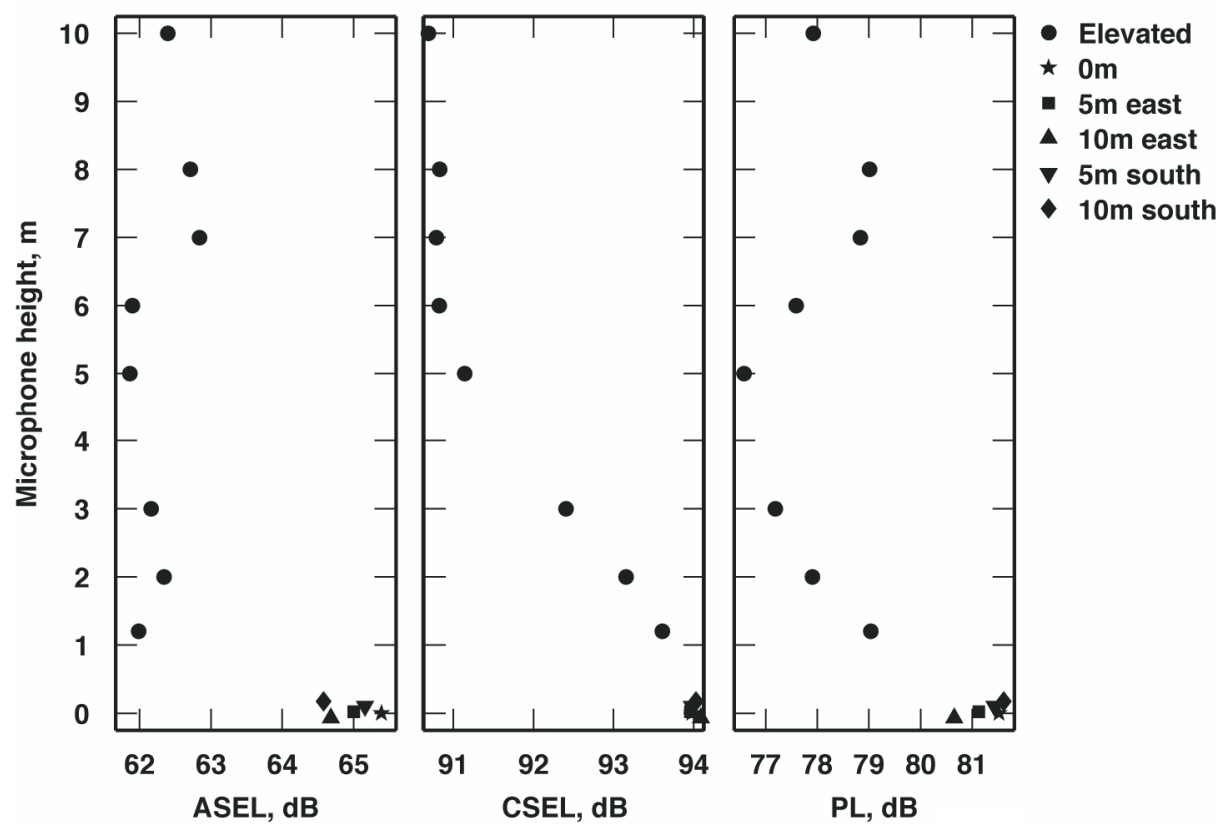

Figure 32. Acoustic levels in ASEL, CSEL, and PL as a function of height; flight 1085, pass 6. 


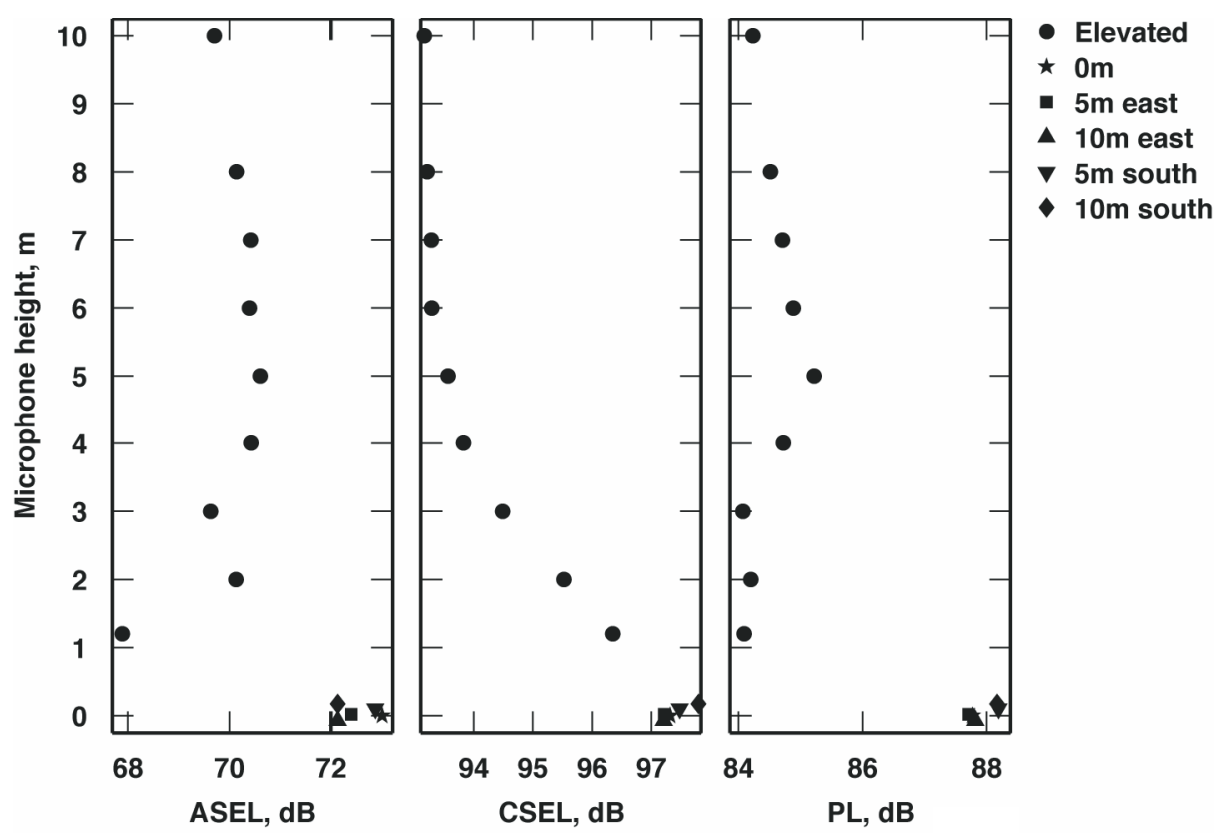

Figure 33. Acoustic levels in ASEL, CSEL, and PL as a function of height; flight 1557, pass 2.

The ASEL and PL data have minimum values at an intermediate height: at $3 \mathrm{~m}$ for Fig. 29; at $5 \mathrm{~m}$ for Fig. 31 and Fig. 32; and at $6 \mathrm{~m}$ for ASEL and $6 \mathrm{~m}$ to $8 \mathrm{~m}$ for PL for Fig. 30; and at $1.2 \mathrm{~m}$ for Fig. 33. Looking at the microphone traces for these heights shows a common shape, namely, these elevated microphones have neither a delay at the halfmaximum overpressure (shown best by a $10 \mathrm{~m}$ microphone trace) nor a merging with the ground microphone trace (shown best by the $1.2 \mathrm{~m}$ microphone in Fig. 26). These shapes of the waveforms are a result of the incident and reflected shock waves combining as a function of the shock wave elevation angle and microphone height above the ground. These minimum ASEL and PL elevated microphone waveforms have the straightest rise to maximum pressure, which is in agreement with simulated sonic boom waveforms investigated by Sullivan and Leatherwood. ${ }^{16}$ Their analysis showed that the minimum subjective loudness occurred when the delay time was equal to the rise time (which results in the straightest rises, as illustrated by the $1.2 \mathrm{~m}$ trace in Fig. 28), and PL is an effective metric for assessing subjective loudness.

The last three sonic booms illustrated are of normal intensity, idealized maximum overpressures of $1.30 \mathrm{lbf} / \mathrm{ft}^{2}$ to $1.48 \mathrm{lbf} / \mathrm{ft}^{2}$, from flight 1087, passes 1 and 6; and flight 1086, pass 1 . In the unshifted time histories of the bow shocks, Fig. 34 through Fig. 36, the same general attributes as the low booms are present, namely shocks striking the tower from top to bottom, and then the reflected shocks from bottom to top. More rippling of the microphone traces can be seen here than in the low-boom data, especially for Fig. 34 from flight 1087, pass 1, which is attributed to atmospheric turbulence. Figure 37 shows the shifted time histories for flight 1086, pass 1, showing the same pattern as for the low sonic booms. 


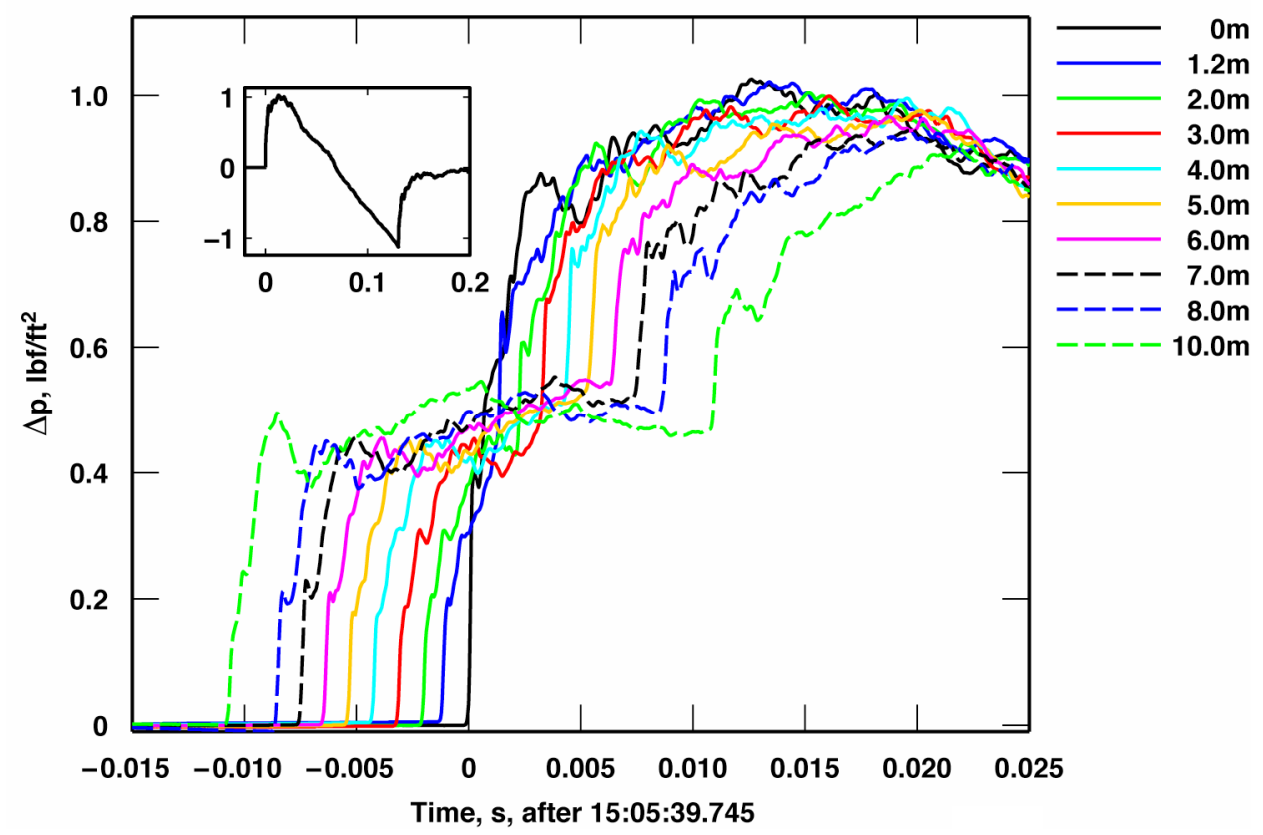

Figure 34. The $10 \mathrm{~m}$ tower microphones, flight 1087, pass 1 .

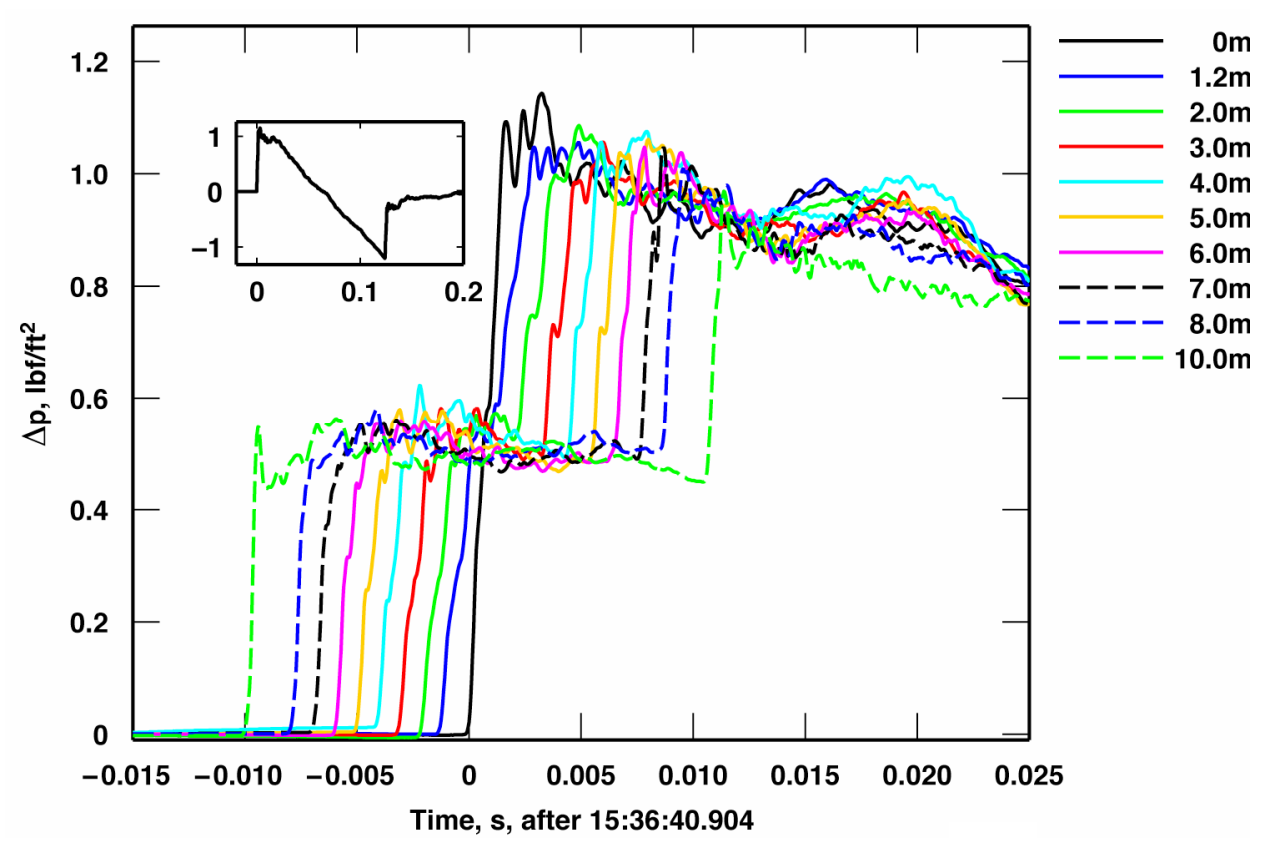

Figure 35. The $10 \mathrm{~m}$ tower microphones, flight 1087, pass 6 . 


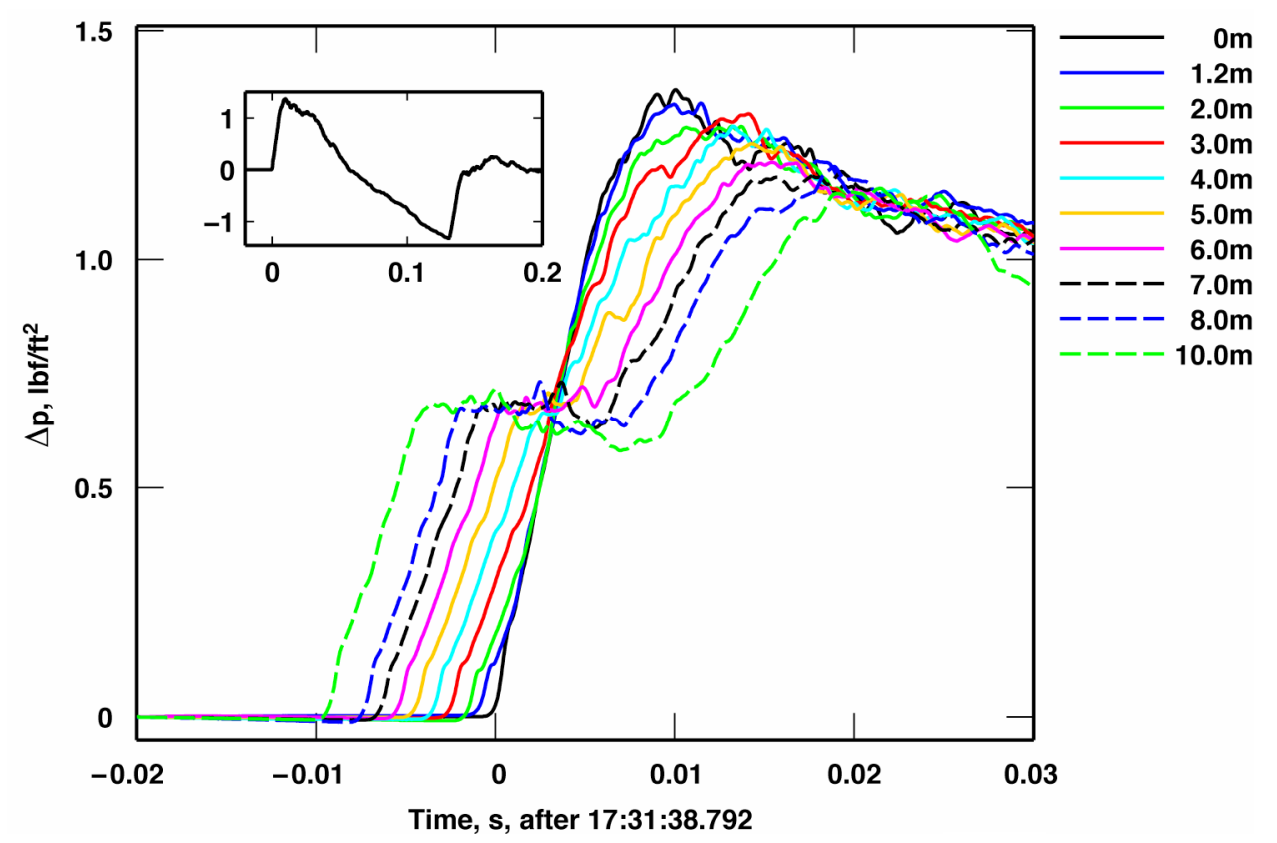

Figure 36. The $10 \mathrm{~m}$ tower microphones, flight 1086, pass 1.

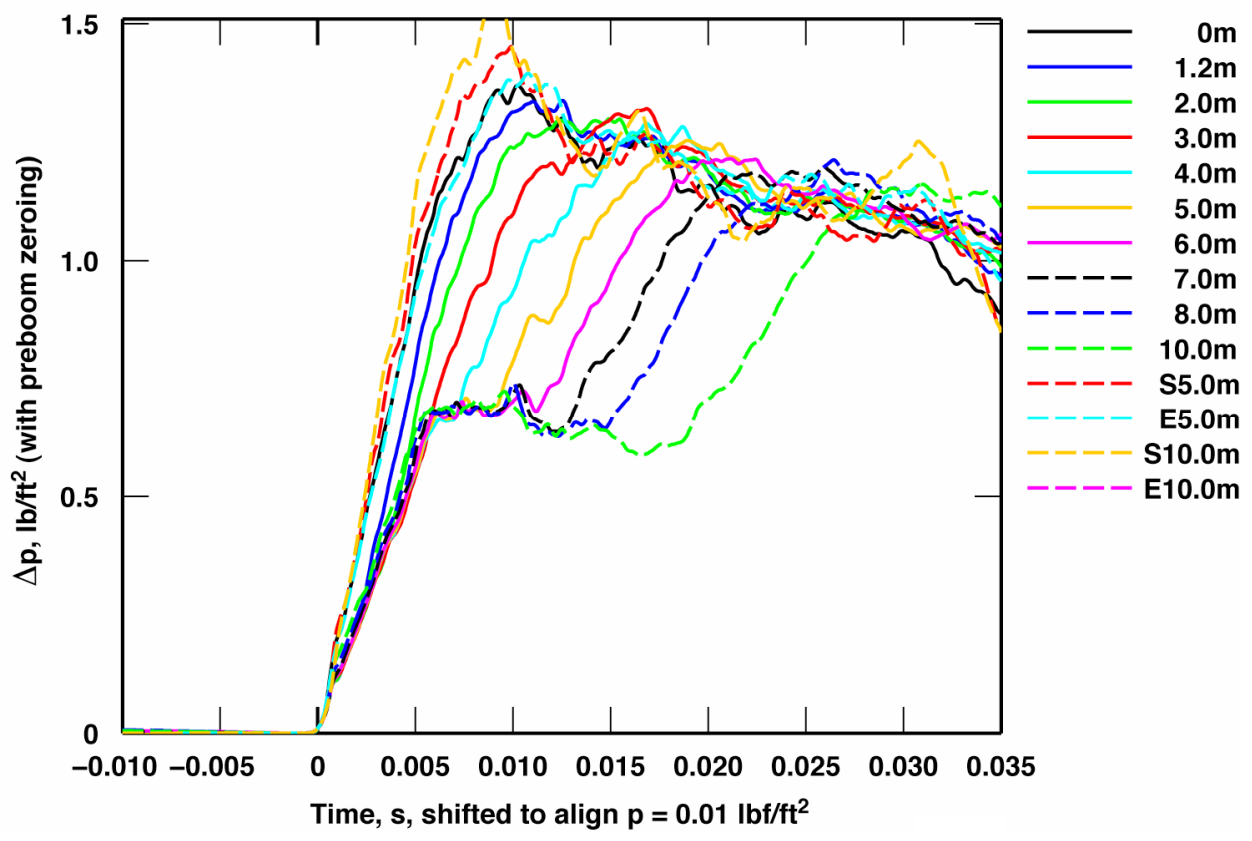

Figure 37. The $10 \mathrm{~m}$ tower microphones, including all five ground microphones, shifted in time to align initial rise; flight 1086, pass 1.

The acoustic levels for the three normal sonic booms are shown in Fig. 38 through Fig. 40. Again the CSEL values generally decrease with increasing height. The ASEL and PL curves in Fig. 38 are fairly constant with height and do not show a minimum for the straightest rise of an elevated microphone, but this shock structure strongly shows the effects of turbulence. Figure 39 has a minimum ASEL value at a $1.2 \mathrm{~m}$ height and a minimum PL value at a $2.0 \mathrm{~m}$ height, with the straightest elevated microphone trace being at $1.2 \mathrm{~m}$ in Fig. 35. Figure 40 shows a minimum 
ASEL value at $3.0 \mathrm{~m}$ and a minimum PL value at $4.0 \mathrm{~m}$, with the straightest elevated microphone trace being at 3.0 $\mathrm{m}$ in Fig. 37.

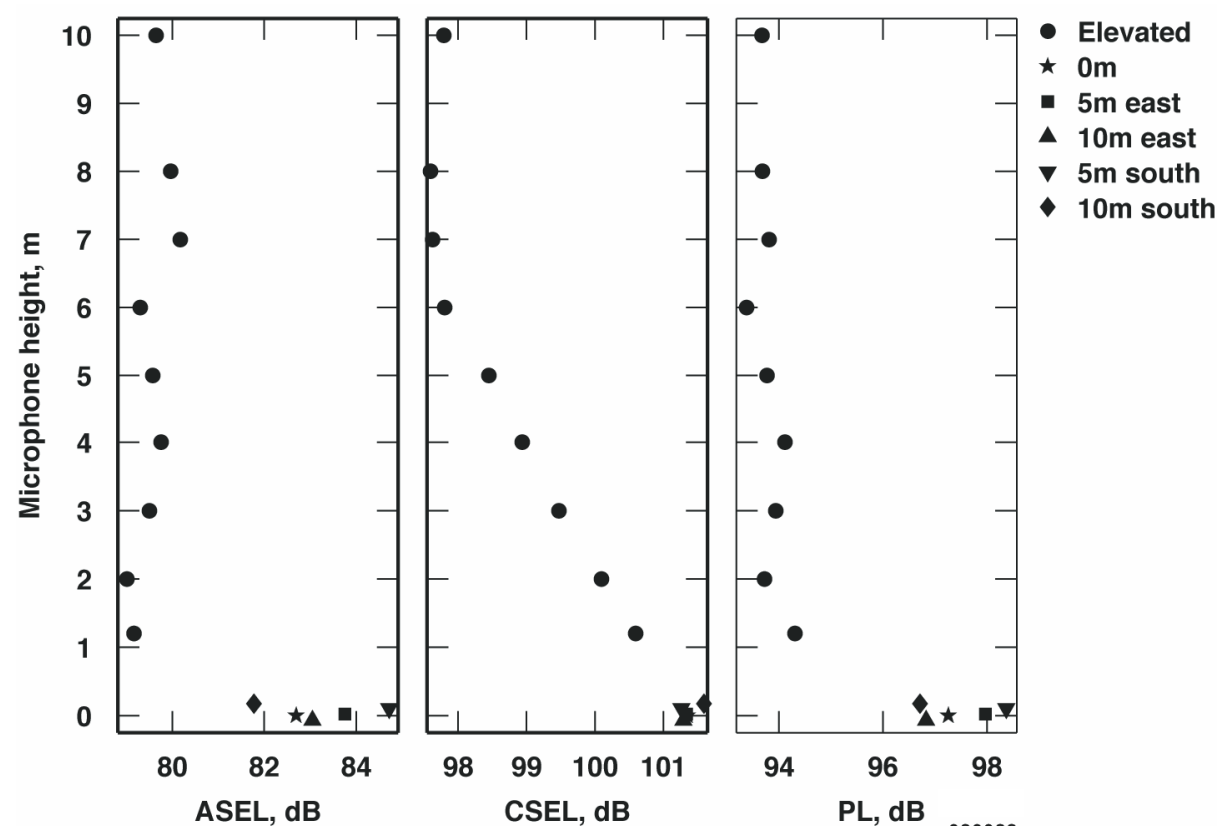

Figure 38. Acoustic levels in ASEL, CSEL, and PL as a function of height; flight 1087, pass 1.

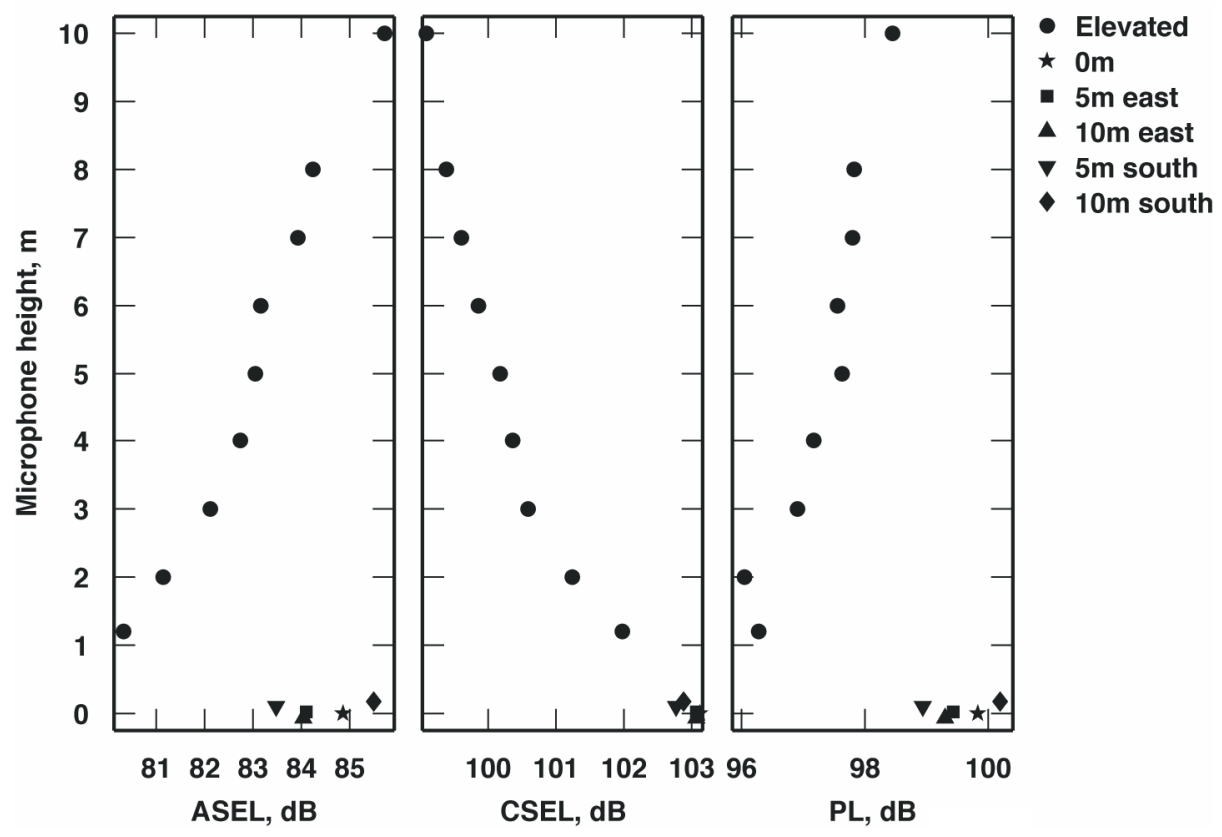

Figure 39. Acoustic levels in ASEL, CSEL, and PL as a function of height; flight 1087, pass 6. 


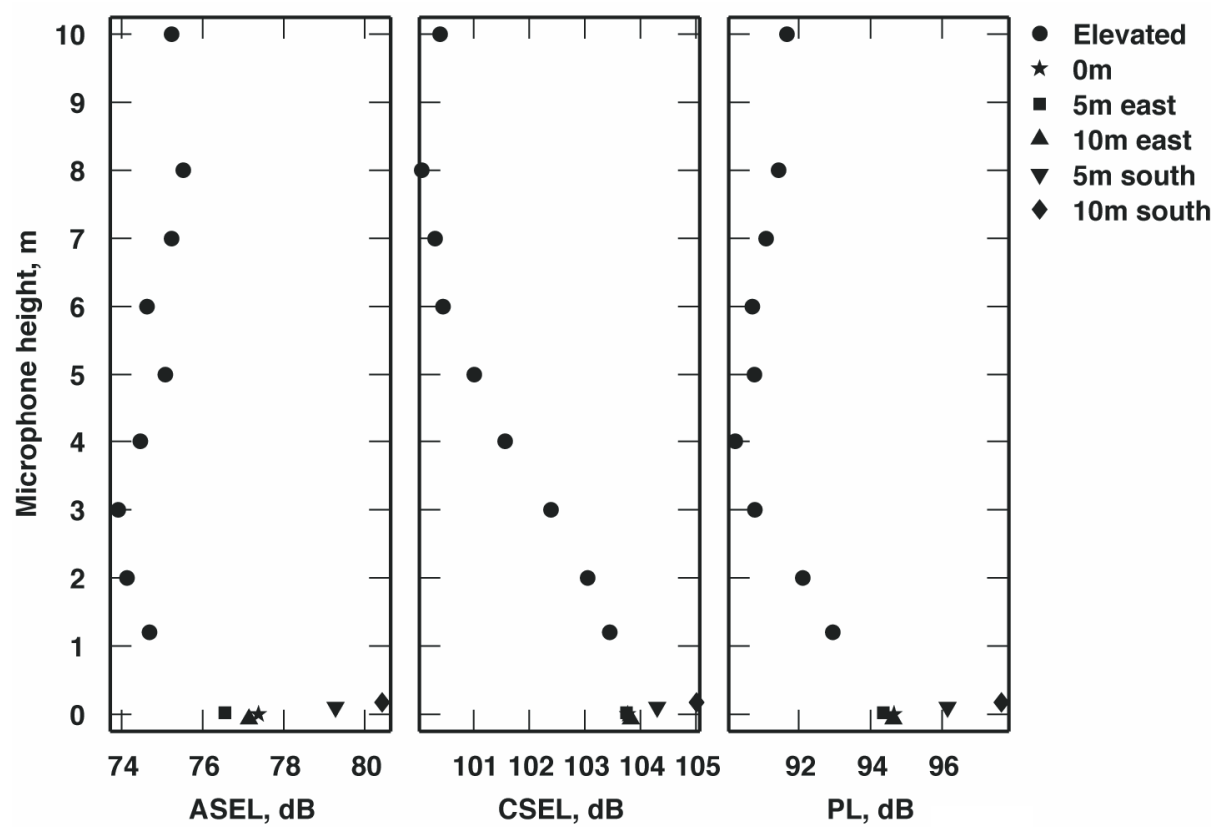

Figure 40. Acoustic levels in ASEL, CSEL, and PL as a function of height; flight 1086, pass 1.

For all three acoustics metrics considered, the acoustic level is greatest at the $0 \mathrm{~m}$ microphone heights. This is because the direct and reflected sonic boom energies are exactly time-aligned on the ground, yielding the least rise times and highest overpressures. However, unless one is lying down on the ground, the sonic booms actually heard are the ones at $1.2 \mathrm{~m}$ or higher. This means that the typical sonic boom sounds that are heard by individuals are going to tend to be at a slightly lower acoustic level than sonic booms as measured on the ground. The acoustic metrics all indicated that the slight time delay between direct and reflected sonic boom contributions tends to slightly decrease the acoustic level.

\section{BASS Loud Boom Data}

The BASS units located $6 \mathrm{mi}$ to $8 \mathrm{mi}$ from the house, see Fig. 7, recorded booms with overpressures greater than $2.0 \mathrm{lbf} / \mathrm{ft}^{2} 12$ times, with one recording up to $5.0 \mathrm{lbf} / \mathrm{ft}^{2}$. PCBoom 4 calculations at these locations have not yet been performed.

\section{B. Sailplane Sonic Boom Results}

Representative sailplane data are shown in Fig. 41, showing the incident and reflected signatures of two low-intensity booms. The incident signature is very clean, rivaling the cleanliness of a ground-measured signature on a calm day. The reflected signature (from a different raypath) shows turbulence effects, having traveled through the planetary boundary layer twice, once toward the ground and again back up to the sailplane. There is no analysis at this time of the reflected sonic booms measured on the sailplane. Using PCBoom4 with the recorded aircraft and atmospheric data, each incident sonic boom was modeled to determine raypaths to the sailplane and tower, as shown in Table VI. These raypaths match to better than one-half of one degree in $\phi$ and a few tenths of one second in tac. Well-matching raypaths between the sailplane and the tower will be considered for determining turbulence filter functions. $^{15}$ 


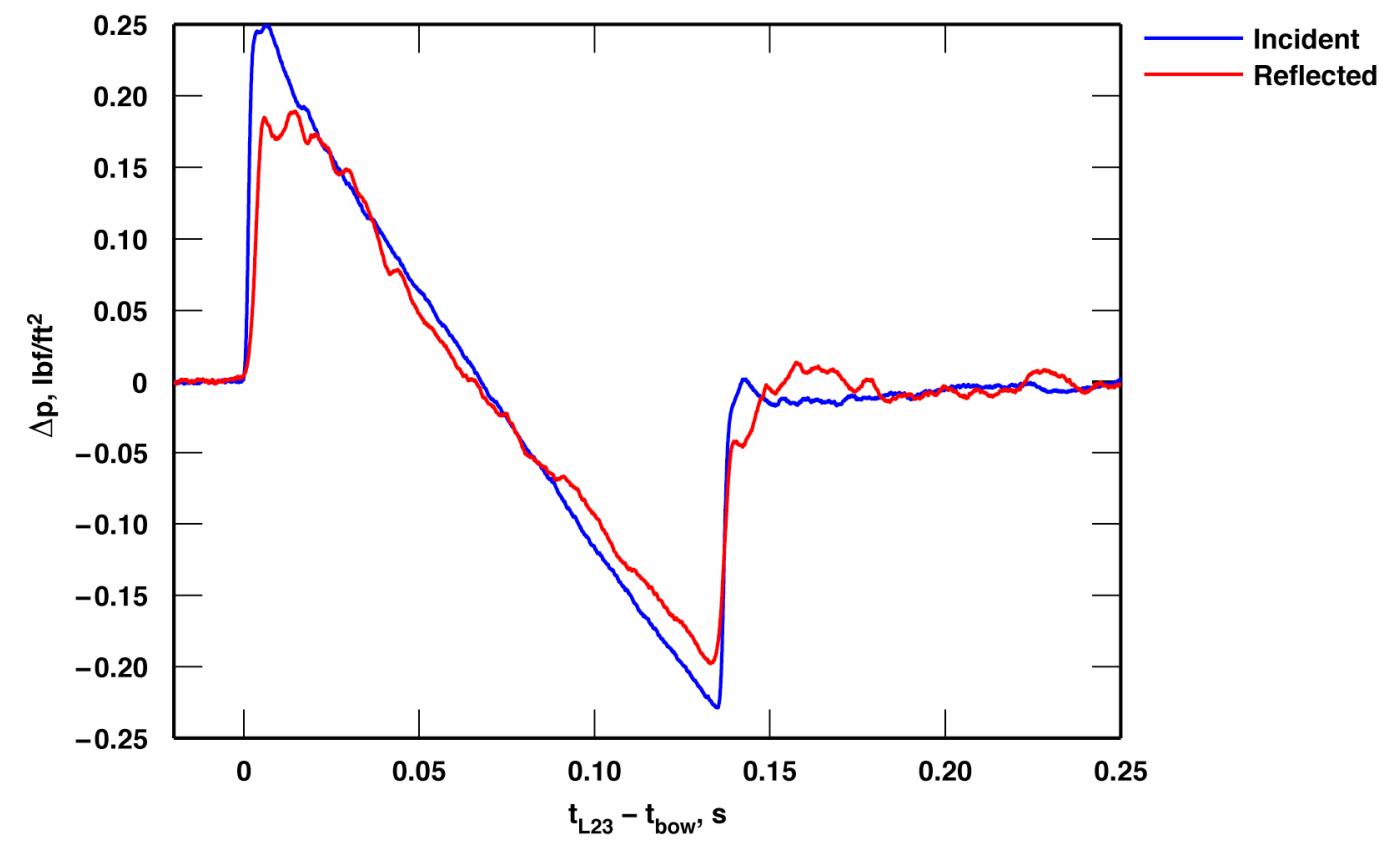

Figure 41. Representative sailplane incident and reflected sonic boom measurements, flight 1085, pass 2 . The

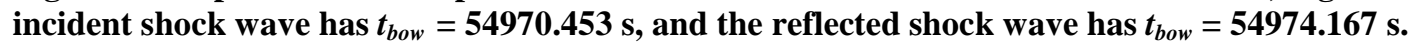

Five filter results are given in Fig. 42 through Fig. 46 for flight 1086, pass 4, showing the corresponding sailplane measurement, ground measurement, and filter output. The quality of the filter can be seen in how well the reconstructed ground measurement agrees with the actual ground measurement after approximately $t-t_{\text {bow }}=0.06 \mathrm{~s}$, which is the end of the doubled sailplane positive pressure data, the filter input. The filter output quality does degrade after approximately $t-t_{\text {bow }}=0.33 \mathrm{~s}$, but in spite of this the PL for the ground-measured data and filter output data agree to better than $0.04 \mathrm{~dB}$, which is considered excellent agreement. Additionally, five filter functions were obtained from a previous flight experiment. ${ }^{17}$ These ten derived filter functions can be convolved with any measured or synthesized shaped-boom waveform ${ }^{15}$ for use in subjective listening tests. In this way, realistic atmospheric turbulence effects can be added to "clean" sonic boom waveforms. Work is also under way to derive filter functions from numerical propagation methods. ${ }^{17}$ 


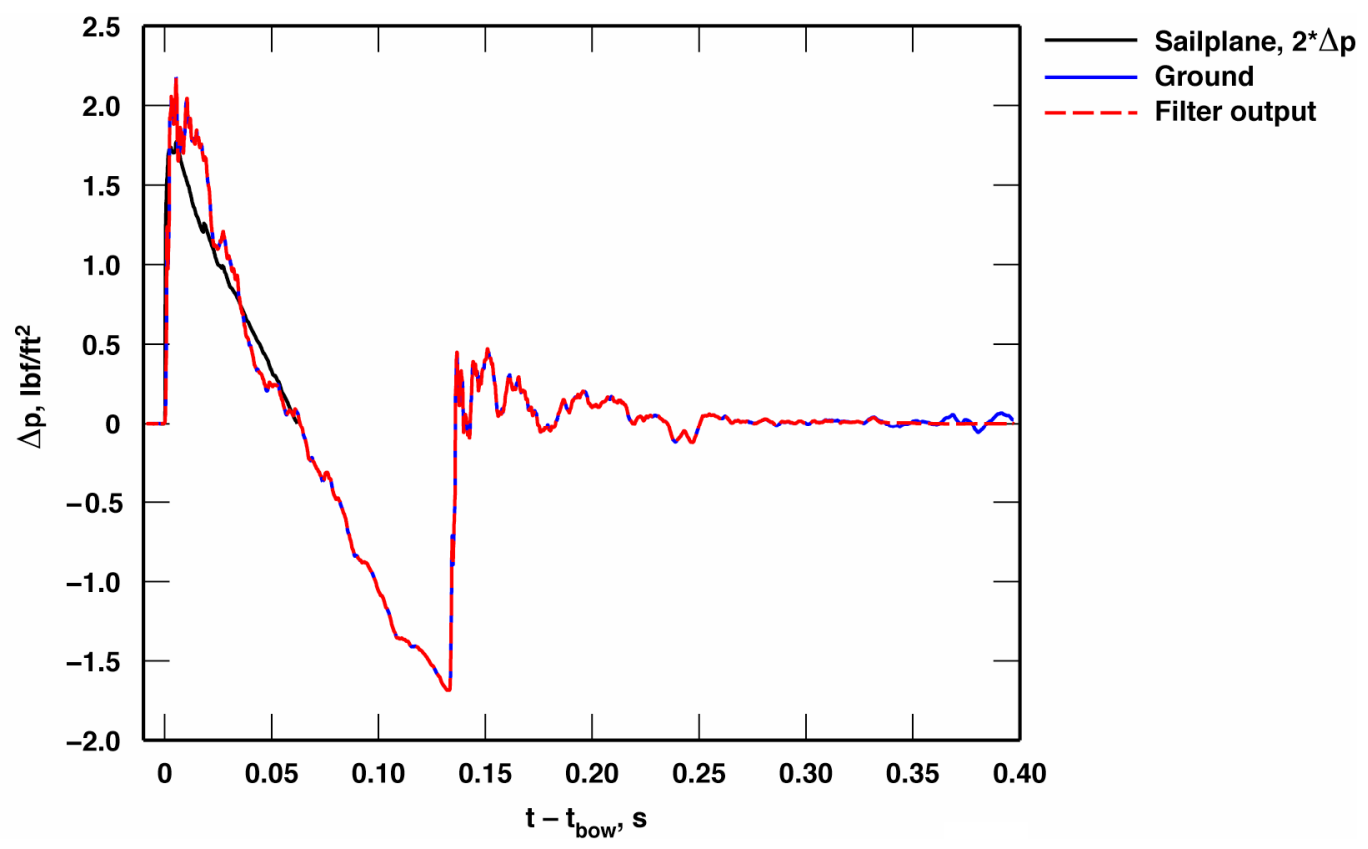

Figure 42. Filter results for flight 1086 , pass 4 , at $10 \mathrm{~m}$ east of the tower; the doubled positive pressure portion of the sailplane data is the input to the filter; the ground-measured data and filter output data are indistinguishable until approximately $0.33 \mathrm{~s}$ after the bow shock.

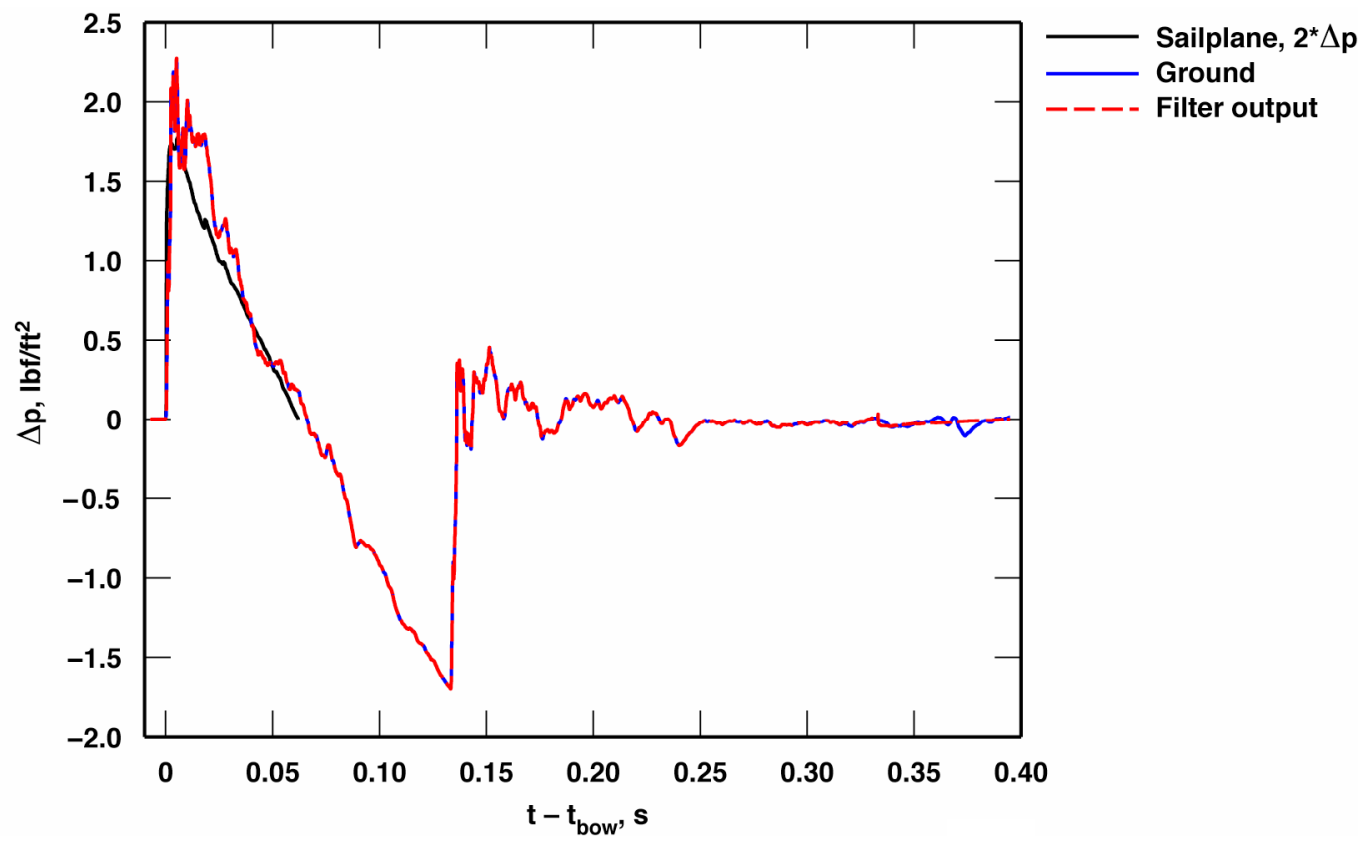

Figure 43. Filter results for flight 1086, pass 4 , at $5 \mathrm{~m}$ east of the tower; the doubled positive pressure portion of the sailplane data is the input to the filter; the ground-measured data and filter output data are indistinguishable until approximately $0.33 \mathrm{~s}$ after the bow shock. 


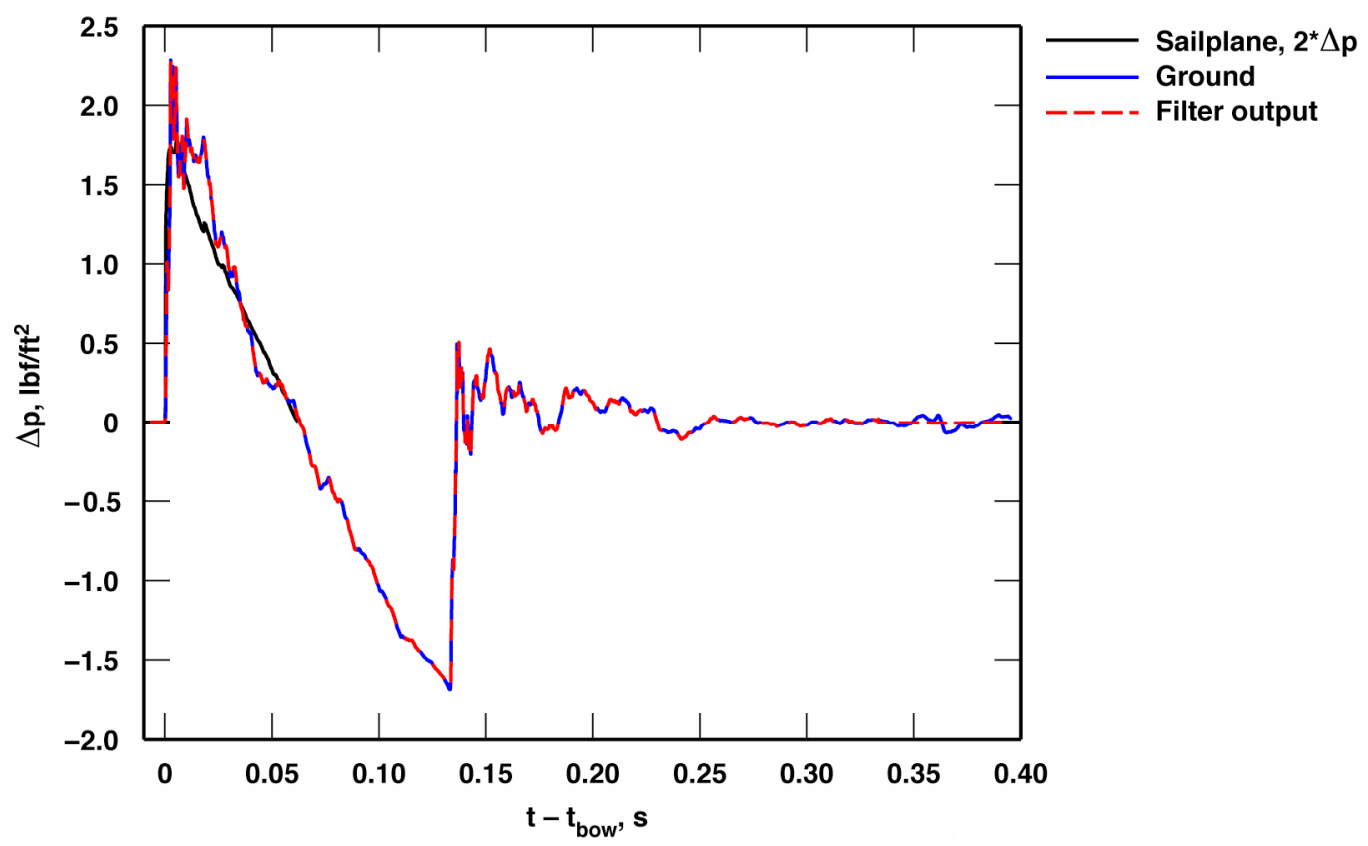

Figure 44. Filter results for flight 1086, pass 4 , at $0 \mathrm{~m}$ height at the tower; the doubled positive pressure portion of the sailplane data is the input to the filter; the ground-measured data and filter output data are indistinguishable until approximately $0.33 \mathrm{~s}$ after the bow shock.

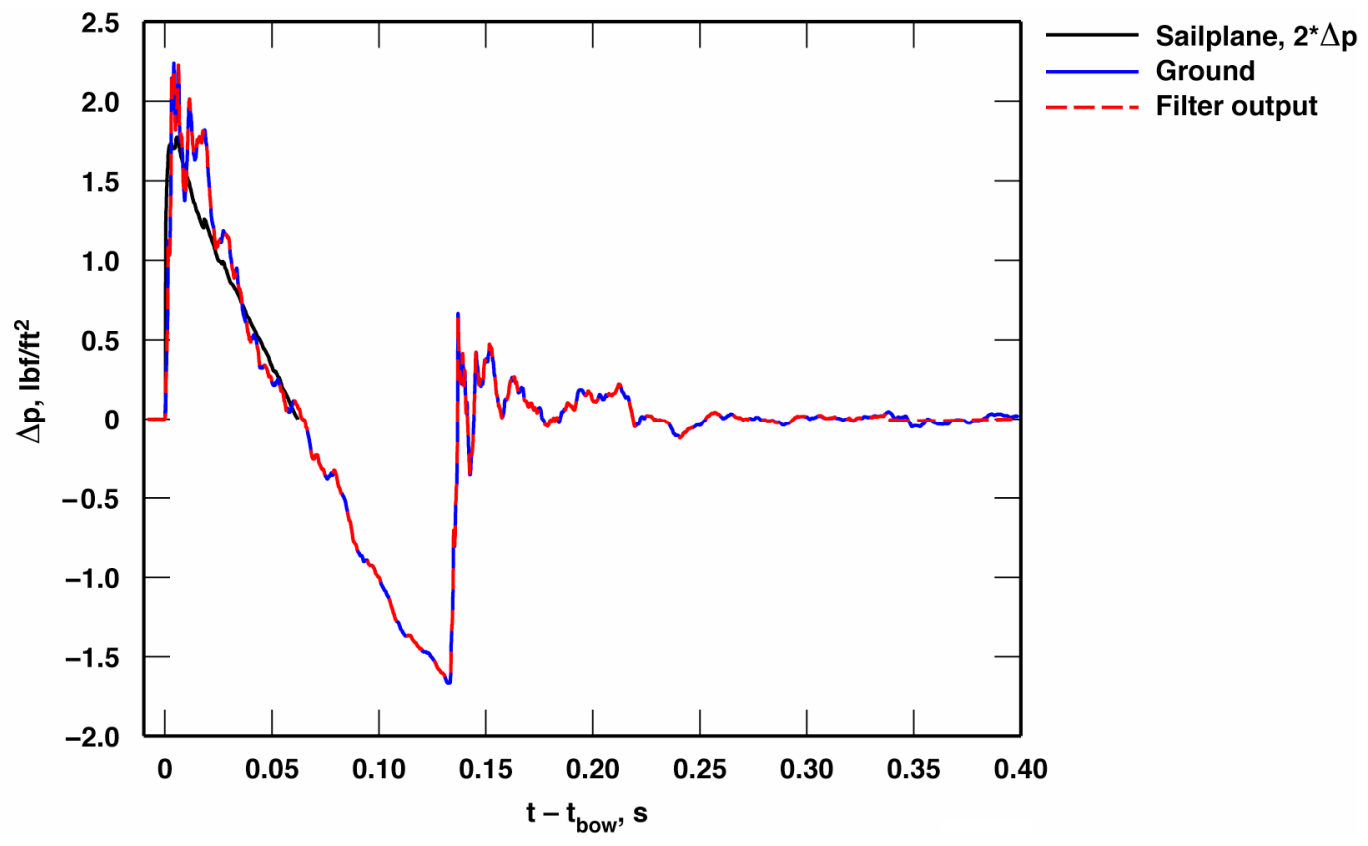

Figure 45. Filter results for flight 1086 , pass 4 , at $5 \mathrm{~m}$ south of the tower; the doubled positive pressure portion of the sailplane data is the input to the filter; the ground-measured data and filter output data are indistinguishable until approximately $0.33 \mathrm{~s}$ after the bow shock. 


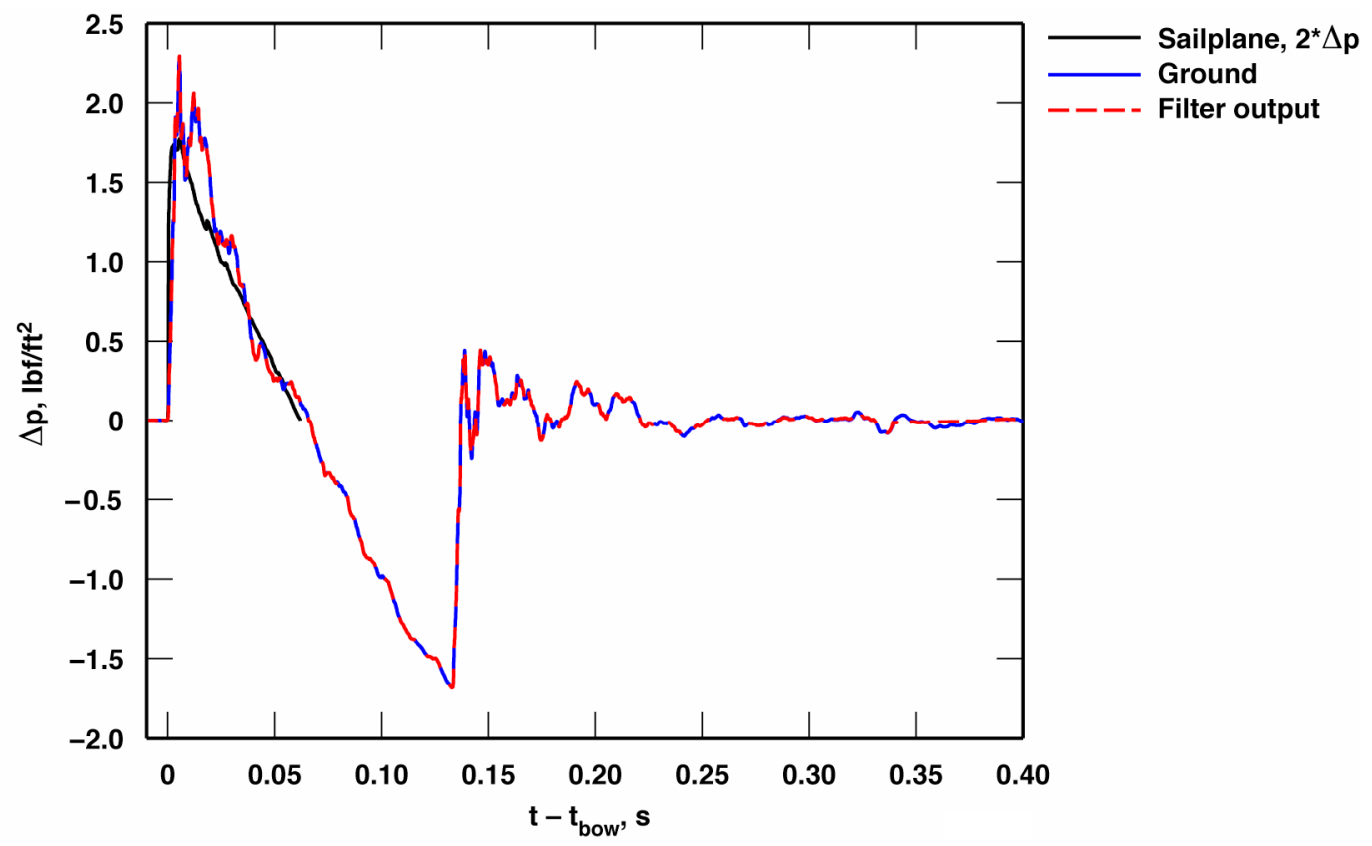

Figure 46. Filter results for flight 1086 , pass 4 , at $10 \mathrm{~m}$ south of the tower; the doubled positive pressure portion of the sailplane data is the input to the filter; the ground-measured data and filter output data are indistinguishable until approximately $0.33 \mathrm{~s}$ after the bow shock.

\section{Conclusion}

An extensive sonic boom propagation database with low- to normal-intensity booms was gathered, and initial results of propagation angles, timing, overpressures, and acoustic level with height above the ground have been presented. Some of these results were compared to values computed by PCBoom4. Sonic boom recordings were also taken by a sailplane to intercept the shock wave before the shock wave reached the ground sensors, and these data were used to generate atmospheric turbulence filter functions. This database will be used to further validate sonic boom propagation codes, and for correlation with a house's structural response database gathered concurrently.

PCBoom4 was used with preflight weather balloon data to effectively place desired overpressure sonic booms on a specific location while preventing loud booms on communities. Overpressures of $0.08 \mathrm{lbf} / \mathrm{ft}^{2}$ to $2.20 \mathrm{lbf} / \mathrm{ft}^{2}$ were recorded in the main test area, while up to $5.0 \mathrm{lbf} / \mathrm{ft}^{2}$ overpressures were recorded near a sonic boom focus region. A high-accuracy airdata calibration in the supersonic flight regime is necessary for accurate sonic boom placement. PCBoom4 was also used to calculate sailplane waypoints for the sonic boom interception. These intercepted sonic boom raypath endpoints were, at times, within a few hundred feet of the ground recording location. This required multidimensional aerial coordination between the aircrew of the F-18 airplane and that of the sailplane.

An idealized value for maximum overpressure of each signature was computed using the initial bow shock and the latter portion of the expansion. The effects of atmospheric turbulence spiking and rounding were negated for comparisons to PCBoom4.

PCBoom4 output matched measured sonic boom arrival time to within $0.22 \mathrm{~s}$ for 70 percent of the signatures, and to within $1.1 \mathrm{~s}$ for all signatures. The idealized maximum overpressures matched computed overpressure to within $0.1 \mathrm{lbf} / \mathrm{ft}^{2}$ for 70 percent of the signatures, and to within $0.3 \mathrm{lbf} / \mathrm{ft}^{2}$ for all signatures.

A three-dimensional microphone array with accurate time tagging can be used to determine the azimuth and elevation angles of an incoming sonic boom. The speed of sound and therefore the ambient air temperature also is computed. Data from the $1.8 \mathrm{~m}$ BADS, the $10 \mathrm{~m}$ tower array, and the $130 \mathrm{~m}$ large triple array were used to compute these values, and they were compared to PCBoom 4 computations and weather measurements. Half of the recorded angles of the sonic booms agreed with PCBoom 4 to within $2.6^{\circ}$ for the BADS, to within $1.5^{\circ}$ for the $10 \mathrm{~m}$ tower, 
and to within $0.6^{\circ}$ for the large triple array. The larger the array, the better the agreement with PCBoom4. There was equal or better agreement in azimuth angles than in elevation angles. Shock thickening can cause near-ground microphones to sense the reflected shock wave during the incident shock wave rise. This overlapping of the incident and reflected shock waves can induce a calculated elevation angle depression on the order of one degree.

The computed temperatures had large differences, up to a $25^{\circ} \mathrm{F}$ difference for the $10 \mathrm{~m}$ tower and $83^{\circ} \mathrm{F}$ for the BADS, which yields speed of sound differences of 2.3 percent and 7.3 percent for the respective arrays. Computed speed of sound for 70 percent of the passes was within 1.2 percent for the $10 \mathrm{~m}$ tower and 2 percent for the BADS.

Evanescent wave acoustic level metrics show little to no change with height up to $10 \mathrm{~m}$ above the ground, and the elevation angle is nearly zero. Sonic boom CSEL almost always decreases with increasing height above the ground up to at least $10 \mathrm{~m}$. The ASEL and PL data have minimums (at $1.2 \mathrm{~m}$ to $6 \mathrm{~m}$ ) near the height where the pressure rise time history from an elevated microphone is the straightest. This agrees with simulated sonic boom subjective response testing. ${ }^{16}$ Sonic booms with significant atmospheric turbulence effects did not show minimum ASEL and PL values for the straightest pressure rises. The time delay between the incident and reflected sonic boom plays an important part in the acoustic level as a function of height. Sonic booms measured on the ground with zero time delay between direct and reflected waves typically give the highest acoustic level.

The noseboom-mounted microphone on the sailplane produces sonic boom recordings the quality of which rival ground-level recordings on a calm day. Slight altitude variations of the sailplane produce microphone variations, but these are readily removed without affecting the sonic boom recording. A time-domain filter was used to improve the low-frequency response of the microphone from $0.54 \mathrm{~Hz}$ down to $0.1 \mathrm{~Hz}$. An atmospheric turbulence filter was generated from sailplane data and ground data, which shows excellent agreement with the ground-level data. This filter can be used on "clean" sonic boom waveforms to induce realistic atmospheric turbulence effects.

Ground impedance data was taken at the $10 \mathrm{~m}$ tower consisting of white noise and swept-sine recordings. Future efforts will include analyzing these data to determine ground impedance as a function of frequency.

A significant loss of data recording occurred for the PC that contained IT security software. Future work is needed to ensure robust recording operations while maintaining mandated IT security.

This extensive variable-intensity sonic boom database, of which only a portion has been analyzed, should serve as an important component in the validation of sonic boom propagation codes in the years to come. PCBoom5 will have three-dimensional structure for both the ground and weather, as compared to PCBoom4 using a flat earth and constant weather data for a given altitude. PCBoom6 will have a Burger's equation solver to calculate more realistic acoustic level metrics than PCBoom4. These codes will be available in the next few years, and will be validated with these data.

\section{Appendix}

Details of the system hardware and flight research techniques are now given, referenced to the section headings in the main body of the paper. These details are necessary for two reasons. The first reason is to properly document the conditions and limitations of this flight database for further analysis, and the second reason is to document flight research techniques that may be used or improved upon in future flight efforts.

\section{A. Section II.A Details (F-18)}

The F-18 airplanes have been converted from U.S. Navy fighter airplanes to research test beds with the installation of research instrumentation. Tail number 852 was the primary airplane used, and it was equipped with a Research Quick Data System (RQDS) which converts normal F-18 airplane 1553 bus parameters into pulse-codemodulated data that is transmitted to the ground. These data are time-tagged (on the aircraft) with GPS-based IRIGB time. Tail number 850 is not equipped with an RQDS, and was used for one data flight. Both F-18 airplanes are equipped with an Ashtech (now Magellan, Santa Clara, California) Z-12 carrier-phase differential GPS (DGPS) receiver, and C-band radar beacons. The GPS data are differential-corrected postflight using a reference DGPS receiver at NASA Dryden to a position accuracy of better than $2 \mathrm{ft}$, and a velocity accuracy of better than $1 \mathrm{ft} / \mathrm{s}$ in flight. ${ }^{18}$ Each F-18 airplane utilized a centerline fuel tank, as pictured on tail number 852 in Fig. 1. 
The RQDS data parameters include airdata measurements such as static and total pressure, INS quantities such as latitude, longitude, altitude, inertial velocities, and Euler angles, and production-aircraft-calibrated quantities that are displayed to the pilot such as Mach number and pressure altitude. Ground-based radar was used to track each flight of the F-18 airplane, since the GPS does not work in inverted flight and the INS experienced some drift in indicated aircraft location.

\section{B. Section II.B Details (Tower)}

The surveyed origin location of the tower is given in Table $\mathrm{I}^{5}$, and the relative positions of the 14 microphones are given in Table $\mathrm{II}^{5}$. The tower used for elevating the microphones was a lightweight, portable structure made by BlueSky Mast, Inc., in Tampa, Florida, USA, primarily for erecting temporary radio antennas. The BlueSky Mast Series II - AL1 is a 2-in. diameter aluminum alloy tubing with interlocking machined flanges between the base pole, 10 primary poles and the guy-line support top pole. A tripod support was staked into the ground and the individual sections of tubing were added to the bottom as needed to create a $10.5 \mathrm{~m}$ tall tower. The final base section allowed the tower to be staked for a fourth attach point. Four guy-lines provided lateral support at the tower apex and were manually fed out as the tower rose. By using a $10.5 \mathrm{~m}$ tall tower, the support guy lines were sufficiently higher than the $10 \mathrm{~m}$ microphone to minimize physical interference with the microphone standoff. At times winds and sonic booms caused the guy-wires to make an audible noise.

The 12-in. microphone standoffs were designed and manufactured at the Dryden Flight Research Center using standard screw-down hose clamps, aluminum "L" and bar stock, and 0.5-in. inside diameter Tygon (Saint-Gobain Performance Plastics, Paris, France) tubing slit longitudinally, as shown in Fig. 2. This provided an inexpensive, easily attachable method to securely fasten the microphones to the tower in the field. Since the tower sections were added to the bottom of the previous section below the screw-down clamp of the tripod, and the microphone standoffs were attached above the screw-down clamp of the tripod, the hose clamps needed to be completely opened, allowing them to go around the tubing to hold the L-stock aluminum brackets to the rising tower. The Tygon tubing provided a snug grip for the 0.5 -inch diameter microphones and provided some sound insulation from the aluminum structure. Holes on the top mounting pole were covered with tape to prevent wind noise and the microphone cables were taped down to prevent cable slap against the tower.

The microphones were facing east, both on the tower and on the $2 \mathrm{ft}$ by $2 \mathrm{ft}$ by $0.75 \mathrm{in}$. plywood groundboards, with $90 \mathrm{~mm}$ Brüel and Kjær (B\&K, Denmark) UA-0237 wind screens in place, spherical on the elevated microphones and cut nearly in half for the ground microphones.

The locations of the tower and groundboards were marked with metal stakes driven into the ground to allow a repeatable placement of the microphones over the 10-day testing period. Early morning setup to avoid wind and heat began four hours before first boom each day of flight with a team of three people. A support truck was parked in the same location each day facing east, $20 \mathrm{~m}$ south of the tower. All of the microphones were calibrated by recording a 1 $\mathrm{kHz}, 94 \mathrm{~dB}$ reference signal using a B\&K Type 4231 sound calibrator each morning before erecting the tower and again after the tower was disassembled.

The microphone type used at all locations was the B\&K Model 4193 0.5-inch condenser microphone with a B\&K Model 2669C preamplifier. The combined sensitivity of each microphone and preamplifier combination was between $11.8 \mathrm{mV} / \mathrm{Pa}$ and $13.5 \mathrm{mV} / \mathrm{Pa}$. The microphones were connected to a B\&K Model 2690-0S4 Nexus conditioning amplifier using a seven-conductor B\&K Model AO-0414 cable of either $30 \mathrm{~m}$ or $150 \mathrm{~m}$ length to provide power to the microphone, read the microphone signal, and allow factory calibration data to be read by the Nexus from each microphone. Final calibration was performed during post-processing using the recorded reference signal. The Nexus outputs, set to provide amplification of $100 \mathrm{mV} / \mathrm{Pa}$, were connected to a 16-channel LDS Dactron (Middleton, Wisconsin, USA) FOCUS II real-time signal analyzer, which acted as an analog-to-digital converter and sampler. The FOCUS II was set to record with a range of $\pm 10 \mathrm{~V}$, which allows booms with overpressures of $\pm 100 \mathrm{~Pa}$ ( or $\pm 2.08 \mathrm{lbf} / \mathrm{ft}^{2}$ ) to be recorded without being clipped. Global positioning system synchronized IRIG-B time signals generated by an Instrumentation Technology Systems (Northridge, California, USA) Model 6155D were also connected to the FOCUS II. The FOCUS II sampled data at 24-bit resolution and 24,000 samples per second for most booms, with five booms sampled at 24-bit resolution and 48,000 samples per second. LDS RTPro software on a Dell (Roundrock, Texas, USA) Latitude ATG D620 laptop computer configured and controlled the FOCUS II and recorded the sampled data through a universal serial bus connection. Previous testing by feeding one GPS IRIG-B pulse signal to all 16 FOCUS inputs had shown that all signals are time aligned for essentially simultaneous 
sampling. All of the amplifiers and recording equipment were run on battery power (Model UBI-2590 military batteries), and were located in the support truck in order to be kept out of the sun.

The recordings were started approximately 2 min before the expected boom arrival and continued for approximately $1 \mathrm{~min}$ after the last of the boom echoes could be heard. RTPro locked up on this computer three times either just before the boom or after the boom such that no data was acquired for these passes. This PC was newly acquired and had various mandated IT security patches to the Windows (Microsoft Corporation, Redmond, Washington, USA) XP operating system installed. Post-processing of the data was also impeded by persistent and frequent software crashes. An older generation PC without the IT security patches (thus never connected to the network) did not experience these software lock-ups in prior tests and so was used to complete postflight processing.

The elevated microphones on the tower receive sonic booms including both incident sonic boom waves and waves reflected from the ground surface. The amplitude of the reflected waves is determined not only by the incident wave but the ground surface itself. Typically, a simplistic reflection coefficient of 2.0 (or 1.9 to account for losses) is used for microphones on the ground; however, it is less clear what the reflection coefficient should be for elevated microphones. To characterize this reflection coefficient in detail, it is necessary to ascertain the complex impedance of the ground, since this is mathematically related to reflection coefficient.

Thus, as an additional component of this experimental database, white noise and swept-sine measurements were made at the tower on July 10, 2007, with a loudspeaker placed $2 \mathrm{~m}$ above the $5 \mathrm{~m}$ east groundboard, Fig. 4 . The recordings were made at 24-bit resolution and 24,000 to 96,000 samples per second at all tower microphone locations with the $5 \mathrm{~m}$ east microphone placed directly in front of the woofer of the loudspeaker as the reference sound.

The purpose of these measurements was to obtain recordings with the tower microphones to better characterize the ground impedance in the vicinity of the tower. Generally, what can be obtained from such measurements is ground impedance as a function of frequency, yielding a reflection coefficient that is a function of frequency.

A data analysis is currently under way to extract the ground impedance as a function of frequency using the white noise and swept-sine data. The method employed is similar to the work of Hess, Attenborough, and Heap. ${ }^{19}$ The resulting reflection coefficient as a function of frequency can then be used to generate synthesized waveforms that can be compared with the waveforms actually recorded at the elevated microphones.

\section{Section II.C Details (Sailplane)}

In a previous flight effort ${ }^{3}$ only the wingtip microphone location was used, which gave good results, but this microphone location is compromised by several nearby noise sources including control surface joints, tip vortex, and tip-wheel support structures. In this test, the noseboom-mounted microphone gave superior results, rivaling the data quality of ground-based microphones. The microphone used for both the wingtip and noseboom locations is the B\&K Model 4193 0.5-inch condenser microphone with a B\&K Model 2669C preamplifier. Each microphone cartridge is fitted with a B\&K Model UA0386 tapered nose cone and the microphone and preamplifier assembly is mounted externally and aligned approximately with what would be the local air flow in steady flight. As at the $10 \mathrm{~m}$ tower array, the same model Nexus amplifier, FOCUS II (but this an 8-channel unit), batteries, and GPS-based IRIG-B timecode generator were used for data acquisition. Seven conductor microphone cables equivalent to those used at the $10 \mathrm{~m}$ tower array were fabricated to the correct length for the sailplane. Each external microphone is sampled simultaneously with two separate gain settings: one setting optimized for normal booms and a second setting for low booms.

Two cockpit microphones (one forward, one aft) are used to record crew and radio comments during the data collection runs. These microphones are pre-polarized G.R.A.S. Sound \& Vibration (North Olmstead, Ohio, USA) 40AE microphones with 26CA preamplifiers. These outputs are connected directly to the FOCUS II.

The FOCUS II is configured and controlled by way of a universal serial bus by a Motion Computing (Austin, Texas, USA) LS800 Tablet PC mounted on the flight-test engineer's (FTE) instrument panel with the data being stored on the Tablet PC. The Tablet PC relies on convective cooling, and experienced overheating problems on previous flight efforts. An in-house designed and fabricated forced-air cooling system was attached to the Tablet PC 
which prevented overheating during the test. This Tablet PC did not have the newly mandated IT security software patches, and the RTPro software never crashed during data acquisition.

The FOCUS II generates a substantial level of radio frequency interference that hinders very high frequency communications using the built-in radio on board the sailplane. Consequently, the pilot or FTE uses a handheld very high frequency transceiver for project and tower communications. Ultra high frequency communication is relatively unaffected by the FOCUS II emissions.

An Ashtech Z-Xtreme carrier-phase DGPS receiver was installed to record GPS position data on a flash memory card, and its position and velocity accuracies are comparable to that of the Z-12 DGPS. The Z-Xtreme DGPS data and GPS-based IRIG time-tagging of the microphone data yielded the position of the sailplane-borne measurement. A separate, portable Garmin (Olathe, Kansas, USA) GPS receiver was used by the flight crew for real-time positioning.

\section{Section II.D Details (Other Sensors)}

Each flight used preflight and flight-time GPSsonde weather balloons, launched approximately $2.5 \mathrm{mi}$ from the house, Fig. 7, and tracked to an altitude of 60,000 ft. The preflight balloon data was used as input to PCBoom4 for waypoint planning, and also for postflight analysis.

Four meteorology measuring towers were placed around the instrumented house and near the tower array to give temperature, wind direction and speed, humidity, pressure, and solar radiation. Various hardware problems resulted in the loss of some weather tower data from some flights.

Three-axis wind velocity measurements from an Atmospheric Systems Corporation (Santa Clarita, California, USA) SODAR (SOnic Detection and Ranging) were requested during each flight, from both a full-sized unit, a SODAR model 2000, approximately 4.0 miles from the house, and also a mini-SODAR model 4000 located approximately 2.5 miles from the house. The full-sized unit gives three-axis wind speeds at $20 \mathrm{~m}$ intervals to $1000 \mathrm{~m}$ above ground level, and the mini-SODAR at $5 \mathrm{~m}$ intervals to $200 \mathrm{~m}$ above ground level. Various hardware and software problems resulted in the loss of SODAR data on several flights.

\section{E. Section III.A Details (Airdata Calibration)}

Since the F-18 airplane uses pitot-static tubes that are on the sides of the radome, there is a position error not only of the static pressure but also of the total pressure, because the pitot-static tube is located aft of the bow shock of the airplane. While the manufacturer has installed pitot and static corrections into the ADC of the airplane, the airdata accuracy requirements for this research exceed those of the manufacturer. As on other supersonic research projects, ${ }^{3}$ a Mach number calibration was performed using DGPS inertial data combined with atmospheric data from GPSsonde weather balloons. Research Quick Data System data were used in the calibration of F-18 airplane tail number 852, while pilot-recorded head-up display (HUD) values were used to calibrate F-18 airplane tail number 850 , in combination with using tail number 852 as a pacer airplane. ${ }^{20}$

It was found that the manufacturer's ADC correction for total pressure is correct in the supersonic region, but the manufacturer's ADC static pressure correction has large errors, on the order of 0.045 Mach, Fig. 47. For the low-boom dives this Mach error manifests as a $1.7 \mathrm{nmi}$ error in shock position. The calibration corrections are seen to be similar for both aircraft. 


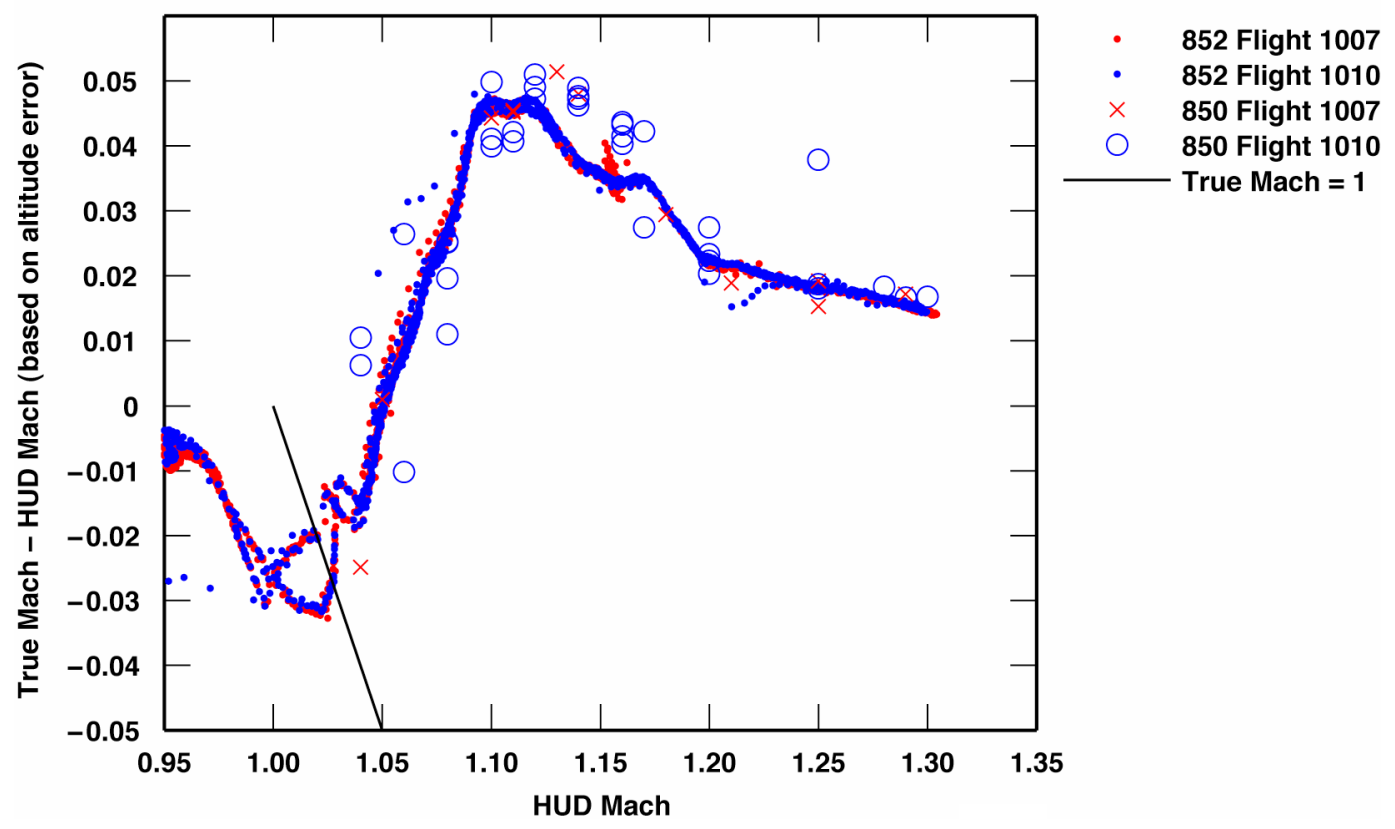

Figure 47. Airdata calibration of F-18 airplanes, tail numbers 852 and 850, showing airdata computer Mach error.

\section{F. Section III.B Details (Low-boom Dive)}

The dive profile, Fig. 48, involves flying at a level attitude at a high subsonic speed and an altitude of nearly $50,000 \mathrm{ft}$ toward a predetermined dive point on a predetermined heading. A $10^{\circ}$ heading change is made $10 \mathrm{nmi}$ before the dive point. At $7.5 \mathrm{nmi}$ from the dive point the aircraft is rolled to an inverted attitude back onto the original heading; a positive $g$ pull to the desired dive angle of $53^{\circ}$ downward to the dive point then is initiated, while the throttle is pulled to the idle position to avoid excessive speed. When the desired dive angle is reached, the aircraft is rolled to an upright attitude, and a Mach number of approximately 1.1 is achieved. At an altitude of $38,000 \mathrm{ft}$ a pull-up is initiated to recover the aircraft at an altitude well above 32,000 ft. The floor of the high altitude supersonic corridor is $30,000 \mathrm{ft}$. 


\section{Dive Flight Maneuver}

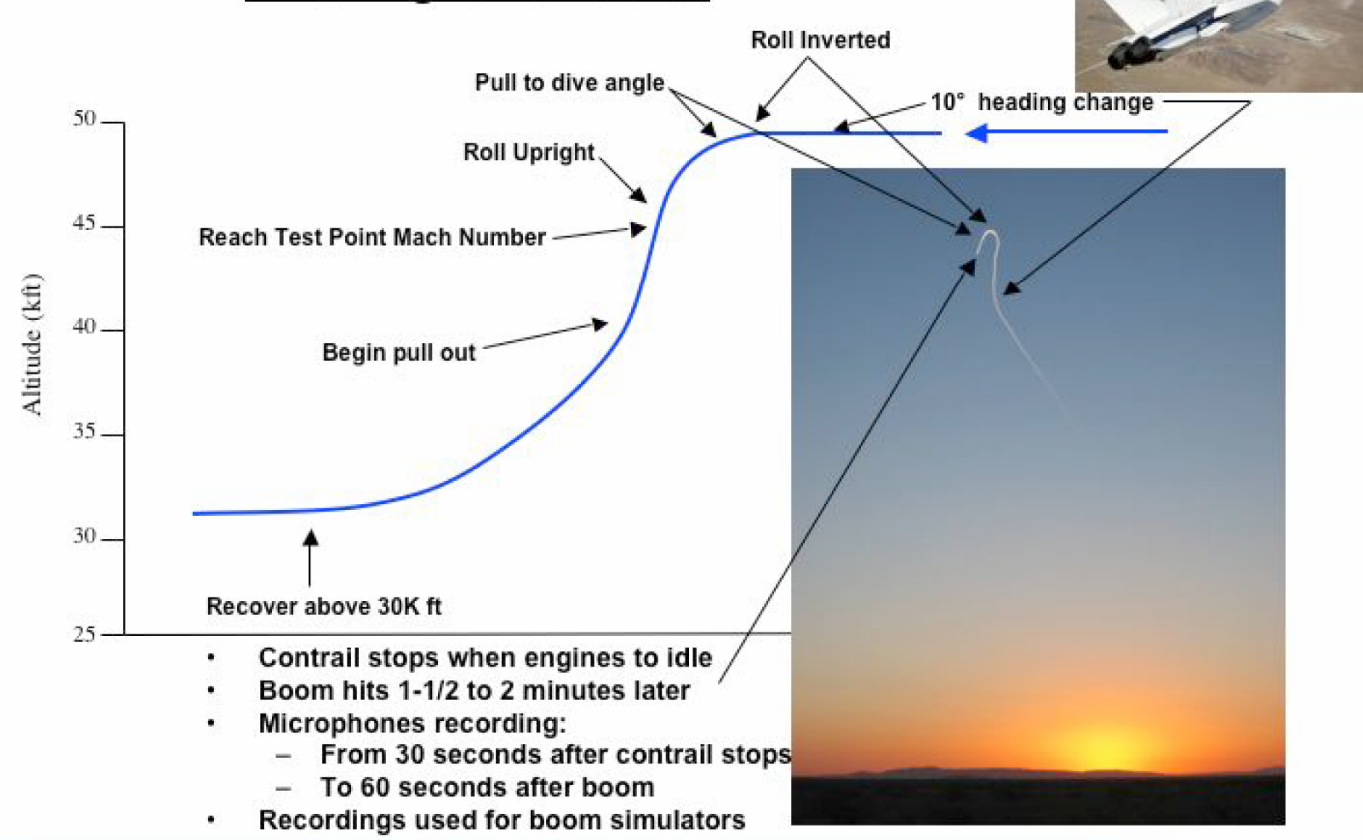

\section{DRYDEN FLIGHT RESEARCH CENTER \\ "...to separate the real from the imagined." .Dr. Hugh L. Dryden}

Figure 48. Schematic of low-boom dive maneuver.

The F-18B airplane has an angle-of-attack limit in this supersonic flight regime, so angle of attack is closely monitored. The F/A-18 avionics allows a dive point to be displayed on the HUD, which greatly aids in maintaining the proper dive angle and heading.

While the steady-state condition of Mach 1.1 at $40,000 \mathrm{ft}$ altitude at a $53^{\circ}$ dive is the idealized test point, the actual maneuver necessary to achieve this test point yields somewhat different results. The F-18 does not trim at this flight condition, but tends to accelerate to higher Mach numbers. This acceleration in speed as well as the curvature of the flight path to achieve the dive results in a focused boom a few thousand feet below the aircraft. The post-focus boom that hits the ground at the tower and house is a "U" wave that hits generally a few seconds after the normal "N" wave. The intended purpose of this dive was to get the minimal shock wave off the top of the aircraft, ${ }^{8}$ but generally the shock wave comes off the side of the F-18. This real-world achievable sonic boom footprint still gives a range of overpressures down to $0.1 \mathrm{lbf} / \mathrm{ft}^{2}$ or less, and therefore still has great utility for this type of sonic boom research.

The pilot made calls of "two minutes to roll in," "thirty seconds to roll in," and "rolling in three-two-one-mark," to enable the sailplane crew and ground personnel to prepare for the test point.

\section{G. Section III.C Details (Normal Booms)}

The above described airdata calibration was used to give indicated values for the pilot to fly, namely Mach 1.23 and an altitude of $31,550 \mathrm{ft}$. The pilot started at a higher altitude and subsonic speed, and initiated a dive approximately $20 \mathrm{nmi}$ prior to the waypoint to accelerate to supersonic speeds for efficiency. The pilot made calls of "two minutes to waypoint," "thirty seconds to waypoint," and "waypoint in three-two-one-mark," to enable the sailplane crew and ground personnel to prepare for the test point.

\section{H. Section III.D Details (Waypoint Planning)}

The principal investigator for the house structural response test defined for each test day the sonic boom overpressures, general direction of propagation, and desired order. The requested overpressures were generally of 
the levels of $0.10,0.35,0.65$, and greater than $1.20 \mathrm{lbf} / \mathrm{ft}^{2}$. Additional constraints placed on the project include remaining in the high altitude supersonic corridor above an altitude of $30,000 \mathrm{ft}$, maximizing opportunities for the sailplane to measure the sonic boom, and a self-imposed constraint of not repeatedly subjecting a community to booms above $2.0 \mathrm{lbf} / \mathrm{ft}^{2}$ for the low-boom dives. While the local communities around Edwards Air Force Base often experience sonic booms, our flights involved sonic booms nominally every six minutes with sometimes seven sonic booms per flight, sometimes with two flights in a day. The nearby proximity of the towns of California City, North Edwards, Aerial Acres, Desert Lake, and Boron, California, Fig. 49, posed significant challenges to flight planning.

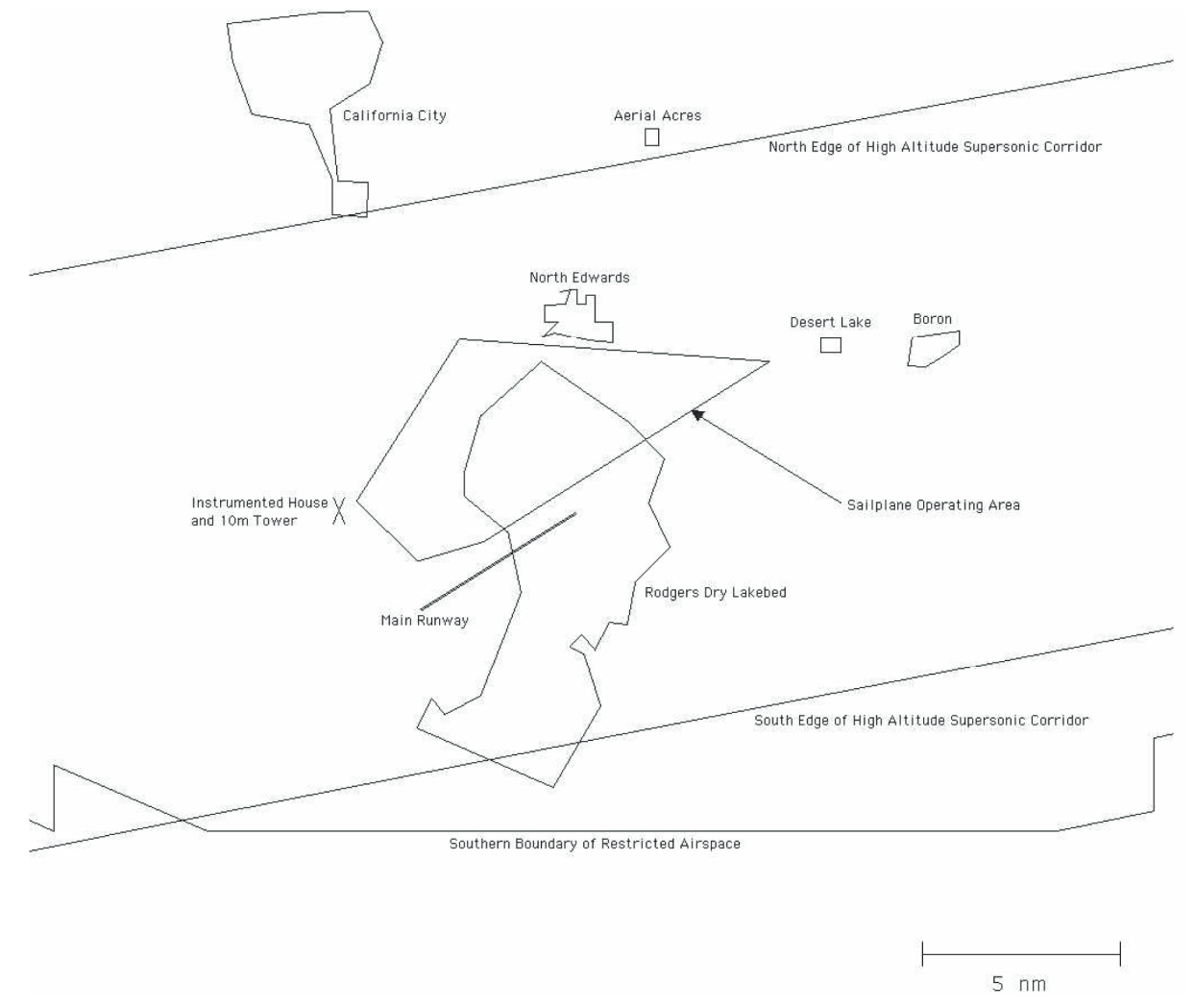

Figure 49. A PCBoom4 graphical output map, without sonic boom footprint and with various landmarks annotated.

Preflight GPSsonde weather balloons were launched usually at 5:00AM local time (1200Z), and the data of temperature and wind profiles were available on the Internet approximately 70 min later. PCBoom 4 reads the balloon data file directly.

\section{Low-boom F-18 Waypoint Planning}

Flight data from a previously-flown low-boom dive is used as a template for future dives. These data of time, position, Mach number, altitude, flight path angle, flight path heading, and the first and second derivatives of Mach number, flight path angle, and flight path heading are adjusted for the atmospheric data from the preflight balloon, and are made into a PCBoom4 input trajectory file. The time of the initial roll into the dive is noted also. PCBoom4 is then executed with these input files, and a graphical output of the sonic boom footprint is generated, as shown in Fig. 50. 


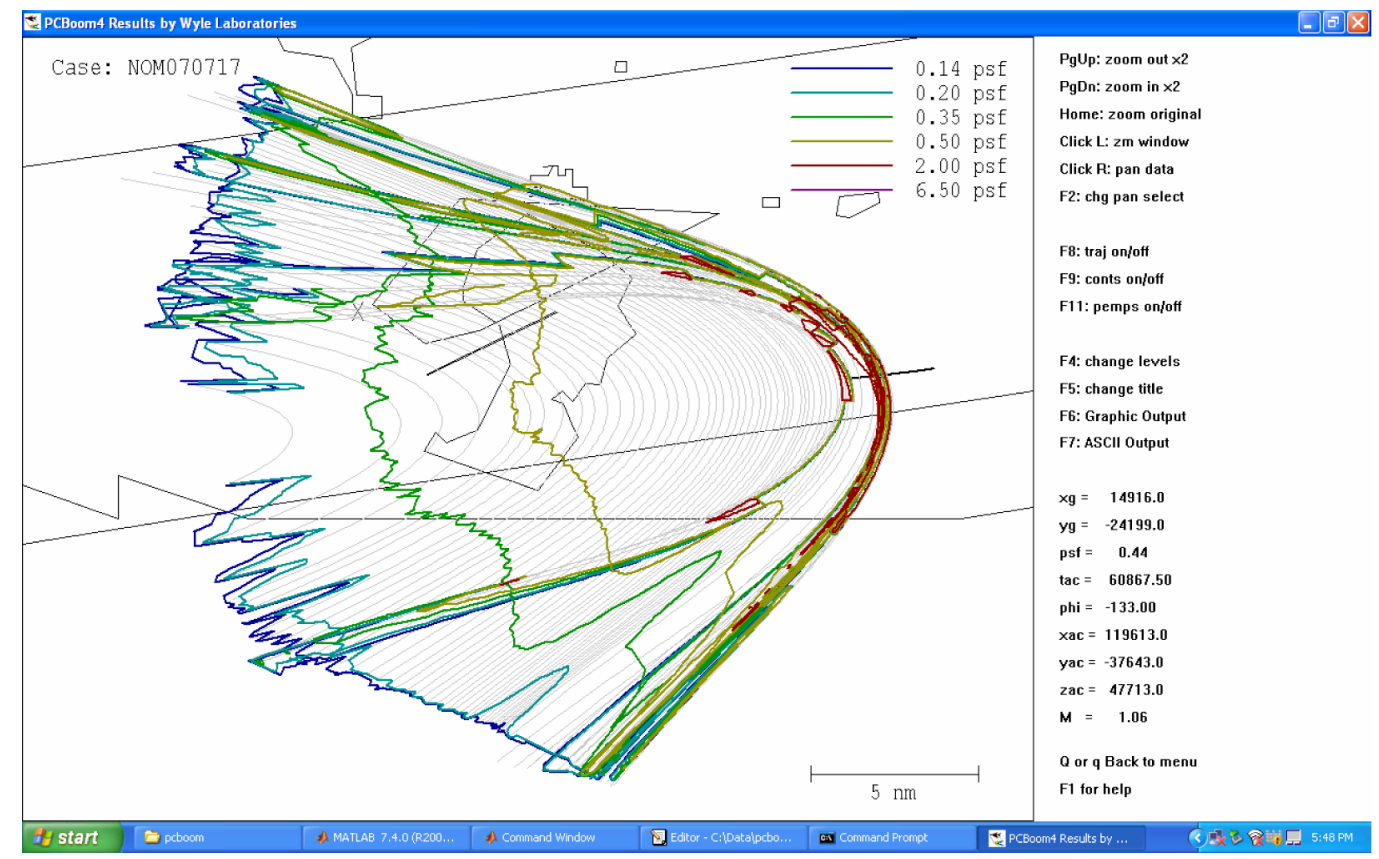

Figure 50. Preflight-predicted PCBoom4 output using July 17, 2007 1200Z atmospheric data, before any trajectory translation.

An isopemp is a curve of sonic boom impact locations on the ground for a given single time at the aircraft, and is generally shaped as a hyperbola. PCBoom4 allows isopemps and pressure contours of user-defined values to be displayed, and the desired overpressures for the day are entered, as well as the $2.0 \mathrm{lbf} / \mathrm{ft}^{2}$ limit for this project. This graphic is inspected for footprint location with respect to the local communities, the location of the instrumented house, and the sailplane operations area, see Fig. 7, Fig. 49, and Fig. 50. In this initial computation in Fig. 50, the town of North Edwards would be subjected to loud booms, and the instrumented house location (marked with an " $\mathrm{x}$ ") does not have the desired overpressure, and furthermore is in a complex region of overlapping isopemps which would give multiple $\mathrm{N}$-wave sonic booms.

In order to place the desired overpressure sonic boom on the instrumented house, the template footprint was translated geographically. While the following procedure could be automated with a computer program, it was found to be relatively quick and simple to make a quick sketch of the footprint and pressure contours on tracing paper placed on the computer screen as an aid in the translation process. The tracing paper footprint image was slid onto the screen to place the instrumented house on the desired pressure contour, and then translated further along the pressure contour to avoid booms of over $2.0 \mathrm{lbf} / \mathrm{ft}^{2}$ from impacting a community. This location was then marked on the tracing paper. This was repeated for all the desired overpressure values. The tracing paper was then returned to its original position on the screen where it was traced. Then the cursor of the computer was moved to each marked location on the paper in turn, when an "R" and "F7" were commanded to determine the shock wave ray intersection with the ground and to save that data to a file.

These files contained the position on the ground that the desired sonic boom hit for the original dive trajectory, which was different than the desired instrumented house location. The difference between these locations was used to adjust the trajectory and the target dive point of the F-18 airplane. The translated trajectory file was once again run through PCBoom4 to confirm that the desired overpressure sonic boom would hit the instrumented house, and the local communities would be spared sonic booms over $2.0 \mathrm{lbf} / \mathrm{ft}^{2}$. This is shown in Fig. 51 through Fig. 53 for the three calculated dive waypoints. 


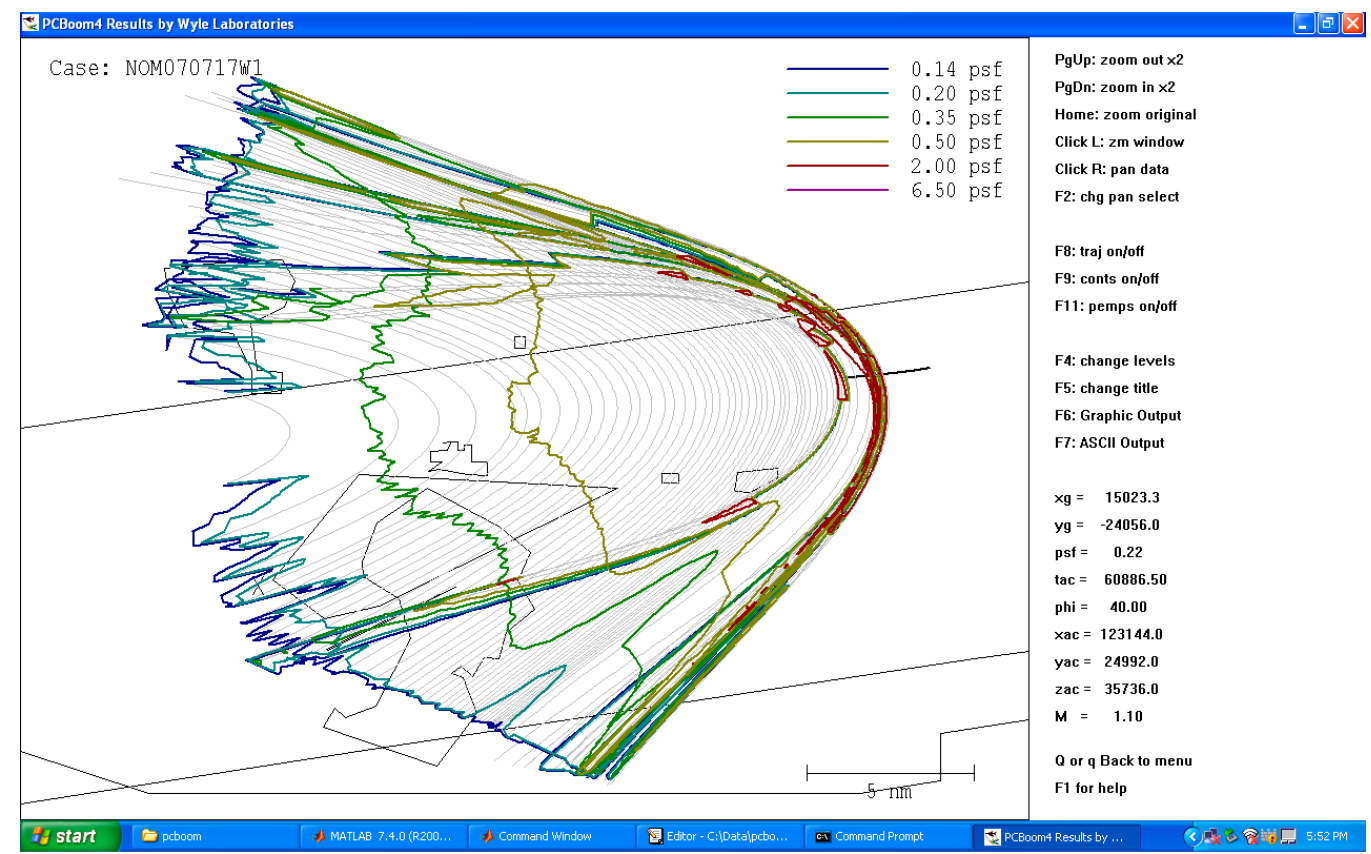

Figure 51. July 17, 2007, 1200Z balloon footprint, waypoint 1.

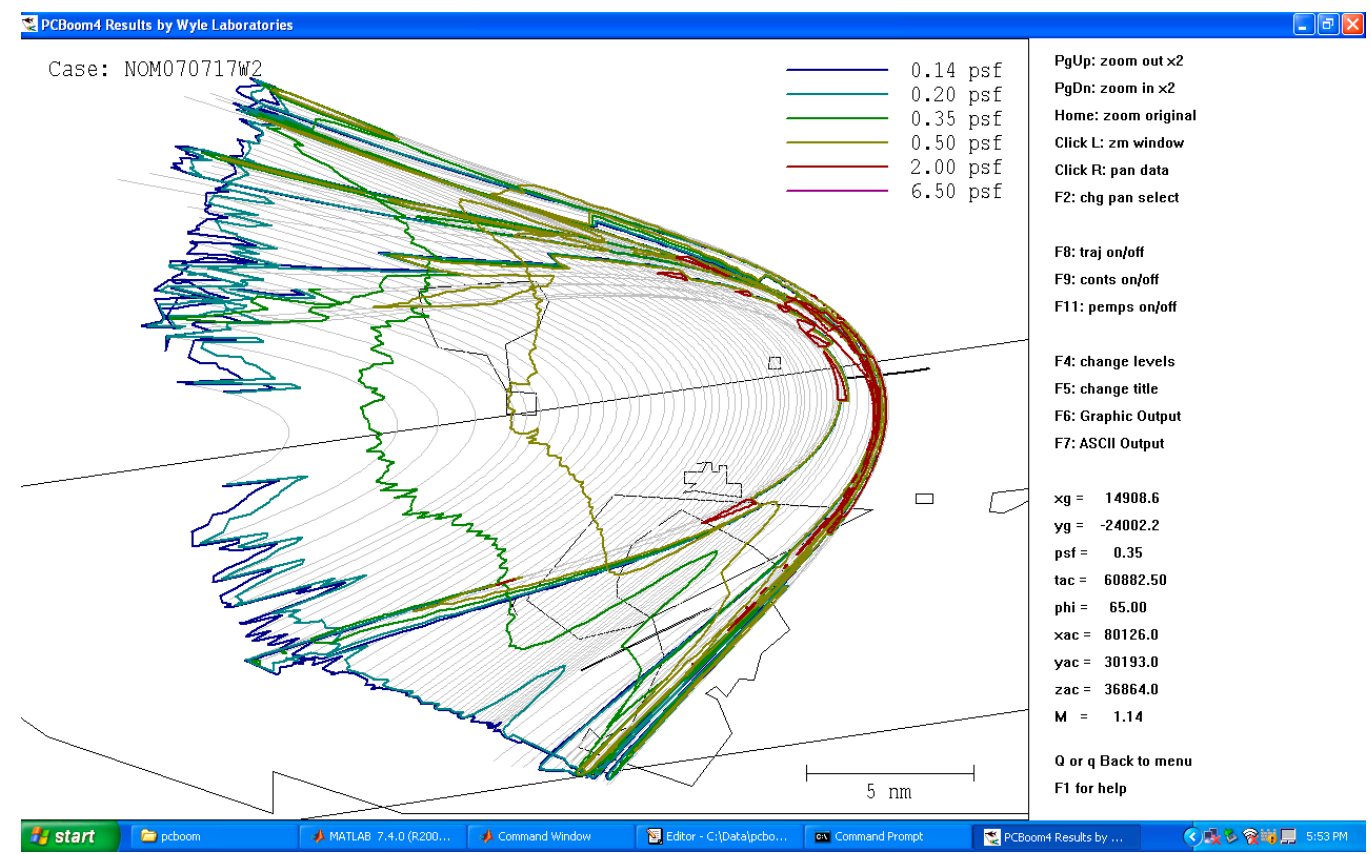

Figure 52. July 17, 2007, 1200Z balloon footprint, waypoint 2. 


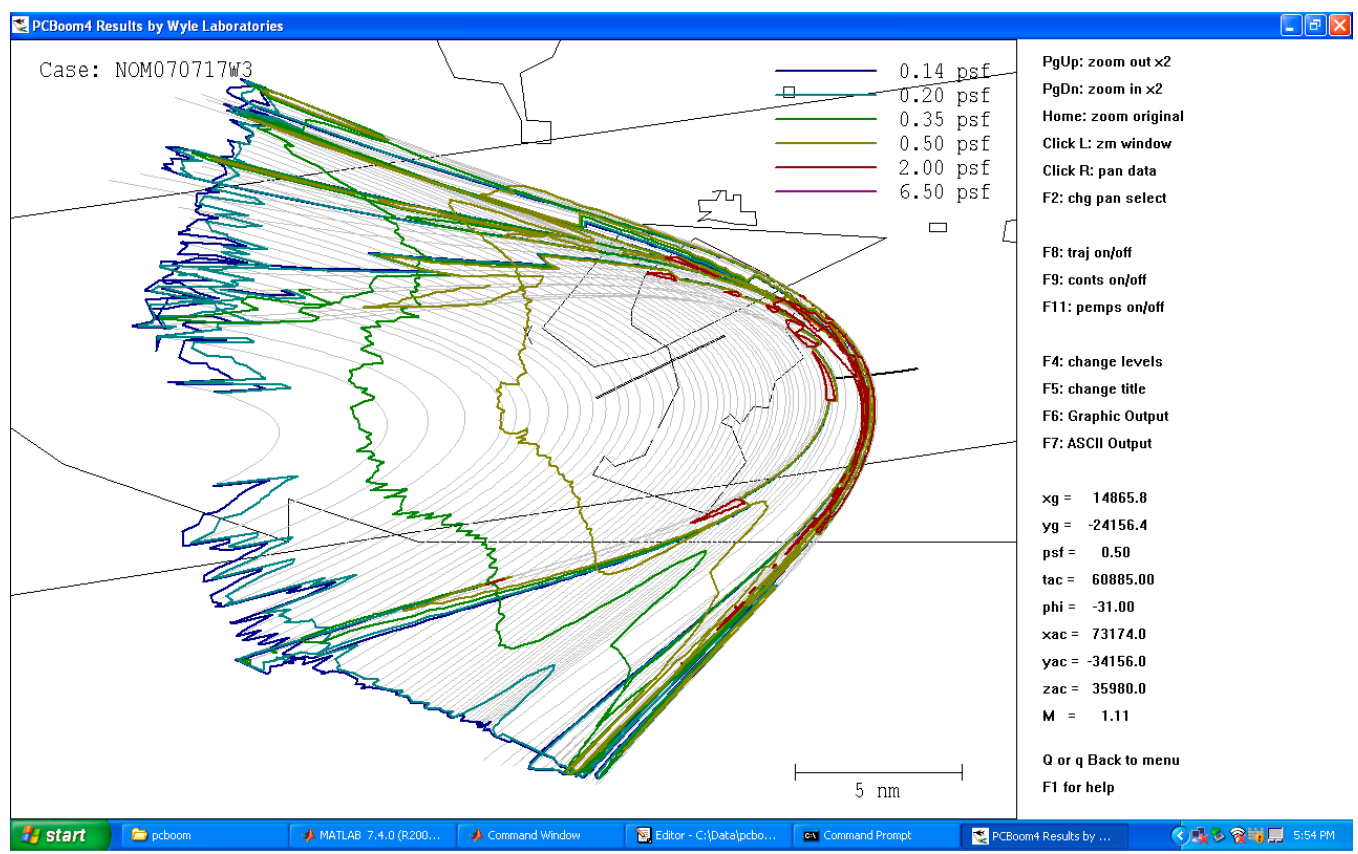

Figure 53. July 17, 2007, 1200Z balloon footprint, waypoint 3.

With the exception of the tracing paper task, all of these elements, including the invocation of PCBoom4 linecommands, were automated within Matlab (The Math Works, Inc., Natick, Massachusetts, USA) scripts. The latitude, longitude, and ground altitude of each dive point calculated were transmitted to the F-18 pilot before takeoff.

Because the effect of the temperature and wind profiles on the footprint is invariant with translated location (within the local area), the simple translated tracing paper method works well. The more generalized case of also changing the aircraft heading requires rerunning PCBoom4 after a rotation, as the wind direction has a different influence, and then iterating rotations until the desired footprint is achieved. During the HouseVIBES program no rotation was needed, but on previous flight research efforts rotation has been needed on some days. For HouseVIBES the nominal F-18 airplane heading for the dive was $260^{\circ}$ true, which is aligned with the high altitude supersonic corridor. The atmospheric conditions of the day can radically change the sonic boom footprint. On strong headwind days the minimum overpressure may not be below $0.3 \mathrm{lbf} / \mathrm{ft}^{2}$, with a strong lateral gradient of overpressure. With strong tailwinds the opposite is true, with minimum overpressures below $0.1 \mathrm{lbf} / \mathrm{ft}^{2}$ and very small lateral gradients of overpressure.

Most of the sonic booms on this project were generated from the northeast of the instrumented house, thus these flight tracks of the F-18 airplane were to the north of the house, as shown in Fig. 51 and Fig. 52. In order to vary the incident angle of the shock waves on the house some passes were flown with the track to the south of the house, as shown in Fig. 53, near the southern boundary of the high altitude supersonic corridor, such that the sonic booms were generated from the east-southeast.

\section{Normal Boom F-18 Airplane Waypoint Planning}

Two normal-level shock wave azimuth angles from true north were selected to approximate those of the low-booms variety, specifically azimuths of $75^{\circ}$ and $105^{\circ}$. Additionally, normal-level shock waves with an azimuth of $285^{\circ}$ from true north were also selected. Matlab scripts were written to generate PCBoom 4 trajectory input files with true Mach numbers of 1.20, 1.25, and 1.30, a pressure altitude of 32,000 ft, and with headings of due east and west, and these were run using the preflight atmospheric data. The PCBoom4 ".out" files from each of these runs were interrogated to find those sonic boom raypaths that are closest to each of the desired azimuth angles of $75^{\circ}$, $105^{\circ}$, and $285^{\circ}$. The ground intercept point of this raypath is differenced with the instrumented house location, and this difference is applied to the sonic boom generation point, and this now becomes the F-18 airplane waypoint. 
PCBoom4 is rerun with this waypoint, and these solutions are inspected to ensure that the overpressure on the ground exceeds $1.2 \mathrm{lbf} / \mathrm{ft}^{2}$ and the aircraft can remain in the high altitude supersonic corridor while supersonic. The minimum Mach number cases for each azimuth angle that satisfies these requirements are used in order to minimize fuel burn (and hopefully get additional test points). The latitude and longitude of these waypoints are transmitted to the pilot before takeoff. The indicated Mach numbers and pressure altitudes for these possible three speeds are also given to the pilot so that the true Mach and altitude values that were simulated will be flown. All normal boom flights were flown at a true Mach number of 1.25 for the HouseVIBES project, but some headwind conditions seen in previous projects would require Mach 1.30 for the sonic boom to reach the ground.

\section{Sailplane Waypoint Planning}

In order to perform the turbulence filter analysis given below, the sailplane needed to intercept the shock wave from the F-18 airplane before this same shock wave hit a ground microphone near the house. This requires preknowledge of a specific sonic boom raypath that connects the F-18 airplane, the sailplane, and the ground microphone. The PCBoom4 runs described in the preceding two sections included output at intermediate altitudes from $11,000 \mathrm{ft}$ to $4,000 \mathrm{ft}$ geometric altitude in $500-\mathrm{ft}$ increments. For each waypoint calculated above, the PCBoom4 ".out" file was interrogated to yield latitude, longitude, propagation direction of the shock wave, propagation time from when the pilot calls "mark," and overpressure at each of these intermediate altitudes. These data were tabulated and graphed as in Fig. 54 to hard copy, and an electronic waypoint file for the sailplane pilot's handheld GPS unit was also generated and given to the pilot before takeoff.

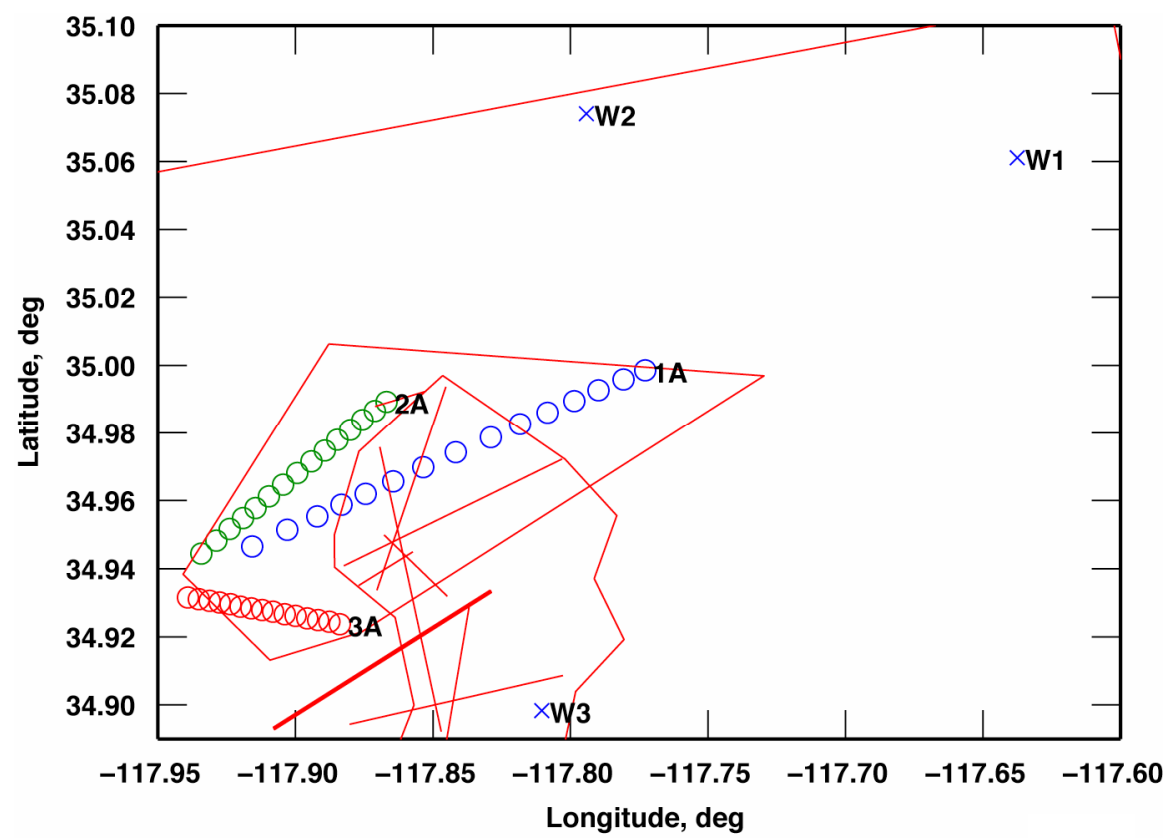

Figure 54. Sailplane operations area; F-18 airplane waypoints marked with " $x$ " and sailplane waypoints marked with "o" for July 17, 2007 using the $1200 Z$ balloon data.

\section{Section III.E Details (Sailplane Waypoint Acquisition)}

Before takeoff, the crew entered the sailplane waypoints appropriate to the planned boom paths into the Garmin GPS receiver. The FTE carries a table of the predicted delay times from the F-18 airplane "mark" call to the boom arrival at each waypoint. The sailplane was towed to $11,000 \mathrm{ft}$ to $12,000 \mathrm{ft}$ above mean sea level and the tow plane with the sailplane loitered in the vicinity of the uppermost sailplane waypoint awaiting the arrival of the F-18 airplane at altitude and subsequent release of the sailplane from the tow plane. The sailplane crew selected a particular waypoint based on their position and altitude and the time to the next boom. The sailplane pilot's task was to achieve the desired waypoint (latitude, longitude, and altitude) at the predetermined time, heading into the shock wave propagation direction, at the most acoustically quiet airspeed, all while remaining within the sailplane operating area. The FTE in the back seat of the sailplane operated the data recorder and assisted with timing determination. 
The pilot of the F-18 airplane made three timing calls for each pass. When the "two-minutes" call was made by the F-18 airplane pilot, the sailplane crew determined the highest waypoint that could be reached given their present position and altitude. A conservative estimate of the minimum sink rate (including maneuvering) is $200 \mathrm{ft} / \mathrm{min}$, so the highest waypoint that was $400 \mathrm{ft}$ to $500 \mathrm{ft}$ below the sailplane altitude at the "two-minutes" call was chosen as the target. The sailplane crew had the table of waypoints and propagation times with respect to the "mark" call. The sailplane pilot established a modified approach pattern to the target waypoint; typically the sailplane was flown in the propagation direction of the shock wave at the "thirty-seconds" call from the pilot of the F-18 airplane. At this "thirty-seconds" call, the FTE started the timer for the tabulated propagation time plus $30 \mathrm{~s}$. The $180^{\circ}$ turn toward the shock wave was made based on the time-to-boom estimate and the position of the sailplane with respect to the waypoint. Spoilers, turns, and airspeed changes were used to adjust the altitude, arrival time, and heading at the waypoint. Immediately prior to the FTE's 30-seconds-to-boom estimate, the sailplane FTE started the data recorder and called "thirty seconds" to annotate the cockpit audio channel of the recorder. The sailplane canopy vents were closed, radio transmissions (except safety-of-flight) terminated, spoilers closed, and the pilot held airspeed at the target airspeed $(45 \pm 3 \mathrm{kn}$ ) holding heading into the oncoming boom, striving to minimize sailplane control inputs during the boom. Normal booms are heard by the flight crew, low booms often are not. The pilot maintained airspeed and heading for at least $20 \mathrm{~s}$ beyond the boom-time estimate. At that point, the data recorder was turned off and the crew began positioning for the next waypoint.

\section{J. Section III.F Details (Raypath Determination)}

In addition to the preflight GPSsonde weather balloons, takeoff time balloon data were used postflight, along with atmospheric analysis of synoptic charts and balloon data from nearby weather stations to determine the atmospheric reference state during the flight times. ${ }^{3,20}$ This atmospheric reference state was used as input to PCBoom4 runs of the actual flight data for each supersonic pass. For F-18B airplane 852, the RQDS, GPS, and ground-based radar data was used, ${ }^{21}$ along with the airdata calibration, to determine the reference trajectory of the airplane. For F-18A airplane 850 on flight 1557, the radar data combined with the atmospheric data was used to determine reference flight conditions, as this airplane is not equipped with an RQDS, and the DGPS malfunctioned on this one flight. The DGPS data from F-18B airplane 852 was very useful for the correction of the INS position data. Although the DGPS does not function during the inverted dive, prior to the dive the DGPS revealed INS lateral drift errors of $600 \mathrm{ft}$ to $1600 \mathrm{ft}$, generally in the direction of the dive, and these drift errors were corrected. Vertical errors of $20 \mathrm{ft}$ to $160 \mathrm{ft}$ were also corrected.

Progressing toward the ground, a sonic boom wavefront propagates forward and downward along a raypath from the point at which the sonic boom was generated. The sonic boom propagation angle $\phi$ is defined as the angle between two geometric planes. The first plane is vertical and contains the aircraft velocity vector. The second plane contains the raypath near the supersonic airplane and the aircraft velocity vector. A $\phi$ of zero describes a wavefront that travels downward and forward from the point it was generated, and wavefronts that travel to the pilot's left side have $\phi$ values that are positive. PCBoom 4 computes the raypaths at discrete times and discrete values of $\phi$. For each of the supersonic passes the tower location was selected in PCBoom4 to report: 1) predicted time that the shock wave hit the tower, $\operatorname{tg}_{t}$; 2) time that the shock wave left the F-18 for the tower, $\operatorname{tac}_{t}$; 3) shock wave sonic boom propagation angle from the F-18 airplane toward the tower, $\phi_{i}$; and 4) shock wave propagation azimuth and elevation angles at the tower, $a z_{t}$ and $e l_{t}$, among other parameters. The sailplane pressure data was examined to determine the times at which the first shock wave hit the sailplane for each pass. These times were used with the sailplane DGPS data to find the sailplane locations (latitude, longitude, and altitude) when the booms were recorded. PCBoom4 was re-run using these sailplane altitudes as a new "ground" altitude. The sailplane latitude and longitude at the boom times were used with the PCBoom4 output to find (as for the tower location) the: 1) predicted time that the shock wave hit the sailplane, $t_{s} ; 2$ ) time that the shock wave left the F-18 airplane for the sailplane, $t a c_{s}$; 3) shock wave sonic boom propagation angle from the F-18 airplane toward the sailplane, $\phi_{s}$; and 4) shock wave propagation azimuth and elevation angles at the sailplane, $a z_{s}$ and $e l_{s}$. If the sailplane were to perfectly intercept the raypath from the F-18 airplane to the tower, then $\operatorname{tac}_{t}=\operatorname{tac}_{s}$ and $\phi_{t}=\phi_{s}$. Mismatches could be caused by a variety of balloon, airdata, PCBoom4, prediction technique, or piloting errors.

In order to assess the how closely the sailplane intercepted the correct raypath, the PCBoom4 solution at the 10 $\mathrm{m}$ tower ground altitude was interpolated to the ray that hit the sailplane. The isopemps for each sample time tac are given in the PCBoom4 ".un6" file, and the isopemps that straddle the time $t_{a c}$ are extracted from this file. The 
ground location on each isopemp corresponding to $\phi_{s}$ is found by performing a cubic spline interpolation, and then the two ground locations are interpolated in time to $t a c_{\mathrm{s}}$ to give the final location, as shown in Fig. 12 and Fig.13.

\section{K. Section III.G.1 Details (Pressure Corrections)}

For each flight of the sailplane, a B\&K Type 4231 sound calibrator was used on the ground for calibration data of the microphone. The bullet nose and windscreen were removed for calibration, and reattached before flight.

The background pressure can now be removed. ${ }^{9}$ Figure 55 shows a typical sailplane-recorded waveform. The boom appears at approximately the five-second point (followed by a ground-reflected boom between $11 \mathrm{~s}$ and $12 \mathrm{~s}$ ). The slow pressure variation from approximately $0.14 \mathrm{lbf} / \mathrm{ft}^{2} \mathrm{~s}$ to $-0.04 \mathrm{lbf} / \mathrm{ft}^{2}$ is not associated with the boom. A portion of the waveform is selected (the vertical red lines show one possible selection) that contains the boom and a smooth section of the background.

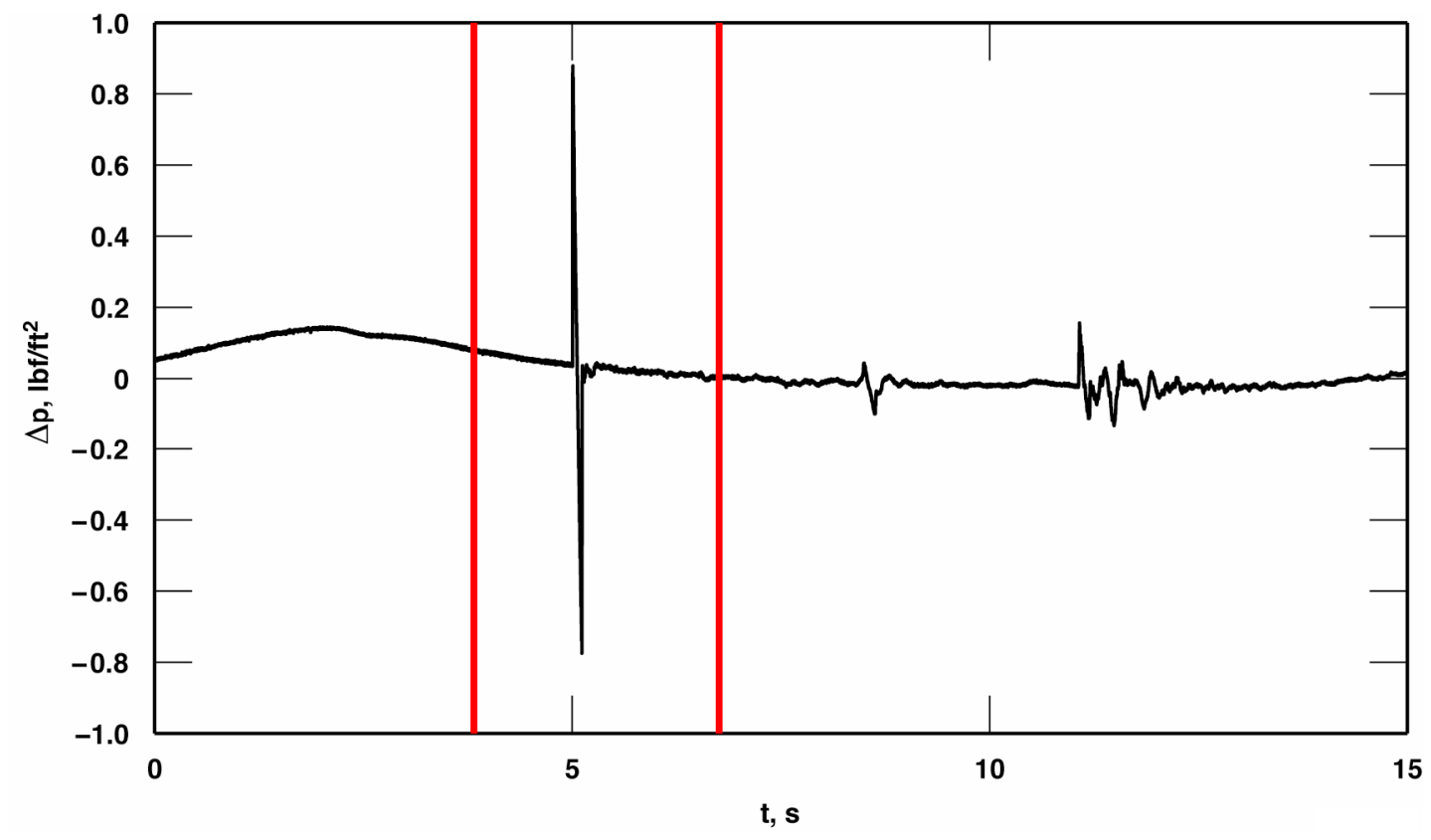

Figure 55. Typical recording from the sailplane microphone for a normal boom, flight 1086, pass 1 . The boom (at $5 \mathrm{~s}$ ) and the ground reflection of the boom (at $11 \mathrm{~s}$ to $12 \mathrm{~s}$ ) ride on a slowly varying background pressure. This background pressure is strongly correlated with altitude fluctuations around the average descent rate. The segment selected for subsequent processing is bracketed by the two red lines.

The background pressure variation will be removed from the selected segment. In the next step, the boom is selected as shown in Fig. 56. 


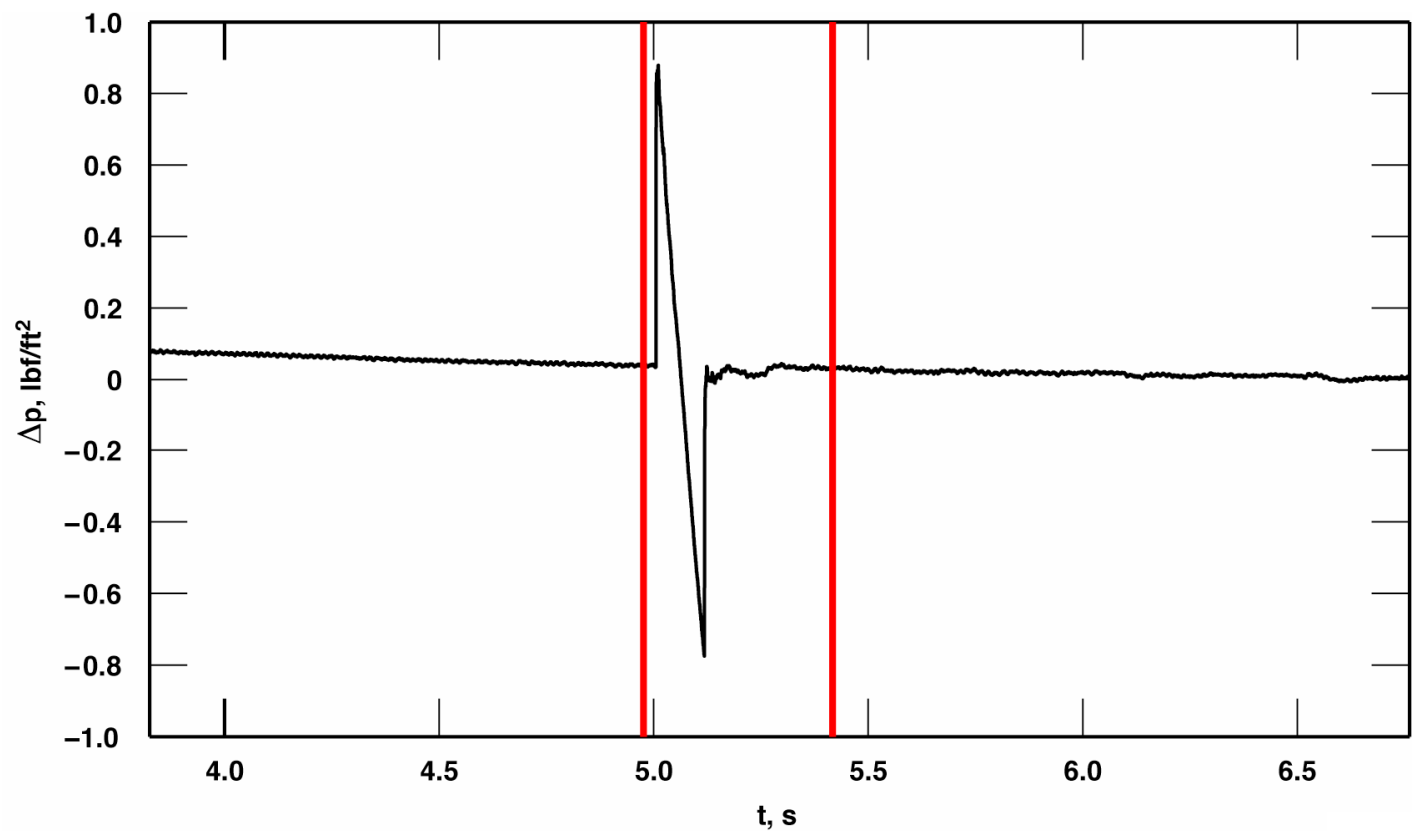

Figure 56. The waveform selected in the previous figure is shown here, flight 1086 , pass 1 . The two vertical red lines in this figure bracket the boom and indicate the section that will be removed (temporarily) prior to curve-fitting the remaining background. The waveform points that remain after the boom is removed are fit with a cubic.

This selection is not critical but the boom and any significant boom-related part of the waveform should be removed so that the background removal process is not biased by the boom itself. The selected portion is removed and the remaining points in the waveform are fit with a cubic. This cubic represents a least-squares approximation of the background pressure variation. The cubic function is subtracted from the original waveform. Use of a low-order polynomial to fit the background pressure ensures that the fit has little sensitivity to fine details in the background pressure.

The boom waveform before (black) and after (blue) background removal is shown in Fig. 57. In addition to removal of the background, the first $0.25 \mathrm{~s}$ is tapered so that the waveform always starts from zero amplitude. This minimizes transient artifacts in the low-frequency response correction filter. 


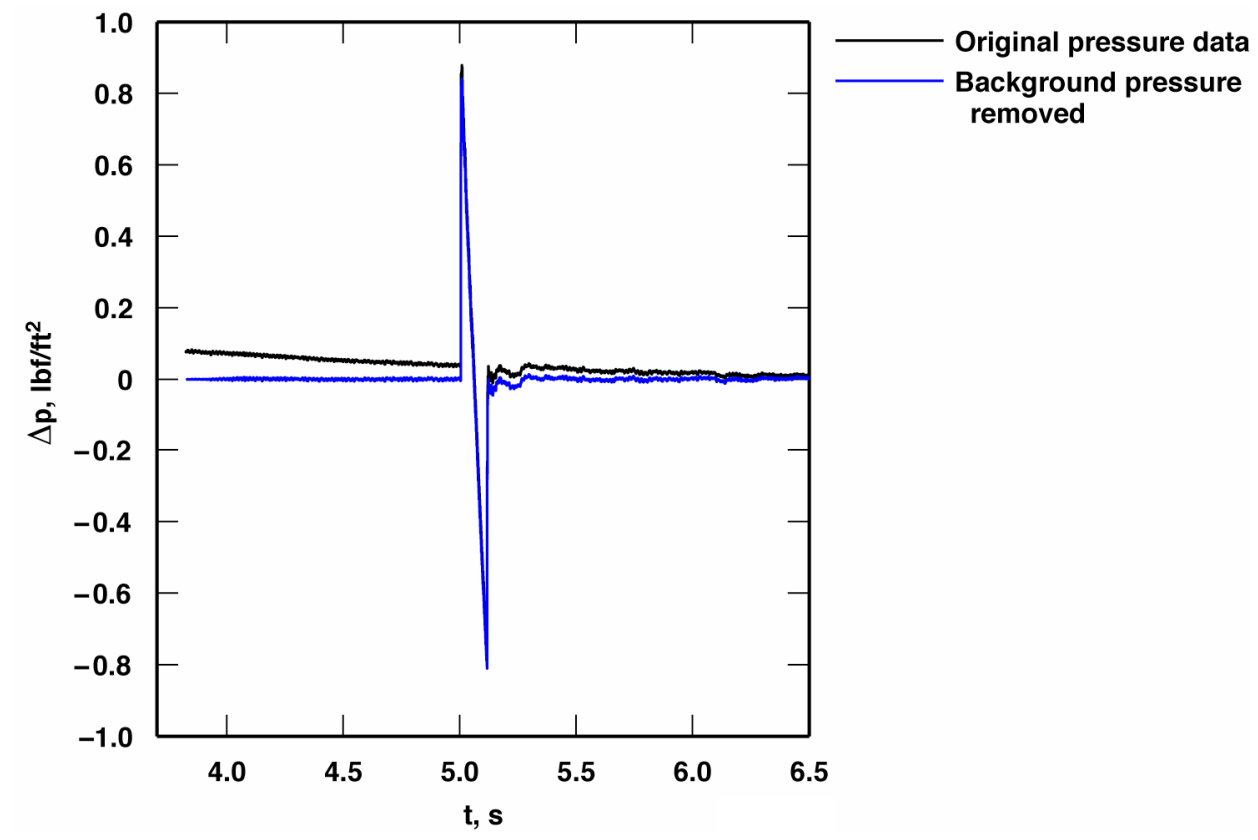

Figure 57. The waveform before (black) and after (blue) removal of the background pressure; flight 1086, pass 1 . The cubic fit to the background is subtracted and then the first $0.25 \mathrm{~s}$ is tapered so that the waveform starts smoothly from zero amplitude.

Once the background pressure variations are removed, a correction filter is applied that flattens the lowfrequency end of the microphone response to $0.1 \mathrm{~Hz}$. This is a time-domain (infinite-impulse response) filter that is based on the previously-identified characteristics of the B\&K Model 2669C microphone preamplifier and the B\&K Model 4193 microphone cartridge. This combination of microphone and preamplifier has a dominant pole in the low-frequency response at $0.54 \mathrm{~Hz}$. The correction filter moves this pole down to $0.1 \mathrm{~Hz}$. The process is sufficiently insensitive to parameter variations in the microphone that an individual calibration for each microphone is unnecessary; a generic correction filter for the Model 4193/2669 combination is adequate. The resulting waveforms are equivalent to those that would be produced by the B\&K model 4193 with the model UC0211 low-frequency adapter. The low-frequency adapter could have been used in flight but the dominant low-frequency components of the background pressure variations would produce much larger artifacts in the boom signature and the overall dynamic range would be reduced. (The background pressure variation would be about as large in amplitude as a normal boom.)

Figure 58 shows the result of applying the correction filter. In order to illustrate the insensitivity to variations in parameters, two correction curves are shown (green and red) in which bracketing values of the original pole are used $(0.57 \mathrm{~Hz}$ and $0.51 \mathrm{~Hz})$. These bracketing values represent the expected manufacturer variations in microphone/preamplifier parameters. The blue curve is the waveform before the low-frequency response correction. 


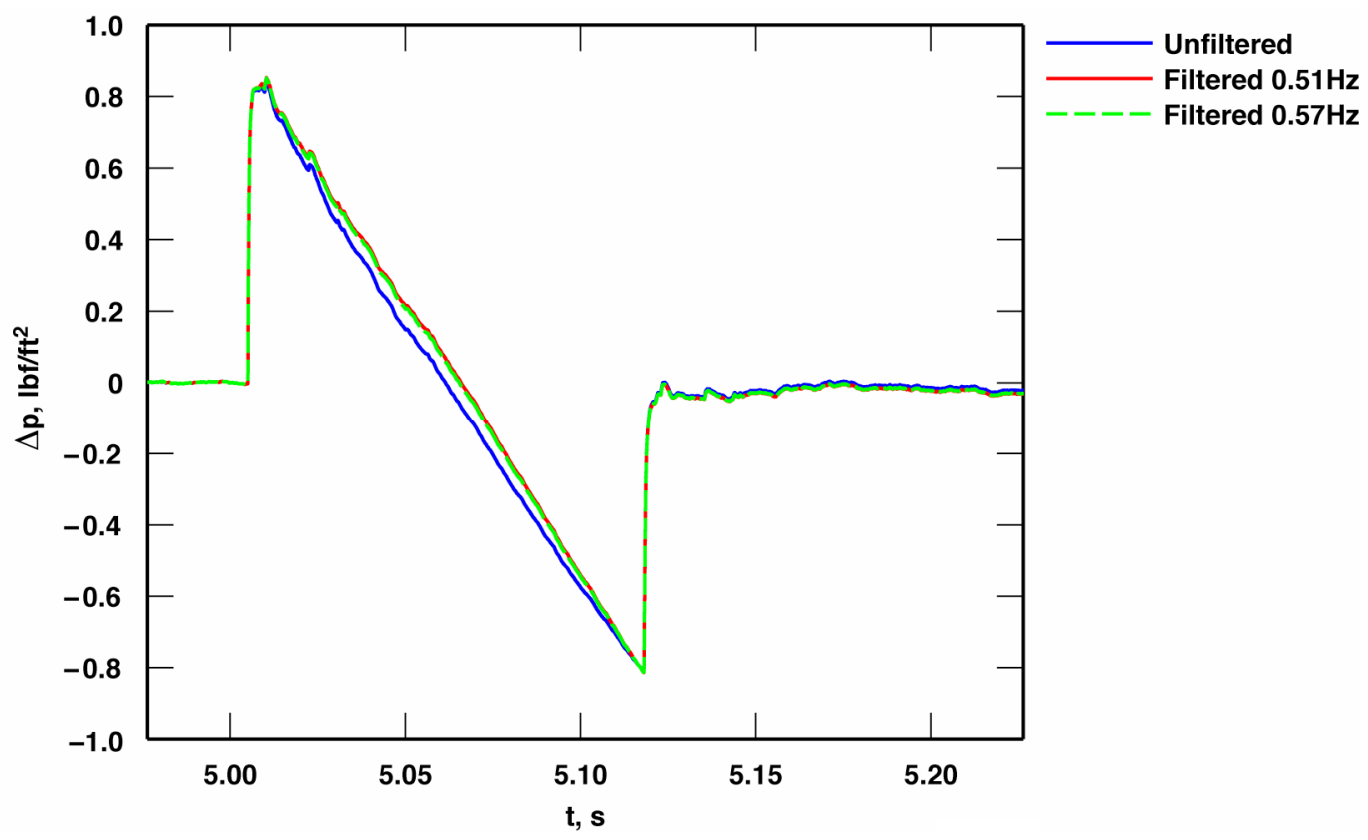

Figure 58. Once the background pressure variations have been removed, the waveform is passed through a low-frequency response correction filter that flattens the frequency response down to $0.1 \mathrm{~Hz}$. The blue curve is the unfiltered signal. The red and green curves are the response-corrected waveforms using the two values for the original low-frequency roll-off pole that represent the upper and lower limits expected from product variations. There is no significant difference between these two corrections, so a generic correction filter is adequate for these applications. Flight 1086, pass 1.

Because these are free-air measurements, there is not the usual 1.9 reflection factor that is present in groundmeasured signatures.

\section{Section III.G.2 Details (Geometric Corrections to Stationary Observer)}

The sailplane measurements were transformed into what would be measured by a stationary observer at the location and altitude of the sailplane using a Doppler correction. Because the sailplane was generally flying in the opposite direction to the propagation of the shock wave, the measurements were compressed in time as compared to the ground signatures. The amount of compression is a function of the dot product of the sailplane airmass-relative velocity with the wavefront airmass-relative velocity. The GPS receiver on the sailplane determined the true time the bow shock is measured, $t_{b o w}$, and the stationary observer time, $t_{s o}$, is given by

$$
t_{s o}=\left(t_{L 23}-t_{b o w}\right)\left(1-\frac{v_{n w}\left(v_{n s}+w_{n s}\right)+v_{e w}\left(v_{e s}+w_{e s}\right)+v_{d w} v_{d s}}{v_{n w}^{2}+v_{e w}^{2}+v_{d w}^{2}}\right)+t_{b o w}
$$

where $t_{L 23}$ is the measured IRIG-B time on the sailplane; $v_{n s}, v_{e s}$, and $v_{d s}$ are the DGPS velocity components in the north, east and down directions of the sailplane; $w_{n s}$ and $w_{e s}$ are the north and east components of wind at the sailplane; and $v_{n w}, v_{e w}$, and $v_{d w}$ are the wavefront north, east, and down airmass-relative velocity components. The wavefront velocity components are determined from the ambient air temperature at the sailplane (from the weather balloon data) and the wavefront azimuth and elevation angles at the sailplane determined by PCBoom4. As the time is expanded from the sailplane to the stationary observer, the effective sample rate of the recording decreases. Altitude changes of the sailplane were neglected when running PCBoom4, but are negligible as the vertical speed was typically less than $5 \mathrm{ft} / \mathrm{s}$ and the duration of the signatures were approximately $120 \mathrm{~ms}$. A previous formulation ${ }^{3}$ of Eq. (7), which uses the velocity of the supersonic aircraft instead of the wavefront and does not use winds, is only correct for aircraft in steady level flight. Equation (7) above does not have this restriction. 
The DGPS position of the sailplane when sonic booms are recorded, given in latitude, longitude, and altitude are converted to Cartesian coordinates for use within PCBoom4 by Eq. (8) and Eq. (9):

$$
\begin{gathered}
x=6076.1155\left[\frac{f t}{n m i}\right] * 60\left[\frac{n m i}{\text { olatitude }}\right] \cos \left(\lambda_{s}\right)\left(\theta_{s}-\theta_{0}\right) \\
y=6076.1155\left[\frac{f t}{n m i}\right] * 60\left[\frac{n m i}{\text { olatitude }}\right]\left(\lambda_{s}-\lambda_{0}\right)
\end{gathered}
$$

where $\lambda_{0}, \theta_{0}$ are the origin latitude and longitude of $35^{\circ}$ north and $-118^{\circ}$ east, respectively, $\lambda_{s}$ and $\theta_{s}$ are the sailplane latitude and longitude, respectively, and $x$ and $y$ are the distances east and north of the origin in feet, respectively. The origin latitude and longitude are merely a close, convenient location to keep the values small that are used within the PCBoom4 input files. The values of $x$ and $y$ for each supersonic pass are given in Table VI. 
Table I. Locations of ground sensors.

\begin{tabular}{|c|c|c|c|}
\hline Sensor or Location & $\begin{array}{c}\text { Latitude, WGS84, } \\
\text { degrees }\end{array}$ & $\begin{array}{c}\text { Longitude, WGS84, } \\
\text { degrees }\end{array}$ & $\begin{array}{c}\text { Altitude, } \mathrm{ft} \text { above } \\
\text { Mean Sea Level }\end{array}$ \\
\hline Origin of $10 \mathrm{~m}$ Tower Array & N34 56’03.18867”' & W117 $56^{\circ} 59.66682^{\prime \prime}$ & 2391.50 \\
\hline BADS node 1 & N34 ${ }^{\circ} 55^{\prime} 59.11191^{\prime \prime}$ & W117 57'00.63394”' & 2395.11 \\
\hline BADS node 2 & N34 ${ }^{\circ} 55^{\prime} 59.13155^{\prime \prime}$ & W117 57'00.70109" & 2395.55 \\
\hline BADS node 3 & $\mathrm{~N} 34^{\circ} 55^{\prime} 59.07423^{\prime \prime}$ & W117'57'00.68771"' & 2395.31 \\
\hline Far West & $\mathrm{N}^{\prime} 4^{\circ} 56^{\prime} 00.06220^{\prime \prime}$ & W117 $57^{\circ} 05.54533^{\prime \prime}$ & 2398.39 \\
\hline BASS B & $\mathrm{N} 34^{\circ} 59^{\prime} 06.21^{\prime \prime}$ & $\mathrm{W} 117^{\circ} 51^{\prime} 40.91^{\prime \prime}$ & 2279 \\
\hline BASS H, July 17, 2007 & $\mathrm{~N} 34^{\circ} 59^{\prime} 49.50^{\prime \prime}$ & $\mathrm{W} 117^{\circ} 50^{\prime} 42.00^{\prime \prime}$ & 2307 \\
\hline $\begin{array}{l}\text { BASS H, July } 12 \text { and } 18 \text {, } \\
2007\end{array}$ & N34 59'05.64” & W117 $51^{\prime} 41.84^{\prime \prime}$ & 2279 \\
\hline BASS G & $\mathrm{N} 34^{\circ} 59^{\prime} 44.88^{\prime \prime}$ & W117'50'43.93”' & 2281 \\
\hline
\end{tabular}

Table II. Positions of $10 \mathrm{~m}$ tower microphones from tower origin.

\begin{tabular}{|c|c|c|c|}
\hline Microphone & $\begin{array}{c}N, \text { Distance North } \\
\text { from Origin, } \mathrm{m}\end{array}$ & $\begin{array}{c}E, \text { Distance East } \\
\text { from Origin, } \mathrm{m}\end{array}$ & $\begin{array}{c}D, \text { Distance } \\
\text { Down from } \\
\text { Origin, } \mathrm{m}\end{array}$ \\
\hline 0m on Tower & -0.11 & 0.00 & 0.00 \\
\hline $1.2 \mathrm{~m}$ on Tower & -0.11 & 0.00 & -1.20 \\
\hline 2m on Tower & -0.11 & 0.00 & -2.00 \\
\hline $3 \mathrm{~m}$ on Tower & -0.11 & 0.00 & -3.00 \\
\hline 4m on Tower & -0.11 & 0.00 & -4.00 \\
\hline 5m on Tower & -0.11 & 0.00 & -5.00 \\
\hline 6m on Tower & -0.11 & 0.00 & -6.00 \\
\hline 7m on Tower & -0.11 & 0.00 & -7.00 \\
\hline 8m on Tower & -0.11 & 0.00 & -8.00 \\
\hline 10m on Tower & -0.11 & 0.00 & -10.00 \\
\hline 5m East from Tower & 0.13 & 4.98 & -0.02 \\
\hline 10m East from Tower & 0.14 & 9.98 & 0.07 \\
\hline 5m South from Tower & -4.88 & 0.00 & -0.10 \\
\hline 10m South from Tower & -9.87 & 0.02 & -0.17 \\
\hline
\end{tabular}


Table III. The $10 \mathrm{~m}$ tower array data with PCBoom4 predictions, idealized maximum overpressures, and corrected acoustic levels.

\begin{tabular}{|c|c|c|c|c|c|c|c|c|c|c|c|c|c|c|c|c|c|c|c|c|}
\hline \multirow[b]{2}{*}{$\begin{array}{l}\text { July } \\
\text { Date, } \\
2007\end{array}$} & \multirow[b]{2}{*}{$\begin{array}{c}\text { Flight } \\
\text { number }\end{array}$} & \multirow[b]{2}{*}{$\begin{array}{c}\text { Pass } \\
\text { number }\end{array}$} & \multicolumn{3}{|c|}{ Time of Sonic Boom at Tower, $\mathrm{s}$} & \multicolumn{3}{|c|}{ azt, degrees } & \multicolumn{3}{|c|}{ elt, degrees } & \multicolumn{3}{|c|}{$\mathrm{T}, \mathrm{F}$} & \multicolumn{3}{|c|}{ Maximum Epp, psf } & \multicolumn{3}{|c|}{$\begin{array}{l}\text { Corrected Acoustic Level of Tower Groun } \\
\text { Microphone }\end{array}$} \\
\hline & & & tbow & tgtower & $\begin{array}{l}\text { tbow- } \\
\text { tgtower }\end{array}$ & calculated & predicted & $\begin{array}{c}\text { calculated } \\
\text { predicted }\end{array}$ & calculated & predicted & $\begin{array}{c}\text { calculated } \\
\text { predicted }\end{array}$ & $\begin{array}{l}\text { calculated at } \\
\text { tower }\end{array}$ & $\begin{array}{c}\text { measured at: } \\
\text { tower-white, } \\
\text { house-aqua; } \\
\begin{array}{c}\text { estimated- } \\
\text { gold }\end{array}\end{array}$ & $\begin{array}{l}\text { calculated } \\
\text { measured }\end{array}$ & Idealized & predicted & $\begin{array}{l}\text { idealized } \\
\text { predicted }\end{array}$ & ASEL & CSEL & PL \\
\hline 11 & 1082 & 1 & 54172.276 & & & 68.9 & & & 3.2 & & & 72.2 & 80.9 & -8.7 & 0.14 & & & 48.8 & 77.7 & 63.8 \\
\hline 11 & 1082 & 2 & 54643.009 & & & 69.7 & & & 4.0 & & & 89.6 & 81.7 & 7.9 & 0.13 & & & 44.9 & 79.1 & 60.3 \\
\hline 11 & 1082 & 3 & 55064.959 & 55065.258 & $\begin{array}{l}-0.299 \\
\end{array}$ & 54.5 & 55.0 & -0.5 & 7.1 & 14.1 & -7.0 & 83.5 & 82.1 & 1.4 & 0.46 & 0.30 & 0.16 & 65.6 & 93.9 & 80.6 \\
\hline 11 & 1082 & 4 & 55439.032 & 55439.582 & -0.550 & 56.9 & 55.5 & 1.4 & 13.9 & 14.6 & -0.7 & 57.3 & 82.1 & -24.8 & 0.40 & 0.30 & 0.10 & 75.2 & 98.4 & 90.9 \\
\hline 11 & 1082 & 5 & 55723.123 & 55723.551 & -0.428 & 89.3 & 89.8 & $\begin{array}{l}-0.5 \\
\end{array}$ & 28.4 & 26.3 & 2.1 & 68.7 & 82.8 & -14.1 & 0.71 & 0.63 & 0.08 & 75.7 & 98.2 & 89.7 \\
\hline 11 & 1082 & 6 & 56243.290 & 56243.547 & -0.257 & 90.1 & 90.7 & -0.6 & 26.3 & 25.7 & 0.6 & 64.5 & 84.1 & -19.6 & 0.64 & 0.57 & 0.07 & 72.2 & 96.6 & 87.9 \\
\hline 12 & 1083 & 1 & 54209.867 & & & 67.9 & & & 0.3 & & & 71.8 & 75.9 & -4.1 & 0.11 & & & 31.7 & 73.2 & 47.3 \\
\hline 12 & 1083 & 2 & 54603.427 & & & 69.0 & & & 4.4 & & & 75.0 & 76.3 & -1.3 & 0.13 & & & 37.1 & 75.9 & 52.4 \\
\hline 12 & 1083 & 3 & 54958.733 & 54959.820 & -1.087 & 54.4 & 56.0 & -1.6 & 14.5 & 16.6 & -2.2 & 70.2 & 76.5 & -6.3 & 0.38 & 0.47 & -0.09 & 58.1 & 91.3 & 73.9 \\
\hline 12 & 1083 & 4 & 55307.242 & 55307.676 & -0.434 & 55.2 & 53.4 & 1.8 & 13.6 & 16.1 & -2.5 & 85.0 & 76.8 & 8.2 & 0.41 & 0.45 & -0.04 & 65.4 & 95.7 & 82.2 \\
\hline 12 & 1083 & 5 & $\begin{array}{l}55684.810 \\
\end{array}$ & 55685.203 & -0.393 & 96.6 & 97.2 & -0.6 & 20.1 & 20.6 & $\begin{array}{l}-0.5 \\
\end{array}$ & 75.3 & 77.1 & -1.8 & 0.52 & 0.52 & 0.00 & 59.5 & 93.4 & 75.7 \\
\hline 12 & 1083 & 6 & 56063.577 & 56063.883 & -0.306 & 98.7 & 98.1 & 0.6 & 18.5 & 20.3 & -1.8 & 82.8 & 77.7 & 5.1 & 0.50 & 0.43 & 0.07 & 64.6 & 94.7 & 80.9 \\
\hline 12 & 1083 & 7 & 56392.507 & 56392.648 & -0.141 & 99.5 & 99.3 & 0.2 & 20.5 & 21.2 & -0.7 & 54.5 & 77.5 & -23.0 & 0.64 & 0.58 & 0.06 & 72.4 & 96.7 & 87.6 \\
\hline 12 & 1084 & 1 & 63162.013 & & & 68.7 & & & $\begin{array}{ll}0.7 \\
\end{array}$ & & & 89.1 & 88.0 & 1.1 & 0.27 & & & 54.6 & 86.8 & 70.2 \\
\hline 12 & 1084 & 2 & 63547.167 & & & 69.6 & & & 4.5 & & & 89.8 & 88.0 & 1.8 & 0.13 & & & 37.1 & 77.6 & 52.7 \\
\hline 12 & 1084 & 3 & & 63851.066 & & 55.6 & 52.4 & 3.2 & 16.2 & 13.7 & 2.5 & 81.9 & 88.5 & -6.6 & 0.38 & 0.36 & 0.02 & 52.9 & 87.3 & 68.4 \\
\hline 12 & 1084 & 4 & 64244.364 & 64245.332 & -0.968 & 55.4 & 52.9 & 2.5 & 12.2 & 14.4 & -2.2 & 100.8 & 89.0 & 11.8 & 0.38 & 0.34 & 0.04 & 56.7 & 87.7 & 71.5 \\
\hline 13 & 1557 & $\frac{7}{1}$ & 60078.404 & 60078.312 & 0.092 & 52.9 & 51.3 & 1.6 & 3.6 & 7.2 & -3.6 & 79.7 & 91.6 & -11.9 & 0.44 & 0.30 & 0.14 & 62.5 & 92.2 & 78.6 \\
\hline 13 & 1557 & 2 & 60399.299 & 60399.219 & 0.080 & 86.0 & 85.8 & 0.2 & 28.0 & 25.4 & 2.6 & 78.9 & 92.6 & -13.7 & 0.66 & 0.55 & 0.11 & 73.0 & 97.3 & 87.8 \\
\hline 13 & 1557 & 3 & 60771.751 & 60771.691 & 0.060 & 89.1 & 88.1 & 1.0 & 30.3 & 25.5 & 4.8 & 86.2 & 92.4 & -6.2 & 0.70 & 0.64 & 0.06 & 73.3 & 97.8 & 88.9 \\
\hline 13 & 1557 & 4 & 61160.465 & 61160.355 & 0.110 & 101.5 & 101.8 & -0.3 & 12.1 & 13.3 & -1.2 & 81.6 & 93.5 & -11.9 & 0.36 & 0.27 & 0.09 & 62.8 & 88.9 & 77.4 \\
\hline 13 & 1557 & 5 & 61518.892 & 61518.781 & 0.111 & 106.4 & 104.5 & 1.9 & 9.7 & 12.9 & -3.2 & 72.1 & 93.2 & -21.2 & 0.33 & 0.32 & 0.01 & 56.2 & 89.6 & 72.1 \\
\hline 13 & 1557 & 6 & 61972.305 & 61972.102 & 0.203 & 97.1 & 99.9 & -2.8 & 0.9 & 2.0 & -1.1 & 72.6 & 93.9 & -21.4 & 0.38 & 0.33 & 0.05 & 63.0 & 91.7 & 78.6 \\
\hline 13 & 1557 & 7 & 62358.435 & 62358.367 & 0.068 & 107.2 & 106.5 & 0.7 & 15.2 & 13.1 & 2.1 & 75.6 & 91.3 & -15.7 & 0.35 & 0.35 & 0.00 & 60.0 & 90.7 & 75.4 \\
\hline 17 & 1085 & 1 & 54610.466 & 54610.402 & 0.064 & 69.2 & 65.2 & 4.0 & 2.2 & 3.7 & -1.5 & 71.0 & 79.5 & -8.5 & 0.26 & 0.12 & 0.14 & 63.5 & 95.0 & 80.2 \\
\hline 17 & 1085 & 2 & 55014.599 & 55014.598 & 0.001 & 68.8 & 63.6 & 5.2 & 2.1 & 3.5 & -1.4 & 75.7 & 80.6 & -4.9 & 0.27 & 0.13 & 0.14 & 50.3 & 82.5 & 66.0 \\
\hline 17 & 1085 & 3 & 55372.436 & 55372.602 & -0.166 & & 50.5 & & & 12.5 & & & 81.0 & & & 0.34 & & & & \\
\hline 17 & 1085 & 4 & 55741.363 & 55741.566 & -0.203 & 51.7 & 49.8 & 1.9 & 10.9 & 12.9 & -2.0 & 88.5 & 81.4 & 7.1 & 0.41 & 0.35 & 0.06 & 63.9 & 91.7 & 78.6 \\
\hline 17 & 1085 & 5 & 56107.658 & 56107.867 & -0.209 & 95.6 & 95.7 & -0.1 & 21.1 & 20.7 & 0.4 & 69.4 & 82.7 & -13.3 & 0.60 & 0.54 & 0.06 & 77.9 & 98.9 & 92.4 \\
\hline 17 & 1085 & 6 & 56552.164 & 56552.316 & -0.152 & 97.7 & 95.8 & 1.9 & 20.1 & 20.7 & -0.6 & 71.1 & 83.5 & -12.4 & 0.57 & 0.48 & 0.09 & 65.4 & 94.0 & 81.5 \\
\hline 17 & 1085 & 7 & 56862.201 & 56862.320 & $\begin{array}{l}-0.119 \\
\end{array}$ & 96.7 & 97.0 & -0.3 & 20.1 & 19.2 & 0.9 & 92.5 & 83.8 & 8.7 & 0.59 & 0.50 & 0.09 & 70.8 & 97.2 & 87.6 \\
\hline 17 & 1086 & 1 & 63098.792 & 63098.656 & 0.136 & 74.1 & 74.8 & -0.7 & 18.4 & 19.0 & -0.6 & 88.8 & 90.7 & -1.9 & 1.48 & 1.18 & 0.30 & 77.4 & 103.8 & 94.7 \\
\hline 17 & 1086 & 2 & 63520.290 & 63520.172 & 0.118 & 74.7 & 75.1 & -0.4 & $\begin{array}{l}19.7 \\
\end{array}$ & 18.6 & 1.1 & 69.0 & 92.0 & -23.0 & 1.30 & 1.30 & 0.00 & 83.3 & 102.1 & 97.8 \\
\hline 17 & 1086 & 3 & 63955.465 & 63955.324 & 0.141 & 76.9 & 75.5 & 1.4 & 19.6 & 18.4 & 1.2 & 68.3 & 92.5 & -24.3 & 1.44 & 1.25 & 0.19 & 82.9 & 101.9 & 97.2 \\
\hline 17 & 1086 & 4 & 64425.782 & 64425.633 & 0.149 & 78.6 & 75.9 & 2.7 & 20.6 & 18.5 & 2.1 & 74.9 & 93.2 & -18.3 & 1.62 & 1.37 & 0.25 & 92.4 & 108.8 & 108.2 \\
\hline 17 & 1086 & 5 & 64838.056 & 64837.996 & 0.060 & 109.1 & 106.6 & 2.5 & 20.9 & 17.7 & 3.2 & 82.7 & 94.0 & -11.3 & 1.47 & 1.40 & 0.07 & 86.0 & 104.1 & 99.9 \\
\hline 17 & 1086 & 6 & 65222.396 & 65222.188 & 0.208 & 285.1 & 284.3 & 0.8 & 23.5 & 19.9 & 3.6 & 93.4 & 94.3 & -0.9 & 1.16 & 1.09 & 0.07 & 89.6 & 107.0 & 104.3 \\
\hline 18 & 1087 & 1 & 54339.745 & 54339.695 & 0.050 & 76.0 & 73.6 & 2.4 & 21.5 & 20.1 & 1.4 & 75.3 & 77.9 & -2.6 & 1.30 & 1.26 & 0.04 & 82.7 & 101.3 & 97.3 \\
\hline 18 & 1087 & 2 & & 54747.879 & & & 73.8 & & & 19.3 & & & 79.0 & & & 1.41 & & & & \\
\hline 18 & 1087 & 3 & & 55115.262 & & & 74.3 & & & 19.6 & & & 80.0 & & & 1.40 & & & & \\
\hline 18 & 1087 & 4 & 55470.913 & 55470.852 & 0.061 & 75.7 & 74.2 & 1.5 & 19.7 & 19.5 & 0.2 & 82.7 & 80.0 & 2.7 & 1.59 & 1.43 & 0.16 & 86.5 & 106.3 & 102.1 \\
\hline 18 & 1087 & 5 & 55839.156 & 55839.410 & -0.254 & 102.2 & 103.8 & -1.6 & 14.3 & 16.5 & -2.2 & 76.7 & 79.9 & -3.2 & 1.12 & 1.19 & -0.07 & 85.1 & 102.5 & 99.4 \\
\hline 18 & 1087 & 6 & 56200.904 & 56200.699 & 0.205 & 283.5 & 284.8 & -1.3 & 20.4 & 21.8 & -1.4 & 79.6 & 80.1 & -0.5 & 1.32 & 1.02 & 0.30 & 84.9 & 103.1 & 99.8 \\
\hline
\end{tabular}


Table IV. BADS data with PCBoom4 predictions.

\begin{tabular}{|c|c|c|c|c|c|c|c|c|c|c|c|c|c|c|}
\hline \multirow{2}{*}{$\begin{array}{c}\text { July Date, } \\
2007\end{array}$} & \multirow{2}{*}{$\begin{array}{l}\text { Flight } \\
\text { number }\end{array}$} & \multirow{2}{*}{$\begin{array}{c}\text { Pass } \\
\text { number }\end{array}$} & \multicolumn{3}{|c|}{ Time of Sonic Boom at BADS, $\mathrm{s}$} & \multicolumn{3}{|c|}{ azB, degrees } & \multicolumn{3}{|c|}{ elB, degrees } & \multicolumn{3}{|c|}{$\mathrm{T}, \mathrm{F}$} \\
\hline & & & tbow & $\operatorname{tg} B$ & tbow-tgB & calculated & predicted & $\begin{array}{c}\text { calculated - } \\
\text { predicted }\end{array}$ & calculated & predicted & $\begin{array}{c}\text { calculated - } \\
\text { predicted }\end{array}$ & $\begin{array}{l}\text { calculated at } \\
\text { BADS }\end{array}$ & $\begin{array}{l}\text { Temperature } \\
\text { measured, } \overline{\mathrm{u} F}\end{array}$ & $\begin{array}{c}\text { calculated- } \\
\text { measured }\end{array}$ \\
\hline 11 & 1082 & 1 & & & & & & & & & & & 80.9 & \\
\hline 11 & 1082 & 2 & 54643.202 & & & 80.116 & & & -12.133 & & & 89.0 & 81.7 & 7.3 \\
\hline 11 & 1082 & 3 & 55065.222 & 55065.52 & -0.298 & 62.209 & 54.8 & 7.409 & 10.06 & 14 & -3.94 & 94.8 & 82.1 & 12.7 \\
\hline 11 & 1082 & 4 & 55439.293 & 55439.855 & -0.562 & 62.822 & 55.3 & 7.522 & 4.764 & 14.5 & -9.736 & 7.0 & 82.2 & -75.2 \\
\hline 11 & 1082 & 5 & 55723.191 & 55723.625 & -0.434 & 90.816 & 89.4 & 1.416 & 29.176 & 26.2 & 2.976 & 75.6 & 82.8 & -7.2 \\
\hline 11 & 1082 & 6 & 56243.354 & \begin{tabular}{|l|l|}
56243.613 \\
\end{tabular} & -0.259 & 90.77 & 90.3 & 0.47 & 28.204 & 25.7 & 2.504 & 87.7 & 84.0 & 3.7 \\
\hline 12 & 1083 & 1 & 54210.074 & & & 67.33 & & & -1.961 & & & 72.3 & 75.9 & -3.6 \\
\hline 12 & 1083 & 2 & \begin{tabular}{|l|l|}
54605.371 \\
\end{tabular} & & & & & & & & & & 76.2 & \\
\hline 12 & 1083 & 3 & 54958.995 & \begin{tabular}{|l|}
54960.074 \\
\end{tabular} & -1.079 & 58.014 & 55.8 & 2.214 & 6.376 & 16.5 & -10.124 & 31.4 & 76.5 & -45.1 \\
\hline 12 & 1083 & 4 & \begin{tabular}{|l|}
55307.506 \\
\end{tabular} & \begin{tabular}{|l|l|}
55307.949 \\
\end{tabular} & -0.443 & 58.101 & 53.2 & 4.901 & 10.488 & 16.1 & -5.612 & 84.2 & 76.8 & 7.4 \\
\hline 12 & 1083 & 5 & 55684.837 & 55685.227 & $\begin{array}{l}-0.39 \\
\end{array}$ & 98.856 & 96.9 & 1.956 & 14.767 & 20.6 & -5.833 & 86.8 & 77.1 & 9.7 \\
\hline 12 & 1083 & 6 & 56063.595 & 56063.902 & -0.307 & 102.695 & 97.8 & 4.895 & 15.47 & 20.3 & $\begin{array}{l}-4.83 \\
\end{array}$ & 105.2 & 77.7 & 27.5 \\
\hline 12 & 1083 & 7 & 56392.516 & 56392.656 & $\begin{array}{l}-0.14 \\
\end{array}$ & 102.414 & 98.9 & 3.514 & 18.432 & 21.2 & -2.768 & 92.6 & 77.5 & 15.1 \\
\hline 12 & 1084 & 1 & 63162.217 & & & 70.702 & & & 1.889 & & & 120.3 & 87.8 & 32.5 \\
\hline 12 & 1084 & 2 & \begin{tabular}{|l|}
63547.369 \\
\end{tabular} & & & 67.876 & & & 3.864 & & & 171.0 & 88.2 & 82.8 \\
\hline 12 & 1084 & 3 & 63850.202 & 63851.289 & -1.087 & 55.963 & 52.2 & 3.763 & 1.082 & 13.6 & -12.518 & 137.1 & 88.5 & 48.6 \\
\hline 12 & 1084 & 4 & \begin{tabular}{|l|l|}
64244.623 \\
\end{tabular} & \begin{tabular}{|l|l|}
64245.602 \\
\end{tabular} & $\begin{array}{ll}-0.979 \\
\end{array}$ & & 52.7 & & & 14.3 & & & 89.0 & \\
\hline 13 & 1557 & 1 & \begin{tabular}{|l|l|}
60078.679 \\
\end{tabular} & \begin{tabular}{|l|}
60078.59 \\
\end{tabular} & 0.089 & 55.637 & 51.1 & 4.537 & -1.01 & 7.1 & -8.11 & 74.9 & 89.0 & -14.1 \\
\hline 13 & 1557 & 2 & \begin{tabular}{|l|}
60399.38 \\
\end{tabular} & \begin{tabular}{|l|l|}
60399.309 \\
\end{tabular} & 0.071 & 88.669 & 85.4 & 3.269 & 27.193 & 25.3 & 1.893 & 101.9 & 89.5 & 12.4 \\
\hline 13 & 1557 & 3 & \begin{tabular}{|l|}
60771.822 \\
\end{tabular} & \begin{tabular}{|l|}
60771.77 \\
\end{tabular} & 0.052 & 89.306 & 87.6 & 1.706 & 29.976 & 25.5 & 4.476 & 89.1 & 90.1 & -1.0 \\
\hline 13 & 1557 & 4 & \begin{tabular}{|l|}
61160.462 \\
\end{tabular} & \begin{tabular}{|l|l|}
61160.352 \\
\end{tabular} & $\begin{array}{ll}0.11 \\
\end{array}$ & $\begin{array}{l}104.208 \\
\end{array}$ & 101.6 & 2.608 & 7.589 & 13.3 & -5.711 & 91.9 & 89.8 & 2.1 \\
\hline 13 & 1557 & 5 & \begin{tabular}{|l|}
61518.871 \\
\end{tabular} & \begin{tabular}{|l|}
61518.77 \\
\end{tabular} & 0.101 & $\begin{array}{l}107.129 \\
\end{array}$ & 104.3 & 2.829 & 6.589 & 12.9 & -6.311 & 76.9 & 90.3 & -13.4 \\
\hline 13 & 1557 & 6 & \begin{tabular}{|l|}
61972.329 \\
\end{tabular} & \begin{tabular}{|l|l|}
61972.113 \\
\end{tabular} & 0.216 & 102.058 & 99.2 & 2.858 & 0.928 & 2 & -1.072 & 87.4 & 90.3 & -2.9 \\
\hline 13 & 1557 & 7 & \begin{tabular}{|l|}
62358.405 \\
\end{tabular} & \begin{tabular}{|l|}
62358.332 \\
\end{tabular} & 0.073 & 107.972 & 106.2 & 1.772 & 11.363 & 13 & -1.637 & 76.2 & 89.8 & -13.6 \\
\hline 17 & 1085 & 1 & & \begin{tabular}{|l|}
54610.621 \\
\end{tabular} & & & 65.1 & & & 4.2 & & & 79.5 & \\
\hline 17 & 1085 & 2 & 55014.822 & \begin{tabular}{|l|}
55014.832 \\
\end{tabular} & $\begin{array}{l}-0.01 \\
\end{array}$ & 62.464 & 63.4 & -0.936 & 1.326 & 3.8 & -2.474 & 101.5 & 80.6 & 20.9 \\
\hline 17 & 1085 & 3 & & \begin{tabular}{|l|l|}
55372.414 \\
\end{tabular} & & & 50.3 & & & 12.6 & & & 81.0 & \\
\hline 17 & 1085 & 4 & 55741.646 & \begin{tabular}{|l|l|}
55741.863 \\
\end{tabular} & -0.217 & 51.415 & 49.6 & 1.815 & 4.155 & 12.8 & -8.645 & 104.7 & 81.4 & 23.3 \\
\hline 17 & 1085 & 5 & & \begin{tabular}{|l|}
56107.895 \\
\end{tabular} & & & 95.3 & & & 20.7 & & & 82.7 & \\
\hline 17 & 1085 & 6 & 56552.2 & 56552.348 & -0.148 & 95.217 & 95.4 & -0.183 & 19.005 & 20.7 & -1.695 & 112.2 & 83.5 & 28.7 \\
\hline 17 & 1085 & 7 & \begin{tabular}{|l|}
56862.227 \\
\end{tabular} & 56862.332 & -0.105 & 98.246 & 96.7 & 1.546 & 15.41 & 19.2 & -3.79 & 118.4 & 83.8 & 34.6 \\
\hline 17 & 1086 & 1 & \begin{tabular}{|l|l|}
63098.951 \\
\end{tabular} & \begin{tabular}{|l|l|}
63098.812 \\
\end{tabular} & 0.139 & 75.601 & 74.5 & 1.101 & 19.393 & 18.8 & 0.593 & 106.5 & 90.7 & 15.8 \\
\hline 17 & 1086 & 2 & \begin{tabular}{|l|}
63520.444 \\
\end{tabular} & \begin{tabular}{|l|l|}
63520.324 \\
\end{tabular} & 0.12 & 77.499 & 74.9 & 2.599 & 18.166 & 18.5 & -0.334 & 85.1 & 92.0 & -6.9 \\
\hline 17 & 1086 & 3 & 63955.612 & \begin{tabular}{|l|}
63955.48 \\
\end{tabular} & 0.132 & 80.35 & 75.2 & 5.15 & 16.764 & 18.3 & -1.536 & 103.4 & 92.5 & 10.9 \\
\hline 17 & 1086 & 4 & \begin{tabular}{|l|l|}
64425.919 \\
\end{tabular} & \begin{tabular}{|l|l|}
64425.789 \\
\end{tabular} & 0.13 & 80.903 & 75.6 & 5.303 & 15.749 & 18.3 & -2.551 & 107.7 & 93.2 & 14.5 \\
\hline 17 & 1086 & 5 & \begin{tabular}{|l|}
64838.02 \\
\end{tabular} & \begin{tabular}{|l|l|}
64837.965 \\
\end{tabular} & 0.055 & 111.84 & 106.3 & 5.54 & 17.686 & 17.9 & -0.214 & 105.2 & 94.0 & 11.2 \\
\hline 17 & 1086 & 6 & \begin{tabular}{|l|l}
65222.414 \\
\end{tabular} & \begin{tabular}{|l|}
65222.207 \\
\end{tabular} & 0.207 & 289.03 & 284.6 & 4.43 & 18.548 & 19.8 & -1.252 & 100.5 & 94.3 & 6.2 \\
\hline 18 & 1087 & 1 & \begin{tabular}{|l|}
54339.898 \\
\end{tabular} & \begin{tabular}{|l|l|}
54339.859 \\
\end{tabular} & 0.039 & 74.993 & 73.3 & 1.693 & 21.349 & 20 & 1.349 & $\begin{array}{l}93.4 \\
\end{array}$ & 77.9 & 15.5 \\
\hline 18 & 1087 & 2 & \begin{tabular}{|l|}
54747.629 \\
\end{tabular} & \begin{tabular}{|l|}
54747.578 \\
\end{tabular} & 0.051 & 77.766 & 73.7 & 4.066 & 18.88 & 19.3 & $\begin{array}{l}-0.42 \\
\end{array}$ & 91.6 & 79.0 & 12.6 \\
\hline 18 & 1087 & 3 & \begin{tabular}{|l|l|}
55114.999 \\
\end{tabular} & \begin{tabular}{|l|l|}
55114.961 \\
\end{tabular} & 0.038 & 76.654 & 74.2 & 2.454 & 18.824 & 19.6 & -0.776 & 95.9 & 80.0 & 15.9 \\
\hline 18 & 1087 & 4 & \begin{tabular}{|l|}
55471.069 \\
\end{tabular} & \begin{tabular}{|l|l|}
55471.012 \\
\end{tabular} & 0.057 & 74.189 & 73.9 & 0.289 & 16.846 & 19.3 & -2.454 & 106.5 & 80.0 & 26.5 \\
\hline 18 & 1087 & 5 & \begin{tabular}{|l|}
55839.142 \\
\end{tabular} & \begin{tabular}{|l|l|}
55839.059 \\
\end{tabular} & 0.083 & $\begin{array}{l}107.529 \\
\end{array}$ & 103.7 & 3.829 & 13.83 & 16.5 & $\begin{array}{l}-2.67 \\
\end{array}$ & 113.4 & 82.4 & 31.0 \\
\hline 18 & 1087 & 6 & \begin{tabular}{|l|}
56200.923 \\
\end{tabular} & \begin{tabular}{|l|l|}
56200.719 \\
\end{tabular} & 0.204 & 288.918 & 285.2 & 3.718 & 21.5 & 21.7 & -0.2 & 64.1 & 82.2 & -18.1 \\
\hline
\end{tabular}


Table V. Far west tower data with large triple array azimuth measurements and PCBoom4 predictions at the $10 \mathrm{~m}$ tall tower.

\begin{tabular}{|c|c|c|c|c|c|c|}
\hline \multirow{2}{*}{$\begin{array}{c}\text { July Date, } \\
2007\end{array}$} & \multirow{2}{*}{$\begin{array}{l}\text { Flight } \\
\text { number }\end{array}$} & \multirow{2}{*}{$\begin{array}{c}\text { Pass } \\
\text { number }\end{array}$} & \multirow{2}{*}{$\begin{array}{c}\text { Time of Sonic } \\
\begin{array}{c}\text { Boom at Far } \\
\text { West, s }\end{array} \\
\text { tbow }\end{array}$} & \multicolumn{3}{|c|}{ az, at Large Triple. Degrees } \\
\hline & & & & calculated & predicted & $\begin{array}{l}\text { calculated - } \\
\text { predicted }\end{array}$ \\
\hline 11 & 1082 & 1 & & & & \\
\hline 11 & 1082 & 2 & 54643.504 & 69.09 & & \\
\hline 11 & 1082 & 3 & 55065.471 & 55.6 & 55.0 & 0.6 \\
\hline 11 & 1082 & 4 & 55439.529 & 54.34 & 55.5 & -1.16 \\
\hline 11 & 1082 & 5 & 55723.503 & 88.86 & 89.8 & -0.94 \\
\hline 11 & 1082 & 6 & 56243.675 & 89.87 & 90.7 & -0.83 \\
\hline 12 & 1083 & 1 & 54210.380 & 67.64 & & \\
\hline 12 & 1083 & 2 & 54603.936 & & & \\
\hline 12 & 1083 & 3 & 54959.232 & 54.35 & 56.0 & -1.65 \\
\hline 12 & 1083 & 4 & 55307.741 & 53.91 & 53.4 & 0.51 \\
\hline 12 & 1083 & 5 & 55685.179 & 96.56 & 97.2 & -0.64 \\
\hline 12 & 1083 & 6 & 56063.944 & 98.12 & 98.1 & 0.02 \\
\hline 12 & 1083 & 7 & 56392.865 & 99.59 & 99.3 & 0.29 \\
\hline 12 & 1084 & 1 & 63162.521 & 67.85 & & \\
\hline 12 & 1084 & 2 & 63547.668 & 67.68 & & \\
\hline 12 & 1084 & 3 & 63850.436 & & 52.4 & \\
\hline 12 & 1084 & 4 & 64244.863 & 55.01 & 52.9 & 2.11 \\
\hline 13 & 1557 & 1 & 60078.910 & 52.33 & 51.3 & 1.03 \\
\hline 13 & 1557 & 2 & 60399.687 & 86.42 & 85.8 & 0.62 \\
\hline 13 & 1557 & 3 & 60772.131 & 88.23 & 88.1 & 0.13 \\
\hline 13 & 1557 & 4 & 61160.819 & 101.55 & 101.8 & -0.25 \\
\hline 13 & 1557 & 5 & 61519.229 & 104.43 & 104.5 & -0.07 \\
\hline 13 & 1557 & 6 & 61972.694 & 97.31 & 99.9 & -2.59 \\
\hline 13 & 1557 & 7 & 62358.755 & 105.98 & 106.5 & -0.52 \\
\hline 17 & 1085 & 1 & 54610.970 & & 65.2 & \\
\hline 17 & 1085 & 2 & 55015.103 & 63.44 & 63.6 & -0.16 \\
\hline 17 & 1085 & 3 & 55372.436 & & 50.5 & \\
\hline 17 & 1085 & 4 & 55741.864 & 49.99 & 49.8 & 0.19 \\
\hline 17 & 1085 & 5 & 56108.030 & & 95.7 & \\
\hline 17 & 1085 & 6 & 56552.543 & 95.09 & 95.8 & -0.71 \\
\hline 17 & 1085 & 7 & 56862.576 & 96.81 & 97.0 & -0.19 \\
\hline 17 & 1086 & 1 & 63099.254 & 73.83 & 74.8 & -0.97 \\
\hline 17 & 1086 & 2 & 63520.755 & 75.13 & 75.1 & 0.03 \\
\hline 17 & 1086 & 3 & 63955.924 & 76.21 & 75.5 & 0.71 \\
\hline 17 & 1086 & 4 & 64426.236 & 78.02 & 75.9 & 2.12 \\
\hline 17 & 1086 & 5 & 64838.366 & 107.03 & 106.6 & 0.43 \\
\hline 17 & 1086 & 6 & 65222.072 & 284.08 & 284.3 & -0.22 \\
\hline 18 & 1087 & 1 & 54340.205 & 74.99 & 73.6 & 1.39 \\
\hline 18 & 1087 & 2 & 54747.929 & & 73.8 & \\
\hline 18 & 1087 & 3 & 55115.309 & & 74.3 & \\
\hline 18 & 1087 & 4 & 55471.377 & 74.63 & 74.2 & 0.43 \\
\hline 18 & 1087 & 5 & 55839.504 & 103.28 & 103.8 & -0.52 \\
\hline 18 & 1087 & 6 & 56200.585 & 284.29 & 284.8 & -0.51 \\
\hline
\end{tabular}


Table VI. Sailplane and F-18 airplane data with PCBoom4 predictions.

\begin{tabular}{|c|c|c|c|c|c|c|c|c|c|c|c|c|c|c|c|c|c|c|c|c|c|c|}
\hline \multirow[b]{2}{*}{$\begin{array}{l}\text { July } \\
\text { Date, } \\
2007\end{array}$} & \multirow[b]{2}{*}{$\begin{array}{c}\text { Flight } \\
\text { number }\end{array}$} & \multirow[b]{2}{*}{$\begin{array}{c}\text { Pass } \\
\text { number }\end{array}$} & \multicolumn{3}{|c|}{ Time of Sonic Boom at Sailplane } & \multicolumn{3}{|c|}{$\begin{array}{c}\text { PCBoom Position of Sailplane When } \\
\text { Boom Recorded }\end{array}$} & \multicolumn{3}{|c|}{ Time Sonic Boom Left F-18 } & \multicolumn{3}{|c|}{$\begin{array}{l}\text { Phi Angle of F-18 for Respective } \\
\text { Sonic Boom, PCB }\end{array}$} & \multicolumn{2}{|c|}{$\begin{array}{c}\text { Mach Number of F-18 } \\
\text { for Resepctive Sonic } \\
\text { Boom, PCB }\end{array}$} & \multicolumn{2}{|c|}{\begin{tabular}{|c} 
Altitude MSL of F-18 for \\
Resective Sonic Boom, \\
PCB
\end{tabular}} & \multicolumn{2}{|c|}{\begin{tabular}{|c|} 
Flight Path Angle of F- \\
18 for Respective \\
Sonic Boom, PCB \\
\end{tabular}} & \multicolumn{2}{|c|}{\begin{tabular}{|c|}
$\begin{array}{c}\text { Flight Path Heading of F- } \\
18 \text { for Respective Sonic } \\
\text { Boom, PCB }\end{array}$ \\
\end{tabular}} \\
\hline & & & $\begin{array}{l}\text { Time } \\
\text { recorded, s } \\
\text { after } \\
\text { midnight } \\
\text { UTC }\end{array}$ & $\begin{array}{c}\text { Time } \\
\text { predicted } \\
\text { (PCB), s after } \\
\text { midnight } \\
\text { UTC }\end{array}$ & $\mathrm{E}_{\mathrm{t}, \mathrm{s}}$ & Latitude & Longitude & \begin{tabular}{|l} 
Z MSL \\
position, \\
$\mathrm{ft}$
\end{tabular} & $\begin{array}{c}\text { Time for sonic } \\
\text { boom that hit } \\
\text { tower (PCB), } \\
\text { s after } \\
\text { midnight UTC }\end{array}$ & $\begin{array}{l}\text { Time for sonic } \\
\text { boom that hit } \\
\text { sailplane } \\
\text { (PCB), s after } \\
\text { midnight UTC }\end{array}$ & $\mathrm{E}_{\mathrm{e}} \mathrm{t}, \mathrm{s}$ & $\begin{array}{c}\text { Phi angle to } \\
\text { tower (PCB), } \\
\text { degrees }\end{array}$ & $\begin{array}{c}\text { Phi angle } \\
\text { to } \\
\text { sailplane } \\
\text { (PCB), } \\
\text { degrees }\end{array}$ & $\begin{array}{l}\text { E phi, } \\
\text { degrees }\end{array}$ & \begin{tabular}{|c|c} 
Mach \\
number for \\
sonic boom \\
at tower
\end{tabular} & $\begin{array}{c}\text { Mach } \\
\text { number for } \\
\text { sonic boom } \\
\text { at sailplane }\end{array}$ & $\begin{array}{l}\text { Z MSL for } \\
\text { sonic boom } \\
\text { at Tower, ft }\end{array}$ & $\begin{array}{c}\text { Z MSL for } \\
\text { sonic boom } \\
\text { at sailplane, } \\
\mathrm{ft}\end{array}$ & \begin{tabular}{|c} 
FPA for \\
sonic \\
boom at \\
tower, \\
degrees
\end{tabular} & \begin{tabular}{|c} 
FPA for \\
sonic \\
boom at \\
sailplane, \\
degrees
\end{tabular} & \begin{tabular}{|c|} 
FPH for \\
sonic boom \\
at tower, \\
degrees
\end{tabular} & \begin{tabular}{|c} 
FPH for \\
sonic boom \\
at saiplane, \\
degrees
\end{tabular} \\
\hline 11 & 1082 & 1 & 54129.712 & 54130.203 & -0.491 & 58675 & -6576 & 10475 & & \begin{tabular}{|l|}
54062.625 \\
\end{tabular} & & & 17.5 & & & 1.104 & & 36895 & & -8.4 & & 257.7 \\
\hline 11 & 1082 & 2 & 54610.465 & 54611.117 & -0.652 & 48029 & -9827 & 8704 & & 54533.750 & & & 18.6 & & & 1.098 & & 35703 & & -9.7 & & 255.4 \\
\hline 11 & 1082 & 3 & 55053.045 & $\begin{array}{l}55053.422 \\
\end{array}$ & -0.377 & 25262 & -16594 & 6445 & $\begin{array}{l}54983.062 \\
\end{array}$ & $\begin{array}{l}54983.121 \\
\end{array}$ & -0.059 & 43.6 & 44.0 & -0.4 & 1.116 & 1.115 & 35775 & 35757 & -16.9 & -16.7 & 256.8 & 256.8 \\
\hline 11 & 1082 & 4 & & & & & & & 55354.184 & & & 40.5 & & & 1.111 & & 38513 & & -17.9 & & 256.1 & \\
\hline 11 & 1082 & 5 & & & & & & & 55666.562 & & & -23.6 & & & 1.142 & & 36833 & & -15.9 & & 254.8 & \\
\hline 11 & 1082 & 6 & & & & & & & 56187.395 & & & -23.3 & & & 1.110 & & 35622 & & -18.4 & & 257.5 & \\
\hline 12 & 1083 & 1 & 54158.813 & 54159.152 & -0.339 & 67009 & -2638 & 10473 & & 54077.312 & & & 18.6 & & & 1.108 & & 37571 & & -9.3 & & 257.2 \\
\hline$\frac{12}{12}$ & \begin{tabular}{|l|}
1083 \\
1083
\end{tabular} & $\frac{2}{3}$ & $\begin{array}{r}54561.466 \\
54946.227\end{array}$ & $\begin{aligned} 54561.691 \\
5943752\end{aligned}$ & $\begin{array}{l}-0.225 \\
-1.125\end{array}$ & 57920 & $\frac{-6651}{-15783}$ & $\frac{9002}{6636}$ & & $\begin{array}{l}54474.086 \\
5462.152\end{array}$ & & & 20.9 & & & 1.103 & & 36352 & & -9.9 & & 257.8 \\
\hline$\frac{12}{12}$ & $\frac{1083}{1083}$ & $\frac{3}{4}$ & $\frac{549+4.247}{55299.356}$ & $\frac{5494.532}{55299.781}$ & $\frac{-1.125}{-0.425}$ & 25349 & $\frac{-15783}{-1868}$ & $\frac{6636}{55257}$ & $\begin{array}{r}54862.219 \\
55224988\end{array}$ & $\frac{54862.152}{5522434}$ & $\frac{0.067}{-0.036}$ & $\frac{128.2}{448}$ & $\frac{128.5}{446}$ & $\frac{-0.3}{0.2}$ & $\frac{1.061}{1.137}$ & 1.059 & 47343 & $\begin{array}{l}47387 \\
3749\end{array}$ & $\begin{array}{r}-52.5 \\
-18.3\end{array}$ & $\begin{array}{r}-52.3 \\
-182\end{array}$ & 255.6 & 255.8 \\
\hline & 1083 & & & & & & & & $\frac{526.500}{55615.391}$ & & & $\frac{-4.0}{-30.6}$ & & & $\frac{1.179}{1.119}$ & 1.150 & $\begin{array}{l}36675 \\
3675\end{array}$ & & $\begin{array}{l}-10.0 \\
-15.2\end{array}$ & -10.2 & $\frac{250.1}{260.5}$ & \\
\hline 12 & 1083 & 6 & & & & & & & 55992.660 & & & -39.5 & & & $\frac{1.117}{1.110}$ & & 37138 & & -18.5 & & 257.9 & \\
\hline 12 & 1083 & 7 & & & & & & & 56329.164 & & & -21.2 & & & 1.101 & & 33768 & & -13.2 & & 268.5 & \\
\hline 12 & 1084 & 1 & & & & & & & 00529.104 & & & -21.2 & & & 1.101 & & 20100 & & -15.2 & & 200.5 & \\
\hline 12 & 1084 & 2 & 63515.276 & 0 & \begin{tabular}{|l|l|}
63515.3 \\
\end{tabular} & 47582 & -10668 & 8977 & & & & & & & & & & & & & & \\
\hline 12 & 1084 & 3 & 839.288 & 63840.5 & \begin{tabular}{|l|}
-1.212 \\
\end{tabular} & 23695 & -16793 & 6364 & 63768.629 & 63768.750 & -0.121 & 35.7 & 36.1 & -0.4 & 1.131 & 1.128 & 37308 & 37257 & -15.3 & -15.4 & 252.3 & 252.3 \\
\hline 12 & 1084 & 4 & 64235.546 & 64236.5 & -0.954 & 22452 & -18036 & 4902 & 64161.539 & 64161.539 & 0.000 & 41.2 & 40.6 & 0.6 & 1.130 & 1.130 & & 38952 & -18.0 & -18.0 & 255.6 & 255.6 \\
\hline 13 & 1557 & 1 & 60050.577 & 60050.484 & 0.093 & 37962 & -4619 & 10791 & 59988.020 & 59988.160 & -0.140 & 54.1 & 54.0 & 0.1 & 1.099 & 1.097 & 36184 & 36127 & -23.1 & -22.4 & 255.7 & 255.7 \\
\hline 13 & 1557 & 2 & 60389.532 & 60389.465 & 0.067 & 24280 & -24694 & 8425 & 60341.895 & 60341.949 & -0.054 & 3.6 & 7.3 & -3.8 & 1.087 & 1.087 & 36725 & 36706 & -19.0 & -18.7 & 267.7 & 267.9 \\
\hline 13 & 1557 & 3 & 60764.616 & 60764.566 & 0.05 & 21632 & -24128 & 6965 & 60715.562 & 60715.695 & -0.133 & -16.8 & -15.9 & -1.0 & 1.107 & 1.105 & 36043 & 35998 & -18.1 & -17.7 & 258.4 & 258.7 \\
\hline 13 & 1557 & 4 & & & & & & & 61069.836 & & & -67.8 & & & & & 38598 & & -26.6 & & 255.7 & \\
\hline 13 & 1557 & 5 & & & & & & & 61429.305 & & & -47.4 & & & 1.080 & & 36994 & & -19.3 & & 265.2 & \\
\hline 13 & 1557 & 6 & & & & & & & 61868.250 & & & -46.9 & & & 1.096 & & 31620 & & -13.7 & & 260.0 & \\
\hline 13 & 1557 & & & & & & & & 62272.664 & & & -55.5 & & & 1.140 & & 34988 & & -18.6 & & 258.5 & \\
\hline 17 & 1085 & 1 & 54556.998 & 54557.137 & -0.139 & 68203 & -180 & 11416 & & 54490.758 & -0.258 & 34.4 & 33.5 & 0.9 & 1.074 & 1.070 & 35093 & 34994 & -12.3 & -11.8 & 259.0 & 259.0 \\
\hline 17 & 1085 & 2 & 54970.453 & 54970.539 & -0.086 & 58897 & $\begin{array}{l}-3955 \\
\end{array}$ & 9933 & 54901.000 & 54901.129 & -0.129 & 39.3 & 40.4 & -1.1 & 1.100 & 1.099 & 33297 & 33272 & -10.0 & $\begin{array}{l}-9.4 \\
\end{array}$ & 261.1 & 261.2 \\
\hline 17 & 1085 & 3 & 55355.653 & 55355.781 & -0.128 & 28553 & -12804 & 6677 & & & 0.043 & 56.8 & 56.9 & 0.0 & 1.148 & 1.149 & 36602 & 36616 & -18.7 & -18.9 & 25 & 259.7 \\
\hline 17 & 1085 & 4 & 55730.23 & 55730.383 & -0.153 & 24364 & -16408 & 5187 & & 55653.035 & 0.074 & 68.7 & 68.7 & 0.0 & 1.1 & 1.136 & 35736 & 35778 & -24.9 & -25.1 & 260.9 & 260.9 \\
\hline 17 & 1085 & 5 & & & & & & & & & & -3 & & & & & 36. & & -13.4 & & & \\
\hline 17 & 1085 & 6 & & & & & & & & & & -32 & & & & & & & -15.4 & & 25 & \\
\hline 17 & 1085 & 7 & & & & & & & & & & & & & & & & & -16.8 & & & \\
\hline 17 & 1086 & 1 & 63075.537 & 63075.453 & 0.084 & 38153 & -17421 & 11590 & & 63033.2 & 1.016 & 19.6 & 17.7 & 1.8 & 1.2 & 1.253 & 33886 & 33888 & -0.1 & -0.1 & 26 & 269.0 \\
\hline 17 & 1086 & 2 & 63501.758 & 63501. & 0.09 & 33492 & -190 & 9933 & & & 0.300 & 18 & 17.9 & 0.5 & 1.2 & 1.249 & 338 & 338 & & & 26 & 268.4 \\
\hline 17 & 1086 & 3 & 63941.5 & 63941. & 0.127 & 28951 & -20. & 8128 & & & -0.0 & & 18 & 0 & 1.2 & 1.2 & 339 & 33920 & & & 26 & 269.0 \\
\hline 17 & 1086 & 4 & 64415.851 & 64415.719 & 0.132 & 25001 & -21641 & 6479 & 64359 & 64359.395 & 0.109 & & 20. & -0. & 1.2 & 1.24 & 343 & 34307 & -1 & & 27 & 270.1 \\
\hline 17 & 1086 & 5 & 64830.797 & 64830.742 & 0.055 & 22271 & -26395 & 5067 & 6477 & 64770.723 & 0.304 & -2. & -22.8 & -0.3 & 1.2 & 1.257 & & 33957 & -0.2 & -0.2 & 19 & 269.9 \\
\hline 17 & 1086 & 6 & & & & & & & $\frac{65159}{51478}$ & & & $\frac{-20}{17}$ & & & 1.2 & & 336 & & & & & \\
\hline$\frac{18}{18}$ & 1087 & 1 & $\begin{array}{r}54313.883 \\
5172012\end{array}$ & $\begin{array}{r}54313.82 \\
5430133\end{array}$ & 0.063 & $\frac{41297}{31898}$ & -16731 & 10970 & $\begin{array}{r}54278.379 \\
5485246\end{array}$ & & 6.059 & 17. & 13 & 4 & 1.26 & 1.26 & 340 & 340 & 0 & 0.0 & 266.8 & 266.5 \\
\hline$\frac{18}{18}$ & 1087 & $\frac{2}{3}$ & 54730.133 & $\frac{54730.133}{5510205}$ & 0 & 31885 & -1924 & 9663 & $\begin{array}{l}54685.246 \\
5552026\end{array}$ & $\begin{array}{r}54684.395 \\
5052.066\end{array}$ & 0.851 & $\begin{array}{l}18.7 \\
15.7\end{array}$ & 17. & 1.0 & 1.255 & $\frac{1.255}{1.27}$ & 33896 & 33896 & 0.4 & 0.0 & 267.5 & 267.5 \\
\hline$\frac{18}{18}$ & $\begin{array}{l}1081 \\
1087\end{array}$ & $\frac{3}{4}$ & $\begin{array}{r}55100.419 \\
55459.249\end{array}$ & $\begin{array}{l}55100.093 \\
55459.184\end{array}$ & 0.024 & $\frac{28940}{26572}$ & $\begin{array}{l}-193 \\
-209 \\
\end{array}$ & $\begin{array}{l}84114 \\
7114\end{array}$ & $\frac{55052.960}{55408.270}$ & $\begin{array}{l}55052.406 \\
55407.445\end{array}$ & 0.5225 & $\frac{15.1}{18.7}$ & $\frac{13.3}{18.5}$ & 2.2 & $\frac{1.246}{1.257}$ & 1.247 & $\frac{34009}{34040}$ & $\frac{34099}{34040}$ & 0. & 0.0 & 265.6 & $\frac{265.6}{267.8}$ \\
\hline 18 & 1087 & 5 & 55831.1 & 55831.016 & 0.084 & 22912 & -26662 & 5603 & 55767.738 & 55767.902 & -0.164 & -24.5 & -24.4 & -0.1 & 1.244 & 1.244 & 34107 & 34107 & -0.1 & -0.1 & 266.7 & 266.7 \\
\hline 18 & 1087 & 6 & 56205.559 & 56205.324 & \begin{tabular}{|l|}
0.235 \\
\end{tabular} & 21038 & -26427 & 4548 & 56137.727 & 56142.754 & -5.027 & -17.2 & -21.5 & 4.4 & 1.244 & 1.234 & 34280 & 34281 & -0.1 & 0.0 & 92.5 & 92.2 \\
\hline
\end{tabular}




\section{Acknowledgments}

The following organizations are acknowledged for their support of this flight research effort: the NASA Aeronautics Research Mission Directorate; the FAA/NASA/Transport-Canada PARTNER Center of Excellence;

Pennsylvania State University; the United States Air Force Test Pilot School; Edwards Air Force Base; Analytical Services and Materials, Inc.; Wyle Labs; and the Gulfstream Corporation. 


\section{References}

${ }^{1}$ Klos, J., and Buehrle, R. D., "Vibro-Acoustic Response of Buildings Due to Sonic Boom Exposure: June 2006 Field Test," NASA/TM-2007-214900, 2007.

${ }^{2}$ Bütikofer, R., and Thomann, G., "Aircraft sound measurements: The influence of microphone height," Acta Acustica united with Acustica, Vol. 91, No. 5, 2005, pp. 907-914.

${ }^{3}$ Haering, E. A., Jr., Murray, J. E., Purifoy, D. D., Graham, D. H., Meredith, K. B., Ashburn, C. E. and Stucky, M., "Airborne Shaped Sonic Boom Demonstration Pressure Measurements with Computational Fluid Dynamics Comparisons," AIAA-2005-0009, 2005.

${ }^{4}$ Plotkin, K. J., and Grandi, F., "Computer Models for Sonic Boom Analysis: PCBoom4, CABoom, BooMap, CORBoom," Wyle Report WR 02-11, 2002.

${ }^{5}$ National Geospatial-Intelligence Agency, SNS Edwards NGA Support Team, Edwards AFB, California, "House Variable Intensity Boom Effect on Structures (VIBES) Program," Publication 07-1E11, July 2007.

${ }^{6}$ Range Commanders Council, "IRIG Serial Time Code Formats," IRIG Standard 200-98, May 1998.

${ }^{7}$ Plotkin, K. J., Haering, E. A., Jr., Murray, J. E., Maglieri, D. J., Salamone, J., Sullivan, B. M., and Schein, D., "Ground Data Collection of Shaped Sonic Boom Experiment Aircraft Pressure Signatures," AIAA-2005-0010, 2005.

${ }^{8}$ Haering, E. A., Jr., Smolka, J. W., Murray, J. E., and Plotkin, K. J., "Flight Demonstration of Low Overpressure N-Wave Sonic Booms and Evanescent Waves," Innovations In Nonlinear Acoustics: ISNA17 - 17th International Symposium on Nonlinear Acoustics including the International Sonic Boom Forum," AIP Conference Proceedings, Vol. 838, Melville, New York, 2006, pp. 647-650.

${ }^{9}$ Gabrielson, T. B., Willits, S. M., Marston, T. M., Haering, E. A., Jr., Murray, J. E., and Stucky, M., “Acoustic Background Noise from Sailplane-Mounted Microphones," Proc. of Inter-noise 2006, C. Burroughs and G. Maling, Eds., Institute of Noise Control Eng., Washington, DC 2006.

${ }^{10}$ Pierce, A. D., and Maglieri, D. J., "Effect of Atmospheric Irregularities on Sonic-Boom Propagation," The Journal of the Acoustical Society of America, Vol. 51, No. 2, Part 3, 1972, pp. 702-721.

${ }^{11} \mathrm{http} / / /$ www.mathworks.com/access/helpdesk_r13/help/techdoc/ref/arithmeticoperators.html\#8559 [cited April 4, 2008 ].

${ }^{12}$ Shepherd, K. P., and Sullivan, B. M., "A Loudness Calculation Procedure Applied to Shaped Sonic Booms," NASA Technical Paper 3134, 1991.

${ }^{13}$ Stevens, S. S., "Perceived Level of Noise by Mark VII and Decibels(E)," J. Acoust. Soc. Am. 54(2) pt.2, pp. 575-601 (1972).

${ }^{14}$ American National Standards Institute (ANSI), “Acoustical Terminology,” ANSI S1.1-1994 (R2004), 2004.

${ }^{15}$ Locey, L. L., and Sparrow, V. W., "Modeling Atmospheric Turbulence as a Filter for Sonic Boom Propagation," Noise Control Eng. J. Vol. 55 No. 6, 2007, pp. 495-503.

${ }^{16}$ Sullivan, B. M, and Leatherwood, J. D., "Subjective Response to Simulated Sonic Booms with Ground Reflections," NASA Technical Memorandum 107764, 1993.

${ }^{17}$ Locey, L., "Sonic Boom Postprocessing to Include Atmospheric Turbulent Effects," AIAA-2008-3035, 2008.

${ }^{18}$ Haering, E. A., Jr., Ehernberger, L. J., and Whitmore, S. A., "Preliminary Airborne Measurements for the SR-71 Sonic Boom Propagation Experiment," NASA Technical Memorandum 104307, 1995.

${ }^{19}$ Hess, H. M, Attenborough, K., and Heap, N. W., "Ground Characterization by Short-Range Propagation Measurements," J. Acoust. Soc. Am., Vol. 87, No. 5, 1990, p. 1975.

${ }^{20}$ Haering, E. A., Jr., “Airdata Measurement and Calibration,” NASA Technical Memorandum 104316, 1995.

${ }^{21}$ Haering, E. A., Jr., and Whitmore, S. A., "FORTRAN Program for the Analysis of Ground-Based Radar Data: Usage and Derivations, Version 6.2,” NASA Technical Paper 3430, 1995. 